\title{
Clinical management of Rett syndrome
}

Citation for published version (APA):

Halbach, N. S. J. (2013). Clinical management of Rett syndrome. [Doctoral Thesis, Maastricht University]. Universitaire Pers Maastricht. https://doi.org/10.26481/dis.20130605nh

Document status and date:

Published: 01/01/2013

DOI:

$10.26481 /$ dis.20130605nh

Document Version:

Publisher's PDF, also known as Version of record

\section{Please check the document version of this publication:}

- A submitted manuscript is the version of the article upon submission and before peer-review. There can be important differences between the submitted version and the official published version of record.

People interested in the research are advised to contact the author for the final version of the publication, or visit the DOI to the publisher's website.

- The final author version and the galley proof are versions of the publication after peer review.

- The final published version features the final layout of the paper including the volume, issue and page numbers.

Link to publication

\footnotetext{
General rights rights.

- You may freely distribute the URL identifying the publication in the public portal. please follow below link for the End User Agreement:

www.umlib.nl/taverne-license

Take down policy

If you believe that this document breaches copyright please contact us at:

repository@maastrichtuniversity.nl

providing details and we will investigate your claim.
}

Copyright and moral rights for the publications made accessible in the public portal are retained by the authors and/or other copyright owners and it is a condition of accessing publications that users recognise and abide by the legal requirements associated with these

- Users may download and print one copy of any publication from the public portal for the purpose of private study or research.

- You may not further distribute the material or use it for any profit-making activity or commercial gain

If the publication is distributed under the terms of Article $25 \mathrm{fa}$ of the Dutch Copyright Act, indicated by the "Taverne" license above, 


\section{Clinical management of Rett syndrome}


The research presented in this thesis was conducted at the Governor Kremers Centre (GKC) - Department of Clinical Genetics of the Maastricht University Medical Centre (MUMC+) and Rett Expertise Centre of the Maastricht University Medical Centre (MUMC+).

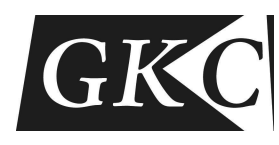

Maastricht UMC+

az Maastricht University

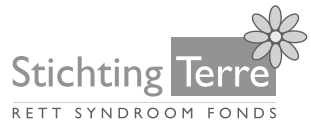

caphri
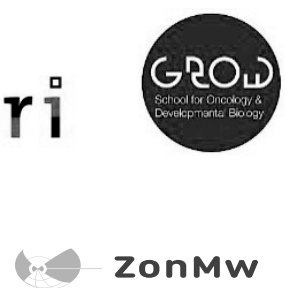

The studies presented in this dissertation were funded by Stichting Terre Rett syndroom fonds (www.stichtingterre.nl) and the Netherlands Organisation for Health Research and Development (ZonMw; project "Participatory research into the quality of life of adults with intellectual disabilities", grant number: 57000005).

Financial support for the printing of this thesis was kindly provided by:

Stichting Terre Rett syndroom fonds (www.stichtingterre.nl)

(C) Copyright Nicky S.J. Halbach, Maastricht 2013.

All rights reserved.

Omslagontwerp: Annika Biemans

Vormgeving en druk: Datawyse | Universitaire Pers Maastricht

ISBN 9789461592286 


\title{
Clinical management of Rett syndrome
}

\author{
PROEFSCHRIFT \\ ter verkrijging van de graad van doctor aan de Universiteit Maastricht, \\ op gezag van de Rector Magnificus, prof. dr. L.L.G. Soete, \\ volgens het besluit van het College van Decanen, \\ in het openbaar te verdedigen, \\ op woensdag 5 juni 2013, om 12.00 uur \\ door \\ Nicky S.J. Halbach \\ geboren op 14 september 1983 te Heerlen
}

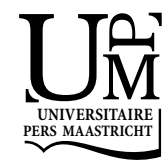




\section{Promotor}

Prof. dr. L.M.G. Curfs

\section{Co-promotor}

Dr. E.E.J. Smeets

\section{Beoordelingscommissie}

Prof. dr. H.W.M. Steinbusch

Prof. dr. J.P.M. Geraedts

Prof. dr. D.F. Swaab (Universiteit van Amsterdam)

Prof. dr. L.J.I. Zimmermann 


\section{Ontmoeting}

Wanneer je goed naar me kijkt

Wanneer ik niet kan doen wat jij zegt

Wanneer ik dingen zie die jij niet ziet

Wil jij dan nog weten wie ik ben?

Wanneer ik helemaal niet reageer

Wanneer mijn woorden niet de jouwe zijn

Wanneer mijn boosheid geen grenzen kent

Wil jij dan nog bij me zijn?

Wanneer ik jou uitleg geef met gebaren en mimiek

Wanneer ik steeds dezelfde rituelen herhaal

Wanneer ik in mijn hoekje zit te wiegen

Weet jij dan wie ik ben?

Wanneer ik jou mijn waardevolle spulletjes laat zien

Wanneer ik al mijn agressie voor jou niet meer nodig heb

Wanneer ik wil varen op jouw kompas

Mag jij weten wie ik ben.

(Onbekende auteur, gedicht gepubliceerd in: Sprekende ogen, wringende handen van Gea van Otterdijk-Smets)

Aan Margo en alle andere Rett meisjes, omdat jullie zo bijzonder zijn.

En aan mijn oma, omdat ik weet hoe trots je zou zijn geweest. 



\section{Contents}

Chapter 1 General Introduction 9

Chapter 2 Genotype-Phenotype Relationships as Prognosticators in Rett 25 Syndrome Should be Handled With Care in Clinical Practice

Chapter 3 Neurophysiology versus Clinical Genetics in Rett Syndrome:

A Multicenter Study

Chapter 4 Altered Carbon Dioxide Metabolism and Creatine

Abnormalities in Rett Syndrome

Chapter 5 Aging in people with specific genetic syndromes: Rett syndrome

Chapter 6 Aging in Rett syndrome: a longitudinal study

Chapter 7 General discussion

Appendix 1 Altered Carbon Dioxide Metabolism and Creatine Abnormalities in Rett Syndrome: a continuing story

Appendix 2 RTT Expertise Centre

Summary

Samenvatting

Dankwoord

147

Curriculum vitae

155

List of publications

157 

Chapter 1

General introduction 


\section{General introduction}

Rett syndrome (RTT) is a severe genetic neurodevelopmental disorder, affecting predominantly females (Rett, 1966; Hagberg et al., 1983; Kerr \& Witt Engerström, 2001; Smeets et al., 2012). The main focus of research in RTT has been to further the understanding of its genetic basis and the search for a possible cure. The aim of this thesis is to contribute to an improved clinical management of this syndrome. This chapter starts with a brief historical and clinical introduction in RTT, including the cascade of emerging features in the four recognised stages, the diagnostic criteria, the genetic background and clinical management in particular. Finally, the research questions and outline of this thesis are presented.

\section{History of Rett syndrome}

In 1954, Andreas Rett, a neuropaediatrician in Vienna, first recognized the characteristic features of the syndrome that later came to bear his name. In his waiting room he noticed two girls, seated next to each other on the lap of their respective mothers, who displayed exactly the same behaviour. He recognized that these girls' hand movements were different from the stereotypic behaviours among other disabled children. He and his nurse were able to recall and examine other girls in their care who demonstrated these same characteristics. His publication in the "Wiener Medizinische Wochenschrift" in 1966, however, remained largely unnoticed (Rett, 1966). It was Professor Hagberg who revealed this unique syndrome to the international medical world with his publication in 1983 titled "A progressive syndrome of autism, dementia, ataxia, and loss of purposeful hand use in girls: Rett's syndrome: Report of 35 cases" (Hagberg et al., 1983). In the years that followed, information about RTT spread rapidly. Today we know that RTT is a neurodevelopmental disorder due to mutation in the gene encoding for the methyl-CpG binding protein 2 (MECP2), a finding first demonstrated by researchers from Professor Zoghbi's laboratory at the Baylor College of Medicine in Houston, Texas (Amir et al., 1999).

\section{Rett syndrome}

RTT is one of the leading causes of severe intellectual disabilities (ID) in females, with an incidence ranging from $1 / 10,000$ to $1 / 15,000$ (Leonard et al., 1997; Bienvenu et al., 2006). Typical RTT is characterized by seemingly normal postnatal development, followed by stagnation in development and the loss of acquired motor and language skills, severe cognitive impairment, gait abnormalities and the replacement of purposeful hand use by typical hand stereotypies, the hallmark of the disorder (Hagberg, 1995; Hagberg et al., 2002; Neul et al., 2010). This period of 
regression is than followed by a "wake-up" period, in which development reaches a plateau or shows quite slow improvement (Mount et al., 2001; Hagberg, 2002; Hagberg et al., 2002; Neul et al., 2010). This stage includes a wide variety of RTT-specific symptoms, such as scoliosis, seizures and autonomic abnormalities. It can last for a variable period, most often for decades, and is followed by late motor deterioration, mainly involving gross motor functions (Hagberg, 2002). This cascade of clinical symptoms was described in four stages: the early-onset stagnation, the rapid developmental regression, a pseudo-stationary stage and a late motor deterioration (Hagberg \& Witt Engerström, 1986). The schematic representation in Figure 1 by Chahrour and Zoghbi provides an indication of a possible course of the RTT clinical phenotype. The lifespan is extremely variable and some individuals survive above 70 years of age (Chahrour \& Zoghbi, 2007).

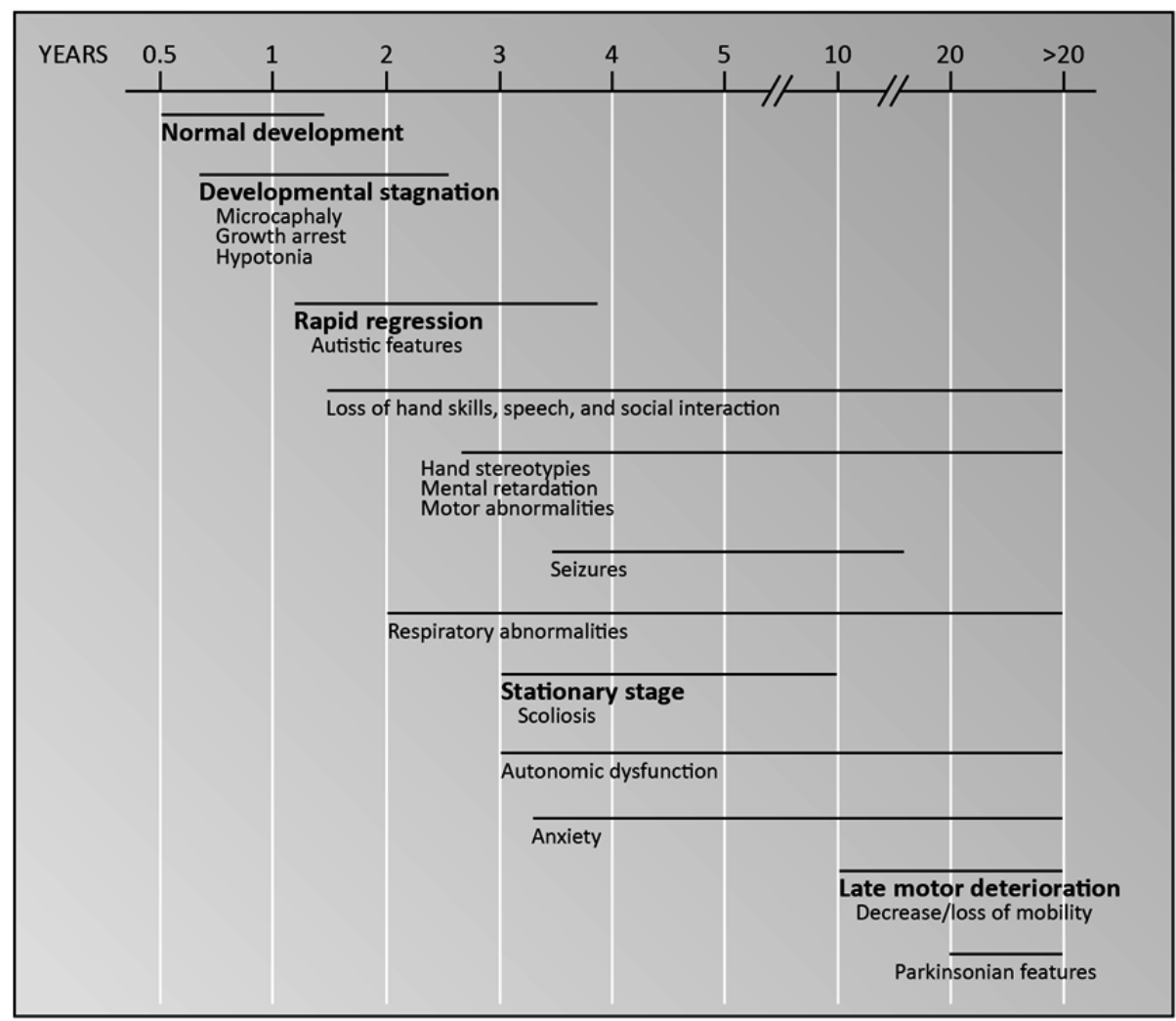

Figure 1 Onset and Progression of RTT Clinical Phenotypes (Chahrour \& Zoghbi, 2007) 


\section{Diagnosis of RTT}

RTT is diagnosed clinically, based on internationally accepted diagnostic criteria that were developed and revised over the years. These clinical criteria are a useful tool for the clinicians who are involved in the first diagnostic work-up and for RTT researchers (Hagberg et al., 2002; Neul et al., 2010). The recently revised diagnostic criteria for typical and atypical RTT are shown in Table 1.

Table 1 Revised diagnostic criteria for RTT 2010 (Neul et al., 2010)

\section{Consider diagnosis when postnatal deceleration of head growth is observed}

\section{Required for typical or classic RTT}

1. A period of regression followed by recovery or stabilization

2. All main criteria and all exclusion criteria

3. Supportive criteria are not required, although often present in typical RTT

\section{Required for atypical or variant RTT}

1. A period of regression followed by recovery or stabilization

2. At least 2 out of the 4 main criteria

3. 5 out of 11 supportive criteria

\section{Main Criteria}

1. Partial or complete loss of acquired purposeful hand skills

2. Partial or complete loss of acquired spoken language

3. Gait abnormalities: Impaired (dyspraxic) or absence of ability

4. Stereotypic hand movements such as hand wringing/squeezing, clapping/tapping, mouthing and washing/rubbing automatisms

\section{Exclusion Criteria for typical RTT}

1. Brain injury secondary to trauma (peri- or postnatally), neurometabolic disease, or severe infection that causes neurological problems

2. Grossly abnormal psychomotor development in first 6 months of life

\section{Supportive Criteria for atypical RTT}

1. Breathing disturbances when awake

2. Bruxism when awake

3 Impaired sleep pattern

4 Abnormal muscle tone

5. Peripheral vasomotor disturbances

6. Scoliosis/kyphosis

7. Growth retardation

8. Small cold hands and feet

9. Inappropriate laughing/screaming spells

10. Diminished response to pain

11. Intense eye communication - "eye pointing"

There is a wide variability in the rate of progression and clinical severity of the disorder. In addition to the typical form of RTT, accounting for three quarters of the cases (Hagberg, 2002), there is a number of recognisable atypical variants where- 
fore diagnostic criteria have been established (Hagberg \& Gillberg, 1993; Hagberg et al., 2002; Neul et al., 2010). These atypical variants include an early seizure variant (Hanefeld, 1985), a preserved speech variant (Zappella, 1992) and a congenital variant (Ariani et al., 2008). Mutations in MECP2 have been found in the majority of the preserved speech variant cases (De Bona et al., 2000; Renieri et al., 2009). In the congenital and the early seizure variant, mutations in other genes have been identified. The congenital variant of RTT is related to mutations in FOXG1 (Ariani et al., 2008; Mencarelli et al., 2010; Florian et al., 2011) and the early seizure variant is related to mutations in CDKL5 (Tao et al., 2004; Archer et al., 2006; Bahi-Buisson \& Bienvenu, 2011). These disorders are now considered as separate entities, different from MECP2-related RTT. The incidence of MECP2 mutations in males is unknown, with conflicting results in previous studies (Moog et al., 2006; Kankirawatana et al., 2006; Villard, 2007; Santos et al., 2009). Clinically it encompasses a wide spectrum of neurological disorders, ranging from mild ID to severe neonatal encephalopathy (Villard, 2007).

\section{MECP2}

RTT is considered a monogenic X-linked dominant disorder, since using a battery of modern mutation detection assays, causative mutations in MECP2 are detectable in at least 95\% of the typical RTT cases (Amir et al., 1999; Percy, 2008; Neul et al., 2008). Up until now, more than 500 different MECP2 mutations have been identified, with eight most common recurrent mutations accounting for approximately 70\% of the cases (http://mecp2.chw.edu.au/mecp2/).

Since MECP2 mutations are neither necessary nor sufficient to make the diagnosis, diagnosis of RTT remains strongly based on clinical criteria (Neul et al., 2010).

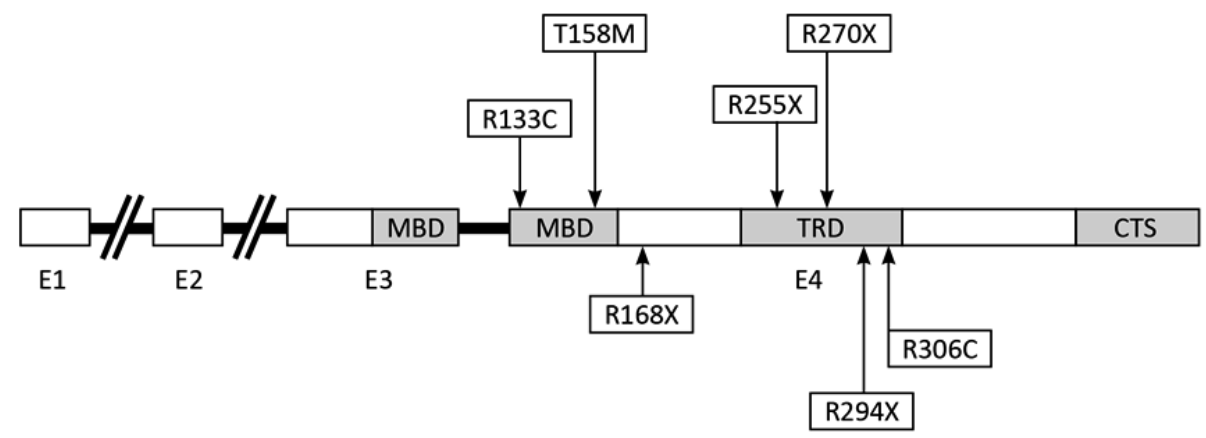

Figure 2 Schematic diagrams of the MECP2 gene and common recurrent mutations in RTT (Adapted from Bradbury et al., 2007) 
MECP2 contains four functional domains: a methyl-CpG-binding domain (MBD), a transcriptional repression domain (TRD), two nuclear localization signals and the Cterminal segment (CTS) (Matijevic et al., 2009). Figure 2 shows a schematic diagram of the gene, including the domains and the common recurrent mutations. The MeCP2 protein is ubiquitously present but particularly abundant in the brain (Amir et al., 1999). It is widely believed to be a transcriptional repressor that targets numerous functional genes essential for normal central nervous system development and functioning (Nan et al., 1997; Chahrour \& Zoghbi, 2007). However, the precise role of MECP2 mutations in producing the clinical RTT phenotype is still unclear (Berger-Sweeney, 2011). Even the concept of RTT as a pure neuronal disorder has been questioned, as a previously unrecognized role for the glial cells in the neuropathology of RTT has recently been published (Zoghbi, 2009; Lioy et al., 2011).

\section{Genotype-phenotype correlations}

Since 1999, a major focus of research has been on identifying the genetic determinants associated with the phenotypic variability in RTT (Amir et al., 2000; Cheadle et al., 2000; Huppke et al., 2000; Auranen et al., 2001; Hoffbuhr et al., 2001; Monros et al., 2001; Nielsen et al., 2001; Yamashita et al., 2001; Hoffbuhr et al., 2002; Huppke et al., 2002; Leonard et al., 2003; Smeets et al., 2003; Weaving et al., 2003; Schanen et al., 2004; Colvin et al., 2004; Charman et al., 2005; Fukuda et al., 2005; Kerr \& Prescott, 2005; Leonard et al., 2005; Smeets et al., 2005; Bebbington et al., 2008; Neul et al., 2008; Smeets et al., 2009; Bebbington et al., 2010; Temudo et al., 2011). Genetic factors that were considered include the type and domain of mutation, common recurrent mutations, and the individual variability in X-chromosome inactivation $(\mathrm{XCl})$ patterns. These studies have yielded conflicting results. Females with the same MECP2 mutation varied significantly in phenotype and clinical severity could not always be explained by $\mathrm{XCl}$ patterns. The limited correlation between genotype and phenotype might be due to the variability in classification of mutations, assessment tools, and structure of the data sets (Ham et al., 2005; Hite et al., 2009; Grillo et al., 2012). Furthermore, other genetic and/or epigenetic mechanisms might modulate the clinical presentation (Ogier \& Katz, 2008; Takahashi et al., 2008; Xinhua et al., 2008; Matijevic et al., 2009).

\section{Clinical management}

Currently no cure for RTT exists, although disease reversibility has been demonstrated in animal models (Guy et al., 2007, Gadalla et al., 2012). Clinical management of RTT is essentially symptomatic and supportive (Ellaway \& Christodoulou, 2001; Weaving et al., 2005; Williamson \& Christodoulou, 2006; Smeets et al., 2012). Only interventions aimed at improving condition and quality of life of RTT females 
are at the moment available. An individualised multidisciplinary team approach is advocated, aimed at optimising each patient's abilities and predicting and treating symptoms and problems as they develop to improve the health, longevity and quality of life of the individuals and their families (Ellaway \& Christodoulou, 2001; Williamson \& Christodoulou, 2006; Julu et al., 2008; Smeets et al., 2012). It is clear that certain RTT features contribute more than others to the clinical severity and may demand complex management strategies. Autonomic features and nutritional problems are major reasons for seeking medical attention in RTT (Julu et al., 2008; Motil et al., 2012). Besides, parents express their concern about the lack of available information on clinical management of their adult RTT daughters.

\section{Autonomic dysfunction}

The brainstem features become prominent at the end of the regression stage and the beginning of stage three and remain present throughout life (Julu \& Witt Engerström, 2005). Breathing abnormalities associated with non-epileptic vacant spells are the most distressing feature to the RTT females. Having a significant deleterious impact on the RTT female as well as on the quality of life of the families, breathing abnormalities are common reasons for seeking medical attention (Smeets et al., 2006; Julu et al., 2008; Ogier \& Katz, 2008; Smeets et al., 2012). The primary pathophysiology is related to a defective control mechanism of carbon dioxide exhalation causing respiratory alkalosis or acidosis (Julu et al., 2008). Since it reflects the immaturity of the brainstem, detailed neurophysiology evaluating the brainstem functions in RTT is required (Julu \& Witt Engerström, 2005). Three cardiorespiratory phenotypes are described, each demanding a specific approach (Julu, 2001; Julu et al., 2005; Julu et al., 2008; Julu et al., 2012).

\section{Nutrition}

Growth retardation and malnutrition often complicate the clinical course of females with RTT. The growth trajectory of RTT deviates from the typical pattern of growth failure in children with chronic illnesses or other central nervous system or chromosomal disorders (Motil et al., 2009). There is deceleration of linear growth during the first 2 years of life. Later on, height and/or weight for height often fall 2 SD below normal (Schultz et al., 1993; Reilly \& Cass, 2001; Motil et al., 2012). Although RTT females have a good appetite, the majority meets the criteria of moderate to severe malnutrition (Rice \& Haas, 1988; Reilly \& Cass, 2001; Motil et al., 2012). The pathophysiology of this malnutrition remains unclear. Both nutritional and nonnutritional factors are thought to contribute. These factors include inadequate dietary intake, malabsorption, altered metabolic processes or increased metabolic rate (Motil et al., 1998; Reilly \& Cass, 2001; Oddy et al., 2007; Motil et al., 2009; Platte et 
al., 2011; Motil et al., 2012). To optimize clinical management of malnutrition, clarification of the pathophysiology is of great importance.

\section{Ageing}

Owing to better life circumstances and major advances in medical care and technology, the life expectancy of persons with childhood onset disorders and/or genetic syndromes has increased (Patja et al., 2000; Donckerwolcke \& Van Zeben-Van der Aa, 2002; Maaskant et al., 2002; Fisher \& Kettl, 2005; Tyler \& Noritz, 2009; Haveman et al., 2010). Consequently, the number of adults with ID has increased substantially during the last decades and expectations are that it will continue to increase in the next years (Janicki \& Breitenbrach, 2000; Bernard et al., 2002; Tyler \& Noritz, 2009; Haveman et al., 2010). Therefore, clinicians are increasingly challenged by the need for care for adults with specific genetic syndromes (Donckerwolcke \& Van ZebenVan der Aa, 2002; Tyler \& Noritz, 2009; Vignoli et al., 2012). Compared to persons without ID, age-specific conditions occur more often and earlier in life (Maaskant et al., 1996; Van Schrojenstein Lantman-De Valk et al., 1997; Haveman et al., 2009). Nevertheless, studies on ageing in RTT are scarce, including a few cross-sectional studies and some longitudinal follow-up case studies (Nielsen et al., 2001; Jacobsen et al., 2001; Cass et al., 2003; Hagberg, 2005; Lotan et al., 2010; Vignoli et al., 2012). The clinical condition of RTT women appears to stabilize over time, and prolonged survival has recently been demonstrated (Freilinger et al., 2010; Kirby et al., 2010). Good knowledge of the clinical course of the syndrome at adult age including the specific healthcare problems is needed to provide for optimal care and support on the long term.

\section{Aim and outline of this thesis}

The aim of this thesis is to contribute to an improved clinical management of RTT. The main research questions in this context are:

\section{What is the role of the genotype in clinical management of the RTT female?}

The limited correlations between the RTT genotype and phenotype might be due to several reasons. In chapter $\mathbf{2}$ one possible reason, namely "the effect of subjectivity among clinicians and researchers completing the scoring lists" is investigated. Chapter 3 presents a collaborative multicentre study evaluating the influence of the genotype on brainstem instability in RTT.

\section{Malnutrition in RTT: could altered metabolic processes be a cause?}

The pathophysiology of malnutrition in RTT remains unclear. Altered metabolic processes, due to the breathing irregularities present in RTT, are suspected. Meta- 
bolic investigations to test this hypothesis are described and discussed in chapter 4 and appendix 1.

\section{What is the phenotype of adult RTT women?}

Given the need for good knowledge of the ageing process in RTT, two ageing studies were carried out. In chapter $\mathbf{5}$ and $\mathbf{6}$ these studies are presented, providing more insight into age-related features in RTT. The first study is a cross-sectional study and the second a longitudinal study.

In chapter 7, is a general discussion reflecting upon the findings and their implication for clinical management of RTT with recommendation for future research. In appendix 2 the important role of autonomic dysfunction in RTT is discussed and a description of the autonomic assessment as performed at the RTT Expertise Centre is provided. 


\section{References}

Amir RE, Van den Veyver IB, Schultz R, Malicki DM, Tran CQ, Dahle EJ, Philippi A, Timar L, Percy AK, Motil KJ, Lichtarge O, Smith EO, Glaze DG, Zoghbi HY. Influence of mutation type and X chromosome inactivation on Rett syndrome phenotypes. Ann Neurol 2000: 47: 670-679.

Amir RE, Van den Veyver IB, Wan M, Tran CQ, Francke U, Zoghbi HY. Rett syndrome is caused by mutations in X-linked MECP2, encoding methyl-CpG-binding protein 2. Nat Genet 1999: 23: 185-188.

Archer HL, Evans J, Edwards S, Colley J, Newbury-Ecob R, O'Callaghan F, Huyton M, O'Regan M, Tolmie J, Sampson J, Clarke A, Osborne J. CDKL5 mutations cause infantile spasms, early onset seizures, and severe mental retardation in female patients. J Med Genet 2006: 43: 729-734.

Ariani F, Hayek G, Rondinella D, Artuso R, Mencarelli MA, Spanhol-Rosseto A, Pollazzon M, Buoni S, Spiga O, Ricciardi S, Meloni I, Longo I, Mari F, Broccoli V, Zappella M, Renieri A. FOXG1 is responsible for the congenital variant of Rett syndrome. Am J Hum Genet 2008: 83: 89-93.

Auranen M, Vanhala R, Vosman M, Levander M, Varilo T, Hietala M, Riikonen R, Peltonen L, Järvelä I. MECP2 gene analysis in classical Rett syndrome and in patients with Rett-like features. Neurology 2001: 56: 611-617.

Bahi-Buisson N, Bienvenu T. CDKL5-Related Disorders: From Clinical Description to Molecular Genetics. Mol Syndromol 2011: 2: 137-152.

Bebbington A, Anderson A, Ravine D, Fyfe S, Pineda M, De Klerk N, Ben-Zeev B, Yatawara N, Percy A, Kaufmann WE, Leonard $\mathrm{H}$. Investigating genotype-phenotype relationships in Rett syndrome using an international data set. Neurology 2008: 70: 868-875.

Bebbington A, Percy A, Christodoulou J, Ravine D, Ho G, Jacoby P, Anderson A, Pineda M, Ben Zeev B, Bahi-Buisson N, Smeets $\mathrm{E}$, Leonard $\mathrm{H}$. Updating the profile of C- terminal MECP2 deletions in Rett syndrome. J Med Genet 2010: 47: 242-248.

Berger-Sweeney J. Cognitive deficits in Rett syndrome: what we know and what we need to know to treat them. Neurobiol Learn Mem 2011: 96(4): 637-646.

Bernard S, Maaskant MA, Gevers JPM, Wierda H. Voorspellingen ten aanzien van het aantal oudere mensen met een verstandelijke handicap in algemene woonvoorzieningen 1996- 2011. Ned Tijdschr Verst Gehand 2002: 27: 166-177.

Bienvenu T, Philippe C, De Roux N, Raynaud M, Bonnefond JP, Pasquier L, Lesca G, Mancini J, Jonveaux P, Moncla A, Feingold J, Chelly J, Villard L. The incidence of Rett syndrome in France. Pediatr Neurol 2006: 34(5): 372-375.

Bradbury, MK, Hoffbuhr, KC, Hoffman, EP. Rett syndrome. eLS 2007.

Cass H, Reilly S, Owen L, Wisbeach A, Weekes L, Slonims V, Wigram T, Charman T. Findings from a multidisciplinary clinical case series of females with Rett syndrome. Dev Med Child Neurol 2003: 45: 325337.

Chahrour M, Zoghbi HY. The story of Rett syndrome: from clinic to neurobiology. Neuron 2007: 56: 422437.

Charman T, Neilson TC, Mash V, Archer H, Gardiner MT, Knudsen GP, McDonnell A, Perry J, Whatley SD, Bunyan DJ, Ravn K, Mount RH, Hastings RP, Hulten M, Orstavik KH, Reilly S, Cass H, Clarke A, Kerr AM, Bailey ME. Dimensional phenotypic analysis and functional categorisation of mutations reveal novel genotype-phenotype associations in Rett syndrome. Eur J Hum Genet 2005: 13: 1121-1130.

Cheadle JP, Gill H, Fleming N, Maynard J, Kerr A, Leonard H, Krawczak M, Cooper DN, Lynch S, Thomas N, Hughes $H$, Hulten $M$, Ravine D, Sampson JR, Clarke A. Long-read sequence analysis of the MECP2 gene in Rett syndrome patients: correlation of disease severity with mutation type and location. Hum Mol Genet 2000: 9: 1119-1129.

Colvin L, Leonard H, de Klerk N, Davis M, Weaving L, Williamson S, Christodoulou Refining the phenotype of common mutations in Rett syndrome. J Med Genet 2004: 41: 25-30.

De Bona C, Zappella M, Hayek G, Meloni I, Vitelli F, Bruttini M, Cusano R, Loffredo P, Longo I, Renieri A. Preserved speech variant is allelic of classic Rett syndrome. Eur J Hum Genet 2000: 8(5): 325-330. 
Donckerwolcke RAMG, Van Zeben-Van der Aa DMCB. Overdracht van de zorg voor adolescenten met chronische ziekten: Van kindergeneeskunde naar specialismen voor volwassenen. Ned Tijdschr Geneeskd 2002: 146: 675-678.

Ellaway C, Christodoulou J. Rett syndrome: Clinical characteristics and recent genetic advances. Disabil Rehabil 2001: 23: 98-106.

Fisher K, Kettl P. Aging with mental retardation: Increasing population of older adults with MR require health interventions and prevention strategies. Geriatrics 2005: 60: 26-29.

Florian C, Bahi-Buisson N, Bienvenu T. FOXG1-Related Disorders: From Clinical Description to Molecular Genetics. Mol Syndromol 2011: 2: 153-163.

Freilinger M, Bebbington A, Lanator I, De Klerk N, Dunkler D, Seidl R, Leonard H, Ronen GM. Survival with Rett syndrome:comparing Rett's original sample with data from the Australian Rett Syndrome Database. Dev Med Child Neurol 2010: 52: 962-965.

Fukuda T, Yamashita Y, Nagamitsu S, Miyamoto K, Jin JJ, Ohmori I, Ohtsuka Y, Kuwajima K, Endo S, Iwai T, Yamagata H, Tabara Y, Miki T, Matsuishi T, Kondo I. Methyl- CpG binding protein 2 gene (MECP2) variations in Japanese patients with Rett syndrome: pathological mutations and polymorphisms. Brain Dev 2005: 27: 211-217.

Gadalla KK, Bailey ME, Spike RC, Ross PD, Woodard KT, Kalburgi SN, Bachaboina L, Deng JV, West AE, Samulski RJ, Gray SJ, Cobb SR. Improved Survival and Reduced Phenotypic Severity Following AAV9/MECP2 Gene Transfer to Neonatal and Juvenile Male Mecp2 Knockout Mice. Mol Ther 2012: Epub ahead of print.

Grillo E, Villard L, Clarke A, Ben Zeev B, Pineda M, Bahi-Buisson N, Hryniewiecka- Jaworska A, Bienvenu T, Armstrong J, Roche-Martinez A, Mari F, Veneselli E, Russo S, Vignoli A, Pini G, Djuric M, Bisgaard AM, Mejaški Bošnjak V, Polgár N, Cogliati F, Ravn K, Pintaudi M, Melegh B, Craiu D, Djukic A, Renieri A. Rett networked database: an integrated clinical and genetic network of Rett syndrome databases. Hum Mutat 2012: 33(7): 1031-1036.

Guy J, Gan J, Selfridge J, Cobb S, Bird A. Reversal of neurological defects in a mouse model of Rett syndrome. Science 2007: 315: 1143-1147.

Hagberg B. Rett syndrome: clinical peculiarities and biological mysteries. Acta Paediatr 1995: 84: 971976.

Hagberg B. Clinical manifestations and stages of Rett syndrome. Ment Retard Dev Disabil Res Rev 2002: 8: 61-65.

Hagberg, B. Rett syndrome. Long-term clinical follow-up experiences over four decades. J Child Neurol 2005: 20(9): 722-726.

Hagberg B, Aicardi J, Dias K, Ramos O. A progressive syndrome of autism, dementia, ataxia, and loss of purposeful hand use in girls: Rett's syndrome: Report of 35 cases. Ann Neurol 1983: 14: 471-479.

Hagberg B, Gillberg C. Rett variants-Rettoid phenotypes. In: Hagberg B, editor. Rett Syndrome, Clinical and Biological Aspects, Clinics in Developmental Medicine. MacKeith Press/Cambridge University Press 1993: 40-60.

Hagberg B, Hanefeld F, Percy A, Skjeldal O. An update on clinically applicable diagnostic criteria in Rett syndrome: Comments to Rett Syndrome Clinical Criteria Consensus Panel Satellite to European Paediatric Neurology Society Meeting, Baden Baden, Germany, 11 September 2001. Eur J Paediatr Neurol 2002: 6: 293-297.

Hagberg B, Witt-Engerström I. Rett syndrome: A suggested staging system for describing impairment profile with increasing age towards adolescence. Am J Med Genet 1986: 24: 47-59.

Ham AL, Kumar A, Deeter R, Schanen NC. Does genotype predict phenotype in Rett syndrome? J Child Neurol 2005: 20: 768-778.

Hanefeld F. The clinical pattern of the Rett syndrome. Brain Dev 1985: 7: 320-25.

Haveman M, Heller T, Lee L, Maaskant M, Shooshtari S, Strydom A. Major Health Risks in Aging Persons With Intellectual Disabilities: An Overview of Recent Studies. JPPID 2010: 7(1): 59-69. 
Haveman MJ, Heller T, Lee LA, Maaskant MA, Shooshtari S, Strydom A. Report on the State of Science on Health Risks and Ageing in People with Intellectual Disabilities. IASSID Special Interest Research Group on Ageing and Intellectual Disabilities/Faculty Rehabilitation Sciences, University of Dortmund, 2009.

Hite KC, Adams VH, Hansen JC. Recent advances in MeCP2 structure and function. Biochem Cell Biol 2009: 87(1): 219-227.

Hoffbuhr K, Devaney JM, LaFleur B, Sirianni N, Scacheri C, Giron J, Schuette J, Innis J, Marino M, Philippart M, Narayanan V, Umansky R, Kronn D, Hoffman EP, Naidu S. MeCP2 mutations in children with and without the phenotype of Rett syndrome. Neurology 2001: 56: 1486-1495.

Hoffbuhr KC, Moses LM, Jerdonek MA, Naidu S, Hoffman EP. Associations between MECP2 mutations, Xchromosome inactivation, and phenotype. Ment Retard Dev Disabil Res Rev 2002: 8: 99-105.

Huppke P, Held M, Handefeld F, Engel W, Laccone F. Influence of mutation type and location on phenotype in 123 patients with Rett syndrome. Neuropediatrics 2002: 33: 63-68.

Huppke P, Laccone F, Kramer N, Engel W, Hanefeld F. Rett syndrome: analysis of MECP2 and clinical characterization of 31 patients. Hum Mol Genet 2000: 9: 1369- 1375.

Jacobsen K, Viken A, Von Tetzchner S. Rett syndrome and ageing: a case study. Disabil Rehabil 2001: 23(3-4): 160-166.

Janicki MP, Breitenbrach N. Ageing \& Intellectual Disabilities - Improving Longevity \& Promoting Healthy Ageing: Summative Report. Geneva, Switzerland: World Health Organization 2000.

Julu POO. The central autonomic disturbance in Rett syndrome. In: Kerr AM, Witt Engerström I, editors. Rett Disorder and the Developing Brain. Oxford: Oxford University Press 2001: 131-181.

Julu PO, Engerström IW, Hansen S, Apartopoulos F, Engerström B, Pini G, Delamont RS, Smeets EE. Cardiorespiratory challenges in Rett's syndrome. Lancet 2008: 371: 1981- 1983.

Julu PO, Witt Engerström I. Assessment of the maturity-related brainstem functions reveals the heterogeneous phenotypes and facilitates clinical management of Rett syndrome. Brain Dev 2005: 27(suppl 1): S43-S53.

Kankirawatana P, Leonard H, Ellaway C, Scurlock J, Mansour A, Makris CM, Dure LS, Friez M, Lane J, Kiraly-Borri C, Fabian V, Davis M, Jackson J, Christodoulou J, Kaufmann WE, Ravine D, Percy AK. Early progressive encephalopathy in boys and MECP2 mutation. Neurology 2006: 67: 164-166.

Kerr AM, Prescott RJ. Predictive value of the early clinical signs in Rett disorder. Brain Dev 2005: 27: S20S24.

Kerr AM, Witt Engerström I. The clinical background to the Rett disorder. In: Kerr AM, Witt Engerström I, editors. Rett Disorder and the Developing Brain. Oxford: Oxford University Press 2001: 1-26.

Kirby RS, Lane JB, Childers J, Skinner SA, Annese F, Barrish JO, Glaze DG, Macleod P, Percy AK. Longevity in Rett syndrome: analysis of the North American database. J Pediatr 2010: 156: 135-138.

Leonard H, Bower C, English D. The prevalence and incidence of Rett syndrome in Australia. Eur Child Adolesc Psychiatry 1997: 6(Suppl 1): 8-10.

Leonard H, Colvin L, Christodoulou J, Schiavello T, Williamson S, Davis M, Ravine D, Fyfe S, de Klerk N, Matsuishi T, Kondo I, Clarke A, Hackwell S, Yamashita Y. Patients with the R133C mutation: is their phenotype different from Rett syndrome patients with other mutations? J Med Genet 2003: 40: e52.

Leonard H, Moore H, Carey M, Fyfe S, Hall S, Robertson L, Wu XR, Bao X, Pan H, Christodoulou J, Williamson S, Klerk Nd. Genotype and early development in Rett syndrome: The value of international data. Brain Dev 2005: 27: S59-S68.

Lioy DT, Garg SK, Monaghan CE, Raber J, Foust KD, Kaspar BK, Hirrlinger PG, Kirchhoff F, Bissonnette JM, Ballas N, Mandel G. A role for glia in the progression of Rett's syndrome. Nature 2011: 29: 497-500.

Lotan M, Merrick J, Kandel I, Morad M. Aging in Persons with Rett Syndrome: An Updated Review. ScientificWorldJournal 2010: 10: 778-787.

Maaskant MA, Gevers JPM, Wierda H. Mortality and live expectancy in Dutch residential centres for individuals with intellectual disabilities, 1991-1995. J Appl Res Int Dis 2002: 15: 200-212. 
Maaskant MA, Van den Akker M, Kessels AG, Haveman MJ, Van Schrojenstein Lantman-De Valk HM, Urlings HF. Care dependence and activities of daily living in relation to aging: Results of a longitudinal study. J Intellect Disabil Res 1996: 40: 535-543.

Matijevic T, Knezevic J, Slavica M, Pavelic J. Rett syndrome: from the gene to the disease. Eur Neurol 2009: 61(1): 3-10.

Mencarelli MA, Spanhol-Rosseto A, Artuso R, Rondinella D, De Filippis R, Bahi- Buisson N, Nectoux J, Rubinsztajn R, Bienvenu T, Moncla A, Chabrol B, Villard L, Krumina Z, Armstrong J, Roche A, Pineda M, Gak E, Mari F, Ariani F, Renieri A. Novel FOXG1 mutations associated with the congenital variant of Rett syndrome. J Med Genet 2010: 47(1): 49-53.

Monros E, Armstrong J, Aibar E, Poo P, Canos I, Pineda M. Rett syndrome in Spain: mutation analysis and clinical correlations. Brain Dev 2001: 23(Suppl 1): S251-S253.

Moog U, Van Roozendaal K, Smeets E, Tserpelis D, Devriendt K, Buggenhout GV, Frijns JP, SchranderStumpel C. MECP2 mutations are an infrequent cause of mental retardation associated with neurological problems in male patients. Brain Dev 2006: 28: 305-310.

Motil KJ, Caeg E, Barrish JO, Geerts S, Lane JB, Percy AK, Annese F, McNair L, Skinner SA, Lee HS, Neul JL, Glaze DG. Gastrointestinal and nutritional problems occur frequently throughout life in girls and women with Rett syndrome. J Pediatr Gastroenterol Nutr 2012: 55(3): 292-298.

Motil KJ, Morrissey M, Caeg E, Barrish JO, Glaze DG. Gastrostomy placement improves height and weight gain in girls with Rett syndrome. J Pediatr Gastroenterol Nutr 2009: 49(2): 237-242.

Motil KJ, Schultz RJ, Wong WW, Glaze DG. Increased energy expenditure associated with repetitive involuntary movement does not contribute to growth failure in girls with Rett syndrome. J Pediatr 1998: 132(2): 228-233.

Mount RH, Hastings RP, Reilly S, Cass H, Charman T. Behavioural and emotional features in Rett syndrome. Disabil Rehabil 2001: 23(3-4): 129-138.

Nan X, Campoy FJ, Bird A. MECP2 is a transcriptional repressor with abundant binding sites in genomic chromatin. Cell 1997: 88: 471-481.

Neul JL, Fang P, Barrish J, Lane J, Caeg EB, Smith EO, Zoghbi H, Percy A, Glaze DG. Specific mutations in methyl-CpG-binding protein 2 confer different severity in Rett syndrome. Neurology 2008; 70: 13131321.

Neul JL, Kaufmann WE, Glaze DG, Christodoulou J, Clarke AJ, Bahi-Buisson N, Leonard H, Bailey ME, Schanen NC, Zappella M, Renieri A, Huppke P, Percy AK, RettSearch Consortium. Rett syndrome: revised diagnostic criteria and nomenclature. Ann Neurol 2010: 68: 944-950.

Nielsen JB, Henriksen KF, Hansen C, Silahtaroglu A, Schwartz M, Tommerup N. MECP2 mutations in Danish patients with Rett syndrome: high frequency of mutations but no consistent correlations with clinical severity or with the X chromosome inactivation pattern. Eur J Hum Genet 2001: 9: 178-184.

Nielsen JB, Ravn K, Schwartz M. A 77-year-old woman and a preserved speech variant among Danish Rett patients with mutations in MECP2. Brain Dev 2001: 23: S230- 232.

Oddy WH, Webb KG, Baikie G, Thompson SM, Reilly S, Fyfe SD, Young D, Anderson AM, Leonard H. Feeding experiences and growth status in a Rett syndrome population. J Pediatr Gastroenterol Nutr 2007: 45(5): 582-590.

Ogier M, Katz DM. Breathing dysfunction in Rett syndrome: understanding epigenetic regulation of the respiratory network. Respir Physiol Neurobiol 2008: 164(1-2): 55-63.

Patja K, livanainen M, Vesala H, Oksanen $\mathrm{H}$, Ruoppila I. Life expectancy of people with intellectual disabilities: A 35-year follow-up study. J Intellect Disabil Res 2000: 44: 591- 599.

Percy AK. Rett syndrome: recent research progress. J Child Neurol 2008: 23(5): 543-549.

Platte $\mathrm{P}$, Jaschke $\mathrm{H}$, Herbert $\mathrm{C}$, Korenke GC. Increased resting metabolic rate in girls with Rett syndrome compared to girls with developmental disabilities. Neuropediatrics 2011: 42(5): 179-182.

Reilly S, Cass H. Growth and nutrition in Rett syndrome. Disabil Rehabil 2001: 23: 118-128.

Renieri A, Mari F, Mencarelli MA, Scala E, Ariani F, Longo I, Meloni I, Cevenini G, Pini G, Hayek G, Zappella M. Diagnostic criteria for the Zappella variant of Rett syndrome (the preserved speech variant). Brain Dev 2009: 31(3): 208-216. 
Rett A. Über ein eigenartiges hirnatrophisches syndrom bei hyperamonaemie im kindesalter. Wien Med Wochenschr 1996: 116: 723-726.

Rice MA, Haas RH. The nutritional aspects of Rett syndrome. J Child Neurol 1988: 3: S35-42.

Santos M, Temudo T, Kay T, Carrilho I, Medeira A, Cabral H, Gomes R, Lourenç̧o MT, Venâncio M, Calado E, Moreira A, Oliveira G and Maciel P. Mutations in the MECP2 Gene Are Not a Major Cause of Rett Syndrome-Like or Related Neurodevelopmental Phenotype in Male Patients. J Child Neurol 2009: 24: 49-55.

Schanen C, Houwink EJ, Dorrani N, Lane J, Everett R, Feng A, Cantor RM, Percy A. Phenotypic manifestations of MECP2 mutations in classical and atypical Rett syndrome. Am J Med Genet 2004: 126A: 129140.

Schultz RJ, Glaze DG, Motil KJ, Armstrong DD, del Junco DJ, Hubbard CR, Percy AK. The pattern of growth failure in Rett syndrome. Am J Dis Child 1993: 147(6): 633-637.

Smeets EE, Chenault M, Curfs LM, Schrander-Stumpel CT, Frijns JP. Rett syndrome and long-term disorder profile. Am J Med Genet Part A 2009: 149A: 199-205.

Smeets EE, Julu PO, Van Waardenburg D, Engerström IW, Hansen S, Apartopoulos F, Curfs LM, SchranderStumpel CT. Management of a severe forceful breather with Rett syndrome using carbogen. Brain Dev 2006: 28(10): 625-632.

Smeets EE, Pelc K, Dan B. Rett syndrome. Mol Syndromol 2012: 2(3-5): 113-127.

Smeets E, Schollen E, Moog U, Matthijs G, Herbergs J, Smeets H, Curfs L, Schrander-Stumpel C, Fryns JP. Rett syndrome in adolescent and adult females: clinical and molecular genetic findings. Am J Med Genet 2003: 122A: 227-233.

Smeets E, Terhal P, Casaer P, Peters A, Midro A, Schollen E, Van Roozendaal K, Moog U, Matthijs G, Herbergs J, Smeets H, Curfs L, Schrander-Stumpel C, Fryns JP. Rett syndrome in females with CTS hot spot deletions: a disorder profile. Am J Med Genet 2005: 132: 117-120.

Tao J, Van Esch H, Hagedorn-Greiwe M, Hoffmann K, Moser B, Raynaud M, Sperner J, Fryns JP, Schwinger E, Gécz J, Ropers HH, Kalscheuer VM. Mutations in the X-linked cyclin-dependent kinase-like 5 (CDKL5/STK9) gene are associated with severe neurodevelopmental retardation. Am J Hum Genet 2004: 75: 1149-1154.

Takahashi S, Ohinata J, Makita Y, Suzuki N, Araki A, Sasaki A, Murono K, Tanaka H, Fujieda K. Skewed X chromosome inactivation failed to explain the normal phenotype of a carrier female with MECP2 mutation resulting in Rett syndrome. Clin Genet 2008: 73(3): 257-261.

Temudo T, Santos M, Ramos E, Dias K, Vieira JP, Moreira A, Calado E, Carrilho I, Oliveira G, Levy A, Barbot C, Fonseca M, Cabral A, Cabral P, Monteiro J, Borges L, Gomes R, Mira G, Pereira SA, Santos M, Fernandes A, Epplen JT, Sequeiros J, Maciel P. Rett syndrome with and without detected MECP2 mutations: an attempt to redefine phenotypes. Brain Dev 2011: 33(1): 69-76.

Tyler CV, Garey Noritz G. Healthcare issues in aging adults with intellectual and other developmental disabilities. Clinical Geriatrics 2009: 17(8): 30-35.

Van Schrojenstein Lantman-De Valk HM, Van den Akker M, Maaskant MA, Haveman MJ, Urlings HF, Kessels AG, Crebolder HF. Prevalence and incidence of health problems in people with intellectual disabilities. J Intellect Disabil Res 1997: 41: 42-51.

Vignoli A, La Briola F, Peron A, Turner K, Savini M, Cogliati F, Russo S, Canevini MP. Medical care of adolescents and women with Rett syndrome: An Italian study. Am J Med Genet Part A 2012: 158A: 1318.

Villard L. MECP2 mutations in males. J Med Genet 2007: 44: 417-423.

Weaving LS, Ellaway CJ, Gécz J, Christodoulou J. Rett syndrome: clinical review and genetic update. J Med Genet 2005: 42(1): 1-7.

Weaving LS, Williamson SL, Bennetts B, Davis M, Ellaway CJ, Leonard H, Thong MK, Delatycki M, Thompson EM, Laing N, Christodoulou J. Effects of MECP2 mutation type, location and X-inactivation in modulating Rett syndrome phenotype. Am J Med Genet 2003: 118A: 103-114.

Williamson SL, Christodoulou J. Rett syndrome: New clinical and molecular insights. Eur J Hum Genet 2006: 14: 896-903. 
Xinhua B, Shengling J, Fuying S, Hong,P, Meirong L, Wu XR. X chromosome inactivation in Rett syndrome and its correlations with MECP2 mutations and phenotype. J Child Neurol 2008: 23: 22-25.

Yamashita Y, Kondo I, Fukuda T, Morishima R, Kusaga A, Iwanaga R, Matsuishi T. Mutation analysis of the methyl-CpG-binding protein 2 gene (MECP2) in Rett patients with preserved speech. Brain Dev 2001: 23(Suppl 1): S157-S160.

Zappella M. The Rett girls with preserved speech. Brain Dev 1992: 14: 98-101.

Zoghbi, H.Y. Rett syndrome: what do we know for sure? Nat Neurosci 2009: 12: 239-240. 



\section{Chapter 2}

Genotype-phenotype relationships as prognosticators in Rett syndrome should be handled with care in clinical practice

Halbach NSJ, Smeets EEJ, Van den Braak N, Van Roozendaal KEP, Blok RMJ, Schrander-Stumpel CTRM, Frijns JP, Maaskant MA, Curfs LMG. 


\begin{abstract}
Rett syndrome (RTT; OMIM 312750) is an X-linked dominant neurodevelopmental disorder leading to cognitive and motor impairment, epilepsy, and autonomic dysfunction in females. Since the discovery that RTT is caused by mutations in MECP2, large retrospective genotype-phenotype correlation studies have been performed. A number of general genotype-phenotype relationships were confirmed and specific disorder profiles were described. Nevertheless, conflicting results are still under discussion, partly due to the variability in classification of mutations, assessment tools, and structure of the data sets. The aim of this study was to investigate relationships between genotype and specific clinical data collected by the same experienced physician in a well-documented RTT cohort, and evaluate its prognostic value in counseling young parents with a newly diagnosed RTT girl regarding her future outcome. The Maastricht-Leuven Rett Syndrome Database is a register of 137 molecularly confirmed clinical RTT cases, containing both molecular and clinical data on examination and follow up by the same experienced physician. Although the general genotype-phenotype relationships were confirmed, the clinical severity was still found to be very variable. We therefore recommend caution in using genotypephenotype data in the prognosis of outcome for children in Rett syndrome. Early diagnosis, early intervention, and preventive management are imperative for better outcomes and better quality of daily life for RTT females and their families.
\end{abstract}




\section{Introduction}

Rett syndrome (RTT; OMIM 312750) is a unique X-linked dominant neurodevelopmental disorder leading to cognitive and motor impairments, epilepsy, and autonomic dysfunctions in females (Hagberg et al., 1983; Williamson \& Christodoulou, 2006; Smeets et al., 2009). Clinical diagnosis is readily confirmed by finding a mutation in the methyl-CpG-binding protein 2 gene (MECP2) located on the $\mathrm{X}$ chromosome (Amir et al., 1999). Since the discovery of MECP2, large retrospective genotype-phenotype correlation studies have been performed. A number of general genotype-phenotype relationships were confirmed and specific disorder profiles were described (Huppke et al., 2002; Leonard et al., 2003; Colvin et al., 2004; Schanen et al., 2004; Charman et al., 2005; Kerr \& Prescott, 2005; Leonard et al., 2005; Smeets et al., 2005; Bebbington et al., 2008; Neul et al., 2008; Smeets et al., 2009; Bebbington et al., 2010). Nevertheless, conflicting results are still under discussion, partly due to the variability in classification of mutations, assessment tools and structure of the data sets (Ham et al., 2005). The aim of this study was to investigate relationships between genotype and specific clinical data collected by the same experienced physician in a well-documented RTT cohort, and to evaluate its prognostic value in counseling young parents with a newly diagnosed RTT girl regarding her future outcome. This study was performed in collaboration with the members of the ESRRA group (see Acknowledgments).

\section{Materials and methods}

\section{The Maastricht-Leuven Rett syndrome database}

The Maastricht-Leuven Rett Syndrome (MLRS) database currently consists of 137 molecularly confirmed RTT cases. It contains both molecular and clinical data on examination and follow-up by the second author, a physician already experienced in RTT. The RTT center of expertise was founded after the discovery of MECP2 mutations as the genetic cause of RTT (Amir et al., 1999). Dutch and Belgian RTT females were referred to this center by general practitioners, pediatricians, and pediatric neurologists for diagnosis or second opinion of RTT. Complementary to the start of the center, the MLRS database was set up in 2000. For the database, diagnosis of RTT was based on the consensus diagnostic criteria for RTT (Hagberg et al., 2002), and confirmed by identifying a mutation in the MECP2 gene. Phenotypic data were collected through clinical evaluations including data on personal history, age at onset of stagnation, age at diagnosis, clinical type, and clinical severity of RTT (scored using the International Scoring System, ISS). The database lacks some older women with RTT, since in this age group clinical and genetic data were often incomplete. 


\section{DNA analysis}

DNA analysis was performed by sequencing the coding and intron regions and by additional Multiplex Ligation-dependent Probe Amplification (MLPA) analysis of $M E C P 2$ to exclude for large deletions. Nomenclature according to the MECP2A isoform reference sequence AF158180 was used, numbering started at the $A$ of the ATG translation initiation codon. X-chromosome inactivation $(\mathrm{XCI})$ was studied only in 22 cases and has been published before (Smeets et al., 2003).

Mutations were classified by location in the gene, including the methyl-CpGbinding domain (MBD), the transcription repression domain (TRD) and the Cterminal segment (CTS) of MECP2 (Table 1). The CTS hot spot region is an area between the base pairs (bp) at position 1030 and 1207 in MECP2 (Huppke et al., 2002). Furthermore, mutations were defined as recurrent when present in five or more females and analyzed separately as individual mutations. The p.R168X mutation is located in the inter-domain region between MBD and TRD. For analysis it is grouped as a mutation in the TRD domain, since this mutation leaves the MBD intact. Finally, since large deletions are not restricted to one domain they are excluded for genotype-phenotype analysis.

Table 1 Mutation type and localization in MECP2

\begin{tabular}{|c|c|c|c|c|c|}
\hline Domain in MECP2 & $M B D(n)$ & $\operatorname{TRD}(\mathrm{n})$ & CTS (n) & Others $(n)$ & Total \\
\hline & p.D97E (1) & p.P225R (1) & p.S373X (1) & Large deletions (8) & \\
\hline & p.L100V (1) & p.R306C (12) & Frameshifts (14) & & \\
\hline & p.P101S (1) & p.R255X (15) & & & \\
\hline & p.R106W (4) & p.R270X (9) & & & \\
\hline & p.Q128P (1) & p.R294X (12) & & & \\
\hline & p.R133C (10) & p.R168X (15) & & & \\
\hline & p.R133H (2) & Frameshifts (9) & & & \\
\hline & p.P152R (5) & & & & \\
\hline & p.F157L (1) & & & & \\
\hline & p.T158M (15) & & & & \\
\hline Total & 41 & 73 & 15 & 8 & 137 \\
\hline
\end{tabular}

MBD: methyl-CpG-binding domain, TRD: transcription repression domain, CTS: C-terminal segment, $\mathrm{n}$ : number of patients (Nomenclature according to the MECP2A isoform reference sequence AF158180, numbering starting at the $A$ of the ATG translation initiation codon)

\section{International scoring system}

Clinical severity was assessed using the International Scoring System (ISS, Table 2) (Kerr et al., 2001). Complete clinical and molecular data were available for the cohort of 137 RTT females, examined and re-examined between 1983 and January 2009. Firstly, the ISS score was used to compare clinical severity in a quantitative 
manner. The clinical scoring system consists of 20 items (features common in RTT, ranging from $A$ to $T$ ), which were scored from 0 to 2; the lower the score, the better the clinical condition. The maximum score being 40, a score above 30 was considered as very severe, a score of 25-29 as severe, and a score of 10-24 as mild to less severe. A score $<10$ indicates the best clinical condition still recognizable as RTT. Secondly, the 20 items of the ISS were grouped into five functional domains: growth and development (A-E), musculoskeletal (F-H), movement (I-M), cortical (N-P), and autonomic features $(\mathrm{Q}-\mathrm{T})$.

Table 2 ISS score (Adapted from Kerr et al., 2001)

\section{The Kerr scoring system}

A Head circumference during the first year

2 Already below the 3rd percentile at birth

1 Normal at birth but decelerating

0 Normal at birth with no deceleration

B Early developmental progress (birth to 12 months)

2 No or virtually no progress

1 Suboptimal progress

0 Normal progress

C Present head circumference (percentile/standard deviations sd)

2 Below 3rd percentile

13 rd to10th percentile

0 Above 10th percentile

D Weight $(\mathrm{kg})$

2 Below 3rd percentile

1 3rd to10th percentile

0 Above 10th percentile

E Height $(\mathrm{cm})$

2 Below 3rd percentile

13 rd to10th percentile

0 Above 10th percentile 


\section{The Kerr scoring system}

\section{MUSCULOSKELETAL}

F Muscle tone (also describe)

2 Severe hypotonia, dystonia or hypertonia

1 Tone mildly abnormal

0 Normal

G Spine posture

2 Severe scoliosis

1 Mild scoliosis

0 No deviation

$\mathrm{H}$ Joint contractures

2 Severe contractures

1 Minor contractures

0 None

\section{MOVEMENT}

I Gross motor function

2 Cannot walk with support

1 Walking impaired

0 Walks normally

J Hand stereotypy (patting, sqeezing, wringing, mouthing)

2 Dominating or constant

1 Mild or intermittent

0 None

$\mathrm{K}$ Other involuntary movements (e.g. tremor, dystonia, chorea, athetosis)

2 Dominating or constant

1 Mild or intermittent

0 None

L Voluntary hand use (e.g. self feeding)

2 None

1 Reduced or poor

0 Hand use normal

M Oro-motor difficulty

2 Severe (e.g. feeding aversion; gagging, choking, tube/button fed)

1 Slight (e.g. delayed chewing, swallowing, on supplements)

0 None

\section{CORTICAL}

$\mathrm{N}$ Intellectual disability (= learning disability = retardation)

2 Apparent profound (infant level)

1 Any except profound

0 No impairment

O Speech

2 Currently uses no real words with meaning

1 Currently uses some real words with meaning

0 Normal speech 


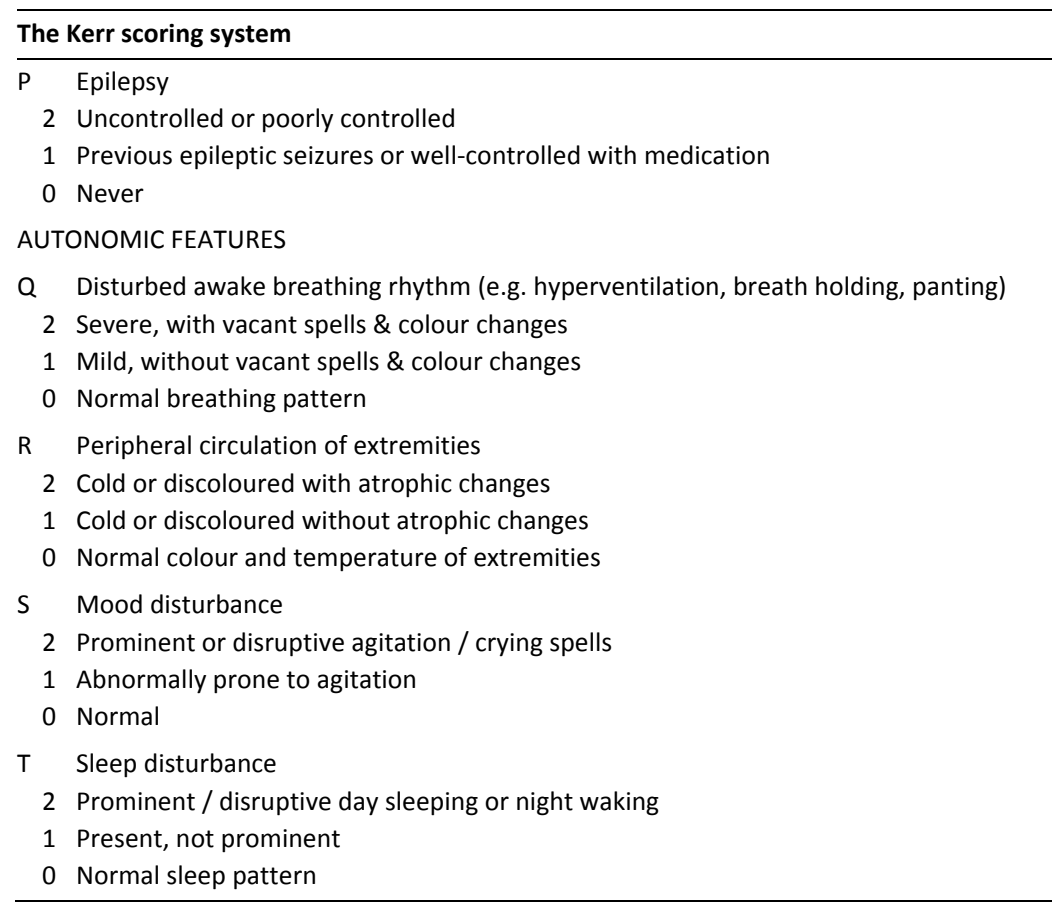

\section{Data analyses}

SPSS version 16.0 was used for analyzing the data. Comparisons of clinical data (age at onset of stagnation, diagnosis, and examination), overall severity score, domain scores, and the individual ISS item scores between the different domains of mutations and the individual recurrent mutations were performed. The Mann-Whitney $U$ test or Kruskal Wallis test (respectively, non-parametric test for two and more than two unrelated groups) were used when the data did not follow normal distribution (i.e., age at onset of stagnation, diagnosis and examination). Independent t-tests (means of two groups) or ANOVA (means of more than two groups) were used when the dependent variable was normally distributed (i.e., ISS). For ISS-total scores and ISS-domain scores, mean scores were computed. The age of examination differed between the respondents (range $2-49$ years; mean: 14.9 years).

Since it is plausible that age at examination did influence the ISS scores, mean total and mean domain scores were corrected for age at examination via ANCOVA. Hereby, based on clinical considerations and to avoid small numbers in subgroups, age at examinations was divided into three age groups: 0-9 years, 10-19 years and above 20 years of age. Chi-square tests were used to compare nominal data (ISS items). In these analyses, no correction for age at examination was performed due to the small sample size. However, it was analyzed by means of Chi-square tests if age at examination was statistically significantly related to the scores on the ISS- 
items, thus was a possible confounder. If this was the case, this was mentioned in the results. A p-value of $\leq 0.05$ (two-sided testing) was used as threshold for statistical significance in all tests.

\section{Results}

Arranged by subject, explanatory remarks are made below.

\section{RTT cases}

Among the 137 females, 80\% ( $n=109)$ were categorized as classic RTT and $20 \%$ $(n=28)$ as variant RTT. The mean age at data collection was 14.9 years (range 2-49, $\mathrm{sd}=10.7$ ). In the majority of the females, stagnation was noted at the age of 12 months (mean 12.0 , range $0-60, \mathrm{sd}=8.2$ ). The mean age at diagnosis was 7.8 years (range $0-46, \mathrm{sd}=9.7$ ). Half of the females were diagnosed between 2 and 4 years of age.

Mean age at onset of stagnation. Mean age at onset was highest in females with a mutation in the MBD domain (13.6 months, $s d=9.6$ ) and almost equal in females with a mutation in the TRD or CTS domain (respectively, 11.5 months, $\mathrm{sd}=8.1$ and 11.6 months, $s d=5.3$ ). The differences in ranking were however not statistically significant (Kruskal Wallis test: $p=0.42$ ). Concerning the recurrent mutations, mean age at onset was substantially lower in females with a p.R168X mutation than females with a p.R306C mutation ( 7.3 months, $s d=5.9$ vs. 18.3 months, $s d=14.7$ ). The differences in ranking of all recurrent mutations were statistically significant (Kruskal Wallis test: $p=0.01$ ).

Mean age at diagnosis. Mean age at diagnosis was highest in females with a mutation in the MBD and TRD domain, followed by females with a mutation in the CTS domain (respectively, 8.2 years, $s d=10.2$, 8.0 years, $s d=10.5$ and 6.9 years, $s d=4.6$ ). The differences in ranking were not statistically significant (Kruskal Wallis test: $p=0.49$ ). In recurrent mutations the age at diagnosis was between 5.4 years $(s d=4.4)$ in females with a p.R294X mutation and 16.0 years ( $s d=16.1)$ in females with a p.R306C mutation. However, the differences in ranking of all recurrent mutations were not statistically significant (Kruskal Wallis test: $p=0.20$ ).

Mean age at examination. Mean age at examination was highest in females with a mutation in the MBD domain, followed by females with a mutation in the CTS and TRD domain (respectively, 16.4 years, sd=11.9, 14.7 years, sd=7.7 and 13.7 years, $s d=10.6)$. The differences in ranking were not statistically significant (Kruskal Wallis test: $p=0.42$ ). In recurrent mutations, the mean age at examination was between 8.6 years $(s d=8.9)$ in females with a p.R270X mutation and 22.1 years $(s d=11.0)$ in females with a p.R133C mutation. The differences in ranking were however not statistically significant (Kruskal Wallis test: $p=0.09$ ). 


\section{MECP2 mutations}

Of all the MECP2 mutations 79\% were recurrent: p.R133C, p.P152R, p.T158M, p.R168X, p.R255X, p.R270X, p.R294X, p.R306C, and the CTS mutations (Table 1). Frameshift mutations clustered in both the TRD and the CTS region. Frameshift mutations in the TRD domain were the result of small deletions, insertions, and duplications. They were located in the center of the TRD with a mean frameshift extension of 15 new amino acids before termination of translation. Frameshift mutations in CTS were all deletions, except for one due to a deletion and insertion. CTS deletions were all located in and around the hotspot region with a mean deletion of 40 nucleotides (range 32-44), nearly all leading to a frameshift within 10 amino acids. One deletion only was leading to a frameshift with an exceptionally long extension (c.1157_1189del33, p.Leu386GInfsX91). All large deletions span over a region encompassing exon 3 and exon 4 . The exact breakpoints were not investigated. In addition, one female showed a complex rearrangement in MECP2. She presented both loss of a part of exon 4 upstream to the hot spot region and a duplication of the 3'UTR end up to half of the IRAK2 gene. Preferential skewing was present in 5 of the $22 \mathrm{RTT}$ cases that were studied ( $\mathrm{XCl}$ with ratios $<20$ or $>80 \%$ ), regarding two females the results were not conclusive. However, skewing could not be related to the clinical severity.

\section{ISS score}

Table 3 shows the mean scores, range, and standard deviation (sd) or standard error (SE) of the ISS scoring list, including the total score, functional domains and individual items for all the RTT females and the MECP2 mutations with the lowest and highest scores.

Table 3 Mean scores, range and standard deviation (sd) or standard error (SE) of the ISS scoring list, including the total score*, score on functional domains* and individual items for all the RTT females and the MECP2 mutations with the lowest and highest scores

\begin{tabular}{llclll}
\hline ISS & MECP2 mutation & Mean score & Range & sd & SE \\
\hline Total ISS score & & 19.4 & $4-34$ & 6.7 & \\
$\quad$ Lowest score & p.R133C & 13.7 & $9-28$ & 2.01 \\
Highest score & p.P152R & 25.2 & $15-34$ & 2.75 \\
Domain Growth and development (ABCDE) & & 3.76 & $0-9$ & 2.5 & \\
Lowest score & p.R133C & 1.8 & $0-6$ & & 0.74 \\
Highest score & p.P152R & 5.5 & $4-7$ & & 1.02 \\
Item A & & 0.47 & $0-2$ & 0.56 \\
Lowest score & p.R294X & 0.17 & $0-1$ & 0.39 \\
Highest score & p.R270X & 0.89 & $0-2$ & 0.60
\end{tabular}




\begin{tabular}{|c|c|c|c|c|c|}
\hline ISS & MECP2 mutation & Mean score & Range & sd & SE \\
\hline Item B & & 0.64 & $0-2$ & 0.57 & \\
\hline Lowest score & p.R133C & 0.20 & $0-1$ & 0.42 & \\
\hline Highest score & p.R168X & 1.0 & $0-2$ & 0.54 & \\
\hline Item C & & 0.98 & $0-2$ & 0.83 & \\
\hline Lowest score & CTS & 0.40 & $0-2$ & 0.74 & \\
\hline Highest score & p.P152R & 1.6 & $1-2$ & 0.55 & \\
\hline Item D & & 0.78 & $0-2$ & 0.77 & \\
\hline Lowest score & p.R133C & 0.50 & $0-2$ & 0.71 & \\
\hline \multirow[t]{2}{*}{ Highest score } & p.R255X & 1.0 & $0-2$ & 0.93 & \\
\hline & p.R270X & 1.0 & $0-2$ & 0.71 & \\
\hline Item E & & 0.93 & $0-2$ & 0.74 & \\
\hline Lowest score & p.R294X & 0.50 & $0-1$ & 0.52 & \\
\hline Highest score & p.P152R & 1.4 & $1-2$ & 0.55 & \\
\hline Domain Musculoskeletal (FGH) & & 2.78 & $0-6$ & 1.9 & \\
\hline Lowest score & p.R306C & 1.3 & $0-5$ & & 0.48 \\
\hline Highest score & p.R168X & 3.9 & $0-6$ & & 0.42 \\
\hline Item F & & 1.09 & $0-2$ & 0.72 & \\
\hline Lowest score & p.R306C & 0.67 & $0-1$ & 0.49 & \\
\hline Highest score & p.R168X & 1.4 & $0-2$ & 0.83 & \\
\hline Item G & & 1.12 & $0-2$ & 0.84 & \\
\hline Lowest score & p.R306C & 0.83 & $0-2$ & 0.72 & \\
\hline Highest score & p.P152R & 1.6 & $0-2$ & 0.89 & \\
\hline Item $\mathrm{H}$ & & 0.54 & $0-2$ & 0.72 & \\
\hline Lowest score & CTS & 0.13 & $0-1$ & 0.35 & \\
\hline Highest score & p.R168X & 0.93 & $0-2$ & 0.96 & \\
\hline Domain Movement (IJKLM) & & 5.28 & $0-10$ & 2.2 & \\
\hline Lowest score & p.R306C & 3.5 & $1-8$ & & 0.61 \\
\hline Highest score & p.P152R & 7.1 & $4-9$ & & 0.92 \\
\hline Item I & & 1.12 & $0-2$ & 0.87 & \\
\hline Lowest score & p.R306C & 0.58 & $0-2$ & 0.79 & \\
\hline Highest score & p.R270X & 1.7 & $1-2$ & 0.50 & \\
\hline Item J & & 1.57 & $0-2$ & 0.57 & \\
\hline Lowest score & p.R294X & 1.2 & $0-2$ & 0.58 & \\
\hline Highest score & p.R270X & 1.9 & $1-2$ & 0.33 & \\
\hline Item K & & 0.50 & $0-2$ & 0.68 & \\
\hline Lowest score & p.R255X & 0.27 & $0-1$ & 0.46 & \\
\hline Highest score & p.P152R & 1.0 & $0-2$ & 0.71 & \\
\hline Item L & & 1.41 & $0-2$ & 0.66 & \\
\hline \multirow[t]{2}{*}{ Lowest score } & p.R306C & 1.1 & $0-2$ & 0.79 & \\
\hline & p.R294X & 1.1 & $0-2$ & 0.79 & \\
\hline Highest score & p.R255X & 1.7 & $0-2$ & 0.59 & \\
\hline Item M & & 0.67 & $0-2$ & 0.67 & \\
\hline Lowest score & p.R133C & 0.30 & $0-1$ & 0.48 & \\
\hline Highest score & p.P152R & 1.2 & $0-2$ & 1.1 & \\
\hline
\end{tabular}




\begin{tabular}{|c|c|c|c|c|c|}
\hline ISS & MECP2 mutation & Mean score & Range & sd & SE \\
\hline Domain Cortical (NOP) & & 4.37 & $2-6$ & 1.1 & \\
\hline Lowest score & CTS & 3.8 & $2-6$ & & 0.27 \\
\hline Highest score & p.P152R & 5.1 & $4-6$ & & 0.47 \\
\hline Item N & & 1.73 & $1-2$ & 0.45 & \\
\hline Lowest score & CTS & 1.4 & $1-2$ & 0.51 & \\
\hline Highest score & p.P152R & 2.0 & $2-2$ & 0 & \\
\hline Item 0 & & 1.85 & $0-2$ & 0.38 & \\
\hline Lowest score & p.R306C & 1.7 & $0-2$ & 0.65 & \\
\hline Highest score & p.P168X & 2.0 & $2-2$ & 0 & \\
\hline Item P & & 0.81 & $0-2$ & 0.74 & \\
\hline Lowest score & p.R270X & 0.56 & $0-2$ & 0.73 & \\
\hline Highest score & p.P152R & 1.2 & $0-2$ & 0.84 & \\
\hline Domain Autonomic features (QRST) & & 3.28 & $0-8$ & 1.7 & \\
\hline Lowest score & p.R270X & 2.7 & $0-4$ & & 0.59 \\
\hline Highest score & p.P152R & 4.2 & $1-7$ & & 0.78 \\
\hline Item Q & & 1.1 & $0-2$ & 0.67 & \\
\hline Lowest score & p.R133C & 0.60 & $0-1$ & 0.52 & \\
\hline Highest score & p.T158M & 1.3 & $1-2$ & 0.49 & \\
\hline Item R & & 0.97 & $0-2$ & 0.66 & \\
\hline Lowest score & p.R306C & 0.67 & $0-2$ & 0.65 & \\
\hline Highest score & p.P152R & 1.2 & $0-2$ & 0.84 & \\
\hline Item S & & 0.57 & $0-2$ & 0.68 & \\
\hline Lowest score & p.R270X & 0.33 & $0-1$ & 0.50 & \\
\hline \multirow[t]{2}{*}{ Highest score } & p.R294X & 1.0 & $0-2$ & 0.85 & \\
\hline & p.P152R & 1.0 & $0-2$ & 1.0 & \\
\hline Item T & & 0.65 & $0-2$ & 0.73 & \\
\hline Lowest score & p.R133C & 0.40 & $0-2$ & 0.70 & \\
\hline Highest score & p.R306C & 1.1 & $0-2$ & 0.72 & \\
\hline
\end{tabular}

* Corrected for age at examination

\section{Total ISS score}

The mean severity score on the ISS scoring list was 19.4 points (range 4-34, sd=6.7). Mild to less severe RTT (ISS score 10-24) was present in 66\%, severe RTT (ISS score $25-29$ ) in $21 \%$, the best clinical condition still recognizable as RTT (ISS score <10) in $7 \%$ and very severe RTT (ISS score $\geq 30$ ) in $5 \%$ of the RTT females.

Total ISS score was lowest in females with a CTS mutation $(15.9, \mathrm{SE}=1.69)$ in contrast to females with a mutation in the $\operatorname{MBD}(18.9, \mathrm{SE}=1.03)$ or TRD domain $(20.5, \mathrm{SE}=0.77)$. This appeared to be statistically significant, which was mainly based on the differences between the CTS and TRD domain (ANCOVA with Bonferroni correction: $p=0.05$ ). As can be seen in Figure 1 , the mean severity scores of the recurrent mutations show a wide range of scores. The lowest score was seen in females with a p.R133C mutation and the highest score in females with a p.P152R 
mutation (13.7, $\mathrm{SE}=2.01$ versus $25.2, \mathrm{SE}=2.75)$. The overall differences were statistically significant (ANCOVA with Bonferroni correction: $\mathrm{p}<0.01$ ).

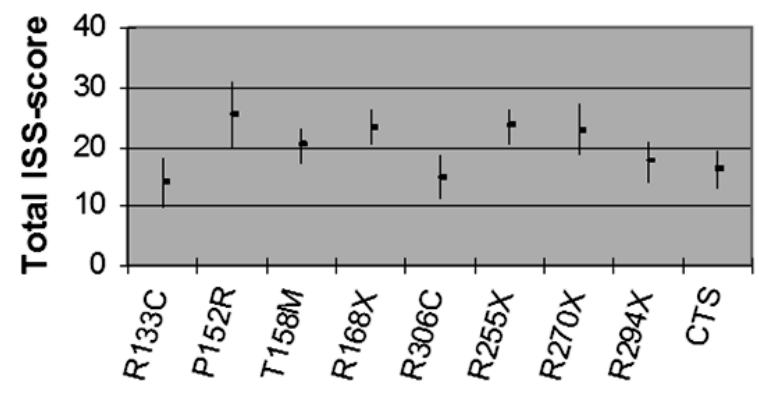

Recurrent mutations

Figure 1 Total ISS score in recurrent MECP2 mutations (corrected for age at examination)

\section{ISS functional domains}

Growth and development (ISS items $A-E$ ). The mean score on the growth and development domain was 3.76 (range $0-9$, sd=2.5). Females with a mutation in the CTS domain scored the lowest with a mean of 2.5 ( $S E=0.64)$, followed by females with a mutation in the MBD and TRD domain (respectively, 3.6, SE=0.39 and 4.1, SE=0.29); these differences were just not statistically significant (ANCOVA with Bonferroni correction: $p=0.08)$. Concerning recurrent mutations, females with a $p . R 133 C$ mutation scored lower than females with a p.P152R mutation $(1.8, S E=0.74$ vs. 5.5, $\mathrm{SE}=1.02$ ). The overall differences were statistically significant (ANCOVA with Bonferroni correction: $p<0.001)$.

Head circumference at birth (item A) was normal in $97 \%$ of the females, without deceleration during the first year in $58 \%$ of the females and with deceleration during the first year in $39 \%$ of the females. The remaining $3 \%$ of the females had already a head circumference below the 3 rd centile at birth. Statistically significant differences were only seen between females with a p.R294X and a p.R270X mutation; $83 \%$ of the females with a p.R294X mutation had a normal head circumference during the first year of life, in contrast to $22 \%$ of the females with a p.R270X mutation (Chi-square test: $p=0.01$ ). Age at examination did not seem to be a confounder, since the scores on this item did not differ significantly between the different age groups (Chi-square test: $p=0.31$ ).

Early developmental progress during the first year of life (item B) was reported normal in $41 \%$, suboptimal in $55 \%$ and (virtually) no progress in $4 \%$ of the females. Statistically significant differences were only seen between females with a p.R133C and a p.R168X mutation; in $80 \%$ of the females with a p.R133C mutation normal progress was reported in contrast to $13 \%$ of the females with a $\mathrm{p} . \mathrm{R} 168 \mathrm{X}$ mutation 
(Chi-square test: $p=0.02$ ). Age at examination did not seem to be a confounder, since the scores on this item did not differ significantly between the different age groups (Chi-square test: $p=0.25$ ).

Present head circumference (item C) was nearly equally distributed, whereas $36 \%$ of the females had a head circumference above the 10 th centile, $31 \%$ between the $3 r d$ and 10 th centile and $33 \%$ below the 3rd centile. Comparing the different domains, $73 \%$ of the females with a CTS mutation had a head circumference above the 10 th centile, in contrast to $29 \%$ of the females with a mutation in the TRD domain and $32 \%$ of the females with a mutation in the MBD domain (Chi-square test: $p=0.03$ ). These differences were also found comparing females with a CTS mutation and females with a p.P152R mutation, all of whom had a head circumference below the 10th centile (Chi-square test: $p=0.05$ ). Age at examination did not seem to be a confounder, since the scores on this item did not differ significantly between the different age groups (Chi-square test: $p=0.50$ ).

Weight (item D) was above the 10 th centile in $43 \%$ of the females, between the $3 r d$ and 10 th centile in $37 \%$ and below the 3rd centile in $20 \%$ of the females. Genotype-phenotype analysis concerning this item showed that females did not differ significantly from each other comparing the different scores (0-1-2) and the different groups of mutations (Chi-square test: $\mathrm{p}>0.21$ ). However, age at examination could be a confounder, since the scores on this item did differ significantly between the different age groups (Chi-square test: $p<0.001$ ). The majority of the youngest females scored zero on this item, in contrast to around two thirds of the females older than 10 years of age who scored one or two on this item.

Height (item E) was above the 10th centile in $31 \%$ of the females, between the $3 r d$ and 10 th centile in $45 \%$ and below the $3 r d$ centile in $24 \%$ of the females. Genotype-phenotype analysis concerning this item showed that females did not differ significantly from each other comparing the different scores (0-1-2) and the different groups of mutations (Chi-square test: $p>0.20$ ). However, age at examination could be a confounder, since the scores on this item did differ significantly between the different age groups (Chi-square test: $p<0.001$ ). The majority of the youngest females scored zero on this item, in contrast to $83 \%$ of the females older than 10 years of age who scored one or two on this item.

Musculoskeletal (ISS items F-H). The mean score on the musculoskeletal domain was 2.78 (range 0-6, sd=1.9). Concerning location of the mutation, differences in mean scores were small and not statistically significant (MBD: 2.5, SE=0.26, TRD: 2.9, $\mathrm{SE}=0.20$, and CTS: 2.4, SE=0.43; ANCOVA with Bonferroni correction: $p=0.35$ ). Comparing recurrent mutations, females with a p.R306C mutation scored significantly lower than females with a p.R168X mutation (1.3, SE $=0.48$ versus 3.9, $\mathrm{SE}=0.42$; ANCOVA with Bonferroni correction $\mathrm{p}<0.01$ ).

A normal muscle tone (item F) was seen in just $22 \%$ of the females, severely abnormal tone was reported in $31 \%$ and mildly abnormal in $47 \%$ of the females. Geno- 
type-phenotype analysis concerning this item showed that females did not differ significantly from each other comparing the different scores (0-1-2) and the different groups of mutations (Chi-square test: $p>0.19$ ). Furthermore, age at examination did not seem to be a confounder, since the scores on this item did not differ significantly between the different age groups (Chi-square test: $p=0.06$ ).

Scoliosis (item G) was present in $70 \%$ of the females, with mild scoliosis in $29 \%$ and severe scoliosis in $41 \%$. Genotype-phenotype analysis concerning this item showed that females did not differ significantly from each other comparing the different scores (0-1-2) and the different groups of mutations (Chi-square test: $p>0.37$ ). However, age at examination could be a confounder, since the scores on this item did differ significantly between the different age groups (Chi-square test: $\mathrm{p}<0.001$ ). The majority of the youngest females scored zero on this item, in contrast to around $10 \%$ of the females older than 10 years of age.

Joint contractures (item $\mathrm{H}$ ) were seen in $43 \%$ of the females. Minor contractures were reported in $29 \%$ and severe contractures in $14 \%$ of the females. Genotype-phenotype analysis concerning this item showed that females did not differ significantly from each other comparing the different scores (0-1-2) and the different groups of mutations (Chi-square test: $\mathrm{p}>0.09$ ). However, age at examination could be a confounder, since the scores on this item did differ significantly between the different age groups (Chi-square test: $p<0.001$ ). $80 \%$ of the youngest females scored zero on this item, in contrast to around $41 \%$ of the females older than 10 years of age.

Movement (ISS items I-M). The mean score on the movement domain was 5.28 (range $0-10, s d=2.2$ ). Concerning location of the gene, the females did not differ statistically significant (MBD: $5.3, \mathrm{SE}=0.35$, TRD: $5.5, \mathrm{SE}=0.26$, and CTS: $4.4, \mathrm{SE}=0.57$; ANCOVA and Bonferroni correction: $p=0.27$ ). However, comparing the recurrent mutations, the lowest score was seen in females with a p.R306C mutation and the highest score in females with a p.P152R mutation. These differences were statistically significant $(3.5, \mathrm{SE}=0.61$ vs. $7.1, \mathrm{SE}=0.92$; ANCOVA with Bonferroni correction $\mathrm{p}=0.001$ and pairwise comparison $\mathrm{p}<0.05)$.

One third of the females could walk normally (item I) and $24 \%$ were ambulant but had some impairment. Of the 61 non-walkers (44\%), nine girls were younger than 5 years. Genotype-phenotype analysis concerning this item showed that females did not differ significantly from each other comparing the different scores (0$1-2$ ) and the different groups of mutations (Chi-square test: $p>0.10$ ). Age at examination did not seem to be a confounder, since the scores on this item did not differ significantly between the different age groups (Chi-square test: $p=0.99$ ).

Hand stereotypy (item J) was reported in $96 \%$ of the females, being mild or intermittent in $36 \%$ of the females and dominating or constant in $61 \%$ of the females. Genotype-phenotype analysis concerning this item showed that females did not differ significantly from each other comparing the different scores (0-1-2) and the 
different groups of mutations (Chi-square test: $p>0.17$ ). Furthermore, age at examination did not seem to be a confounder, since the scores on this item did not differ significantly between the different age groups (Chi-square test: $p=0.39$ ).

Involuntary movements (item $\mathrm{K}$ ) were present in $40 \%$ of the females, being mild or intermittent in $30 \%$ of the females and dominating or constant in $10 \%$. Genotypephenotype analysis concerning this item showed that females did not differ significantly from each other comparing the different scores (0-1-2) and the different groups of mutations (Chi-square test: $p>0.27$ ). Furthermore, age at examination did not seem to be a confounder, since the scores on this item did not differ significantly between the different age groups (Chi-square test: $p=0.38$ ).

Half of the females could not use their hands voluntarily (item L) and $41 \%$ had a poor or reduced hand use. Normal hand use was seen in $9 \%$ of the females. Comparing the different domains, $80 \%$ of the females with a CTS mutation had a poor or reduced hand use, in contrast to $30 \%$ of the females with a mutation in the TRD domain and $44 \%$ of the females with a mutation in the MBD domain (Chi-square test: $p<0.01)$. However, normal hand use was reported in $14 \%$ of the females with a mutation in the TRD domain and none of the females with a CTS mutation. Concerning recurrent mutations, one third of the females with a p.R306C or p.R294X mutation could not use their hands voluntarily compared to $80 \%$ of the females with a p.R255X mutation (Chi-square test: $p=0.01$ ). Age at examination did not seem to be a confounder, since the scores on this item did not differ significantly between the different age groups (Chi- square test: $p=0.83$ ).

Oro-motor difficulties (item $\mathrm{M}$ ) were reported in $56 \%$ of the females, being severe in $10 \%$ of the females. In females with a p.R133C mutation oro-motor difficulties were only reported in $30 \%$, being severe in none of the females. This in contrast to females with a p.P152R mutation, among whom $60 \%$ were reported having oromotor difficulties, all being severe. These differences were statistically significant (Chi-square test: $p=0.01$ ). Age at examination did not seem to be a confounder, since the scores on this item did not differ significantly between the different age groups (Chi-square test: $p=0.27$ ).

Cortical (ISS items $N-P$ ). The mean score on the cortical domain was 4.37 (range $2-6, s d=1.1)$. Concerning location of the gene the females did not differ statistically significant (MBD: 4.4, SE=0.17, TRD: 4.4, SE=0.13, and CTS: 3.8, SE=0.27; ANCOVA and Bonferroni correction: $p=0.10$ ). Comparing recurrent mutations, the lowest score was seen in females with a CTS mutation and the highest score in females with a p.P152R mutation (5.1, SE=0.47). The range in scores were remarkably different in females with a p.P152R mutation with a range of 4-6 points, in contrast to 2-6 points in the total RTT group and in females with a CTS mutation. However, the scores between the different mutations did not vary statistically significant (ANCOVA with Bonferroni correction: $p=0.07$ ) and also pairwise comparisons did not result in statistically significant differences. 
All females were intellectually disabled (item $\mathrm{N}$ ), whereas $73 \%$ functioned on an infantile (profound) level of development and $27 \%$ scored any level except profound. Comparing the different domains, $40 \%$ of the females with a CTS mutation functioned on an infantile level, in contrast to $79 \%$ of the females with a mutation in the TRD domain and $73 \%$ of the females with a mutation in the MBD domain (Chisquare test: $p<0.01)$. These results were confirmed comparing females with a CTS mutation and females with a p.P152R mutation, of whom $100 \%$ functioned on an infantile level (Chi-square test: $p=0.03$ ). Age at examination did not seem to be a confounder, since the scores on this item did not differ significantly between the different age groups (Chi-square test: $p=0.84$ ).

Eighty-six percent of the females could not speak (item 0), 13\% used some meaningful words or two-word sentences at the time of examination and $1 \%$ had a normal speech. Genotype-phenotype analysis concerning this item showed that females did not differ significantly from each other comparing the different scores (0-1-2) and the different groups of mutations (Chi-square test: $p>0.27)$. Age at examination did not seem to be a confounder, since the scores on this item did not differ significantly between the different age groups (Chi-square test: $p=0.27$ ).

A history of epilepsy (item P) was present in $61 \%$ of the females at some time of their life, whereas epilepsy was well-controlled in $42 \%$ and uncontrolled or poorly controlled by medication in $18 \%$ of the females. None of the females in this cohort developed epilepsy before the age of 4, except for a 2-year-old girl. Genotypephenotype analysis concerning this item showed that females did not differ significantly from each other comparing the different scores (0-1-2) and the different groups of mutations (Chi-square test: $p>0.25$ ). Age at examination did not seem to be a confounder, since the scores on this item did not differ significantly between the different age groups (Chi-square test: $p=0.10$ ).

Autonomic functions (ISS items $Q-T$ ). The mean score on the autonomic domain was 3.28 (range $0-8, \mathrm{sd}=1.7$ ). The location of the mutation did not relate to mean scores on this ISS domain (MBD: 3.0, SE=0.27, TRD: 3.5, SE=0.20, and CTS: 2.7, $\mathrm{SE}=0.44$; ANCOVA with Bonferroni correction: $\mathrm{p}=0.21$ ). Also concerning recurrent mutations, the scores between the different mutations did not vary significantly (ANCOVA with Bonferroni correction: $p=0.47$ ). The lowest score was seen in females with a p.R270X mutation (2.7, SE=0.59) and the highest score in females with a p.P152R mutation (4.2, SE=0.78). The range in scores varied widely; in females with a p.R270X mutation with a range of 0-4 points, in contrast to $0-8$ points in the total RTT group and 1-7 in females with a p.P152R mutation.

Breathing problems (item Q) were present in $81 \%$ of the females, of whom $25 \%$ had severe breathing problems with vacant spells and cyanosis. Genotypephenotype analysis concerning this item showed that females did not differ significantly from each other comparing the different scores (0-1-2) and the different groups of mutations (Chi-square test: $p>0.26$ ). Furthermore, age at examination 
did not seem to be a confounder, since the scores on this item did not differ significantly between the different age groups (Chi-square test: $p=0.18$ ).

Poor peripheral circulation (item R) with cold or discolored extremities without atrophic changes were present in $56 \%$ of the females, $22 \%$ had atrophic changes, and another $22 \%$ had normal color and temperature of the extremities. Genotypephenotype analysis concerning this item showed that females did not differ significantly from each other comparing the different scores (0-1-2) and the different groups of mutations (Chi-square test: $p>0.16$ ). However, age at examination could be a confounder, since the scores on this item did differ significantly between the different age groups (Chi-square test: $p=0.004$ ). Only $8 \%$ of the youngest females scored two on this item, in contrast to around $15 \%$ of the females older than 20 years of age who scored zero on this item.

Mood disturbances (item S) were reported in approximately half of the females, of whom $12 \%$ had prominent or disruptive agitation/ crying spells. Genotypephenotype analysis concerning this item showed that females did not differ significantly from each other comparing the different scores (0-1-2) and the different groups of mutations (Chi-square test: $p>0.06$ ). Furthermore, age at examination did not seem to be a confounder, since the scores on this item did not differ significantly between the different age groups (Chi- square test: $p=0.88$ ).

Sleep disturbances (item T) were present in half of the females, being prominent in $16 \%$ of the females. Genotype-phenotype analysis concerning this item showed that females did not differ significantly from each other comparing the different scores (0-1-2) and the different groups of mutations (Chi-square test: $p>0.21$ ). Furthermore, age at examination did not seem to be a confounder, since the scores on this item did not differ significantly between the different age groups (Chi-square test: $\mathrm{p}=0.25$ ).

Lowest and highest scores. In Table 3 the lowest and highest scores concerning the recurrent MECP2 mutations are reported separately. The following mutations frequently scored the lowest score on the total, domain, and/or individual ISS score: p.R133C, CTS, p.R294X, and p.R306C. Females with a p.R133C mutation had the lowest total score. Females with a p.R133C or a CTS mutation had low scores in almost all domains. Females with a p.R294X had low scores on four individual items belonging to different domains of the ISS scoring list. Females with a p.R306C mutation had low scores on several domains and items, but especially concerning the musculoskeletal and movement domain. In contrast to these mutations, the following mutations frequently scored the highest score on the total, domain, and/or individual ISS score: p.P152R and p.R168X. Females with a p.P152R mutation had the highest total score and high scores in almost all domains. Females with a p.R168X had high scores on several domains and items, but especially concerning the musculoskeletal domain. At last, females with a p.R270X mutation scored high 
on the domains growth and development and movement, but low on the autonomic features domain.

\section{Discussion}

At present, conflicting results in genotype-phenotype studies are still under discussion, partly due to the variability in classification of mutations, assessment tools, and structure of data sets. The aim of this study was to investigate relationships between genotype and specific clinical data in a well-documented RTT cohort of 137 RTT females and evaluate its prognostic value in counseling young parents with a newly diagnosed RTT girl regarding her future outcome. In this study all RTT females were seen by the same experienced physician and had a MECP2 mutation.

Clinical severity was defined using the ISS scoring list. Concerning location of the MECP2 mutation, an overall mild phenotype was confirmed in females with a mutation in the CTS domain (Huppke et al., 2002; Colvin et al., 2004; Smeets et al., 2005; Neul et al., 2008; Smeets et al., 2009; Bebbington et al., 2010). In line with previous reports, these females were more likely to have a normal head circumference with more preserved cognitive functions, and hand skills were more likely to be retained (De Bona et al., 2000; Zappella et al., 2001; Huppke et al., 2002; Hoffbuhr et al., 2002; Smeets et al., 2005; Bebbington et al., 2010). Scoring the frequency of mutations regarding the lowest and highest scores on the total, domain, and individual items of the ISS scoring list, milder and severe phenotypes concerning recurrent mutations can be distinguished. In this way a milder phenotype was confirmed in females with a p.R133C, p.R294X, and p.R306C mutation and a severe phenotype in females with a p.R168X mutation (Leonard et al., 2003; Colvin et al., 2004; Schanen et al., 2004; Kerr \& Prescott, 2005; Smeets et al., 2005; Neul et al., 2008; Bebbington et al., 2008; Smeets et al., 2009; Bebbington et al., 2010). In our study, females with a p.R133C mutation tend to have a late onset of stagnation (Bebbington et al., 2008) and less severe oro-motor difficulties. In females with a p.R294X mutation head circumference was less likely to decline during the first year of life. Hand skills were more likely to be retained both in females with a p.R294X and p.R306C mutation, as has already been reported by Bebbington and colleagues (Bebbington et al., 2008). Furthermore, females with a p.R306C mutation were less likely to have problems on the musculoskeletal and movement domain, which is in line with the already published better walking ability in these females (Schanen et al., 2004). This is in contrast to females with a p.P152R mutation, who are more likely to have problems in the movement domain. Moreover, none of these females had a normal head circumference, all functioned on an infantile level of development and oro-motor difficulties tend to be more severe. Concerning females with a p.R168X mutation, our study confirms that they have an early onset of stagnation and are more likely to have problems in the musculoskeletal domain (Neul et al., 2008). At last, females 
with a p.R270X mutation showed a contrasting phenotype. These females tend to have more severe problems in both the movement and growth and development domain, in contrast to less severe problems in the autonomic features domain.

Overall, general genotype-phenotype relationships were confirmed. The strength of our study was the use of a well-defined group of RTT girls, by whom clinical data were collected by the same experienced physician in Rett syndrome. Only due to these strict inclusion criteria, our study is hampered by the small sample size. Both these factors could explain why we did not confirm a late onset of regression in females with a CTS, p.R294X, and p.R306C mutation, and a better hand use in females with a p.R133C mutation (Huppke et al., 2002; Smeets et al., 2005; Neul et al., 2008; Bebbington et al., 2010). On the other hand, we report in our study on females with a p.R133C mutation who tend to have less severe oro-motor difficulties and females with a p.R294X mutation whose head circumference was less likely to decline during the first year of life. Concerning gross motor function, we did not confirm a better walking ability in females with a CTS mutation (Neul et al., 2008; Bebbington et al., 2010). Besides above mentioned factors, this could also be explained by two other factors. First of all, in the ISS score no difference is made between females who lost their walking ability and those who never acquired walking. In our study normal gait was reported if a RTT female was able to walk independently without any support. Furthermore, despite the fact that age did not seem to be a confounder analyzing the scores between the different age groups, only 9 of the 61 non-walkers were younger than 5 years of age. Concerning weight, females with a CTS mutation were reported to be more likely to have a normal weight (Bebbington et al., 2010). Since in our study the youngest females scored remarkably lower than the females older than 10 years of age, age at examination could be a possible confounder. This is in accordance with previous studies, in which weight for height falls below the 5th centile at a later age (Schultz et al., 1993; Reilly \& Cass, 2001). Furthermore, we do not confirm the higher prevalence of scoliosis in females with a CTS mutation, as has been reported by others (Smeets et al., 2005). This can be explained by the age dependent factor as well as overall high prevalence scores in the total RTT population (Kerr et al., 2003; Halbach et al., 2008). The high prevalence scores could also explain why we did not confirm a better communication ability in females with a CTS, p.R133C and p.R306C mutation (Leonard et al., 2003; Schanen et al., 2004; Neul et al., 2008; Bebbington et al., 2010). Furthermore, the contrasting phenotype in females with a p.R270X mutation is in difference to others, who report a p.R270X mutation causing an overall severe phenotype (Colvin et al., 2004; Charman et al., 2005; Leonard et al., 2005; Bebbington et al., 2008; Smeets et al., 2009). This most likely could be explained by the limited attention for autonomic features in previous studies. However, since the autonomic features are of great influence on the health status of RTT females and their families, one should pay special attention to this subject in the counseling of parents (Halbach et al., 
2008; Julu et al., 2008). Furthermore, one should realize that scoring systems and "bed- side" clinical evaluation are insufficient to determine the contribution of autonomic dysfunction to the clinical severity in individual cases. At last, in our study females with a p.P152R mutation had a severe phenotype, which has only been published before by Kondo \& Yamagata (2002). This could be explained by the low prevalence of this mutation.

The aim of this study was to investigate relationships between genotype and specific clinical data, and evaluate its prognostic value in counseling young parents with a newly diagnosed RTT girl regarding her future outcome. Despite the fact that all clinical data were collected by the same experienced physician, every mutation is still associated with a wide range of severity scores. This should be kept in mind when counseling parents. We suggest that the range of scores for the individual ISS items may be found to be helpful in advising the parents of a newly diagnosed Rett girl. In addition, we share the general opinion of others that $\mathrm{XCl}$ may still affect clinical severity; however $\mathrm{XCl}$ status is unlikely to be useful as a prognosticator for individual cases, with the exception of those with extreme skewing (Archer et al., 2007).

In conclusion, general genotype-phenotype relationships were confirmed. Despite the fact that all RTT females were seen by the same experienced physician, the clinical severity was still found to be very variable. Due to this variability, these relationships have limited prognostic value in counseling young parents with a newly diagnosed RTT girl regarding her future outcome. We therefore recommend caution in using genotype-phenotype data in the prognosis of outcome for children in Rett syndrome. Early diagnosis, early intervention, and preventive management measures are imperative for good outcomes and better quality of daily life for RTT females and their families. 


\section{References}

Amir RE, Van den Veyver IB, Wan M, Tran CQ, Francke U, Zoghbi HY. Rett syndrome is caused by mutations in X-linked MECP2, encoding methyl-CpG-binding protein 2. Nat Genet 1999: 23: 185-188.

Archer H, Evans J, Leonard H, Colvin L, Ravine D, Christodoulou J, Williamson S, Charman T, Bailey ME, Sampson J, de Klerk N, Clarke A. Correlation between clinical severity in patients with Rett syndrome with a p.R168X or p.T158M MECP2 mutation, and the direction and degree of skewing of Xchromosome inactivation. J Med Genet 2007: 44: 148-152.

Bebbington A, Anderson A, Ravine D, Fyfe S, Pineda M, de Klerk N, Ben-Zeev B, Yatawara N, Percy A, Kaufmann WE, Leonard $\mathrm{H}$. Investigating genotype-phenotype relationships in Rett syndrome using an international data set. Neurology 2008: 70: 868-875.

Bebbington A, Percy A, Christodoulou J, Ravine D, Ho G, Jacoby P, Anderson A, Pineda M, Ben Zeev B, Bahi-Buisson N, Smeets $\mathrm{E}$, Leonard H. Updating the profile of C-terminal MECP2 deletions in Rett syndrome. J Med Genet 2010: 47: 242-248.

Charman T, Neilson TC, Mash V, Archer H, Gardiner MT, Knudsen GP, McDonnell A, Perry J, Whatley sd, Bunyan DJ, Ravn K, Mount RH, Hastings RP, Hulten M, Orstavik KH, Reilly S, Cass H, Clarke A, Kerr AM, Bailey ME. Dimensional phenotypic analysis and functional categorisation of mutations reveal novel genotype-phenotype associations in Rett syndrome. Eur J Hum Genet 2005: 13: 1121-1130.

Colvin L, Leonard H, de Klerk N, Davis M, Weaving L, Williamson S, Christodoulou J. Refining the phenotype of common mutations in Rett syndrome. J Med Genet 2004: 41: 25-30.

De Bona C, Zappella M, Hayek G, Meloni I, Vitelli F, Bruttini M, Cusano R, Loffredo P, Longo I, Renieri A. Preserved speech variant is allelic of classic Rett syndrome. Eur J Hum Genet 2000: 8: 325-330.

Hagberg B, Hanefeld F, Percy A, Skjeldal O. An update on clinically applicable diagnostic criteria in Rett syndrome. Comments to Rett syndrome Clinical Criteria Consensus Panel Satellite to European Paediatric Neurology Society Meeting, Baden Baden, Germany, 11 September 2001. Eur J Paediatr Neurol 2002: 6: 293-297.

Hagberg B, Aicardi J, Dias K, Ramos O. A progressive syndrome of autism, dementia, ataxia, and loss of purposeful hand use in girls: Rett's syndrome: Report of 35 cases. Ann Neurol 1983: 14: 471-479.

Halbach NS, Smeets EE, Schrander-Stumpel CT, Van Schrojenstein Lant- man de Valk HH, Maaskant MA, Curfs LM. Aging in people with specific genetic syndromes: Rett syndrome. Am J Med Genet Part A 2008: 146A: 1925-1932.

Ham AL, Kumar A, Deeter R, Schanen NC. Does genotype predict phenotype in Rett syndrome? J Child Neurol 2005: 20: 768-778.

Hoffbuhr KC, Moses LM, Jerdonek MA, Naidu S, Hoffman EP. Associations between MeCP2 mutations, Xchromosome inactivation, and phenotype. Ment Retard Dev Disabil Res Rev 2002: 8: 99-105.

Huppke P, Held M, Hanefeld F, Engel W, Laccone F. Influence of mutation type and location on phenotype in 123 patients with Rett syndrome. Neuropediatrics 2002: 33: 63-68.

Julu PO, Engerström IW, Hansen S, Apartopoulos F, Engerström B, Pini G, Delamont RS, Smeets EE. Cardiorespiratory challenges in Rett's syndrome. Lancet 2008: 371: 1981-1983.

Kerr AM, Prescott RJ. Predictive value of the early clinical signs in Rett disorder. Brain Dev 2005: 27: S20S24.

Kerr AM, Nomura Y, Armstrong D, Anvret M, Belichenko PV, Budden S, Cass H, Christodoulou J, Clarke A, Ellaway C, d'Esposito M, Francke U, Hulten M, Julu P, Leonard H, Naidu S, Schanen C, Webb T, Witt Engerström I, Yamashita Y, Segawa M. Guidelines for reporting clinical features in cases with MECP2 mutations. Brain Dev 2001: 23: 208-211.

Kerr AM, Webb P, Prescott RJ, Milne Y. Results of surgery for scoliosis in Rett syndrome. J Child Neurol 2003: 18: 703-708.

Kondo I, Yamagata H. Mutation spectrum and genotype-phenotype correlation of MECP2 in patients with Rett syndrome. No To Hattatsu 2002: 34: 219-223. 
Leonard H, Colvin L, Christodoulou J, Schiavello T, Williamson S, Davis M, Ravine D, Fyfe S, de Klerk N, Matsuishi T, Kondo I, Clarke A, Hackwell S, Yamashita Y. Patients with the R133C mutation: Is their phenotype different from patients with Rett syndrome with other mutations? J Med Genet 2003: 40: e52.

Leonard H, Moore H, Carey M, Fyfe S, Hall S, Robertson L, Ru Wu X, Bao X, Pan H, Christodoulou J, Williamson S, de Klerk N. Genotype and early development in Rett syndrome: The value of international data. Brain Dev 2005: 27: S59-S68.

Neul JL, Fang P, Barrish J, Lane J, Caeg EB, Smith EO, Zoghbi H, Percy A, Glaze DG. Specific mutations in methyl-CpG-binding protein 2 confer different severity in Rett syndrome. Neurology 2008: 70: 13131321.

Reilly S, Cass H. Growth and nutrition in Rett syndrome. Disabil Rehabil 2001: 23: 118-128.

Schanen C, Houwink EJF, Dorrani N, Lane J, Everett R, Feng A, Cantor RM, Percy A. Phenotypic manifestations of MECP2 mutations in classical and atypical Rett syndrome. Am J Med Genet Part A 2004: 126A: 129-140.

Schultz RJ, Glaze DG, Motil KJ, Armstrong DD, del Junco DJ, Hubbard CR, Percy AK. The pattern of growth failure in Rett syndrome. Am J Dis Child 1993: 147: 633-637.

Smeets EE, Chenault M, Curfs LM, Schrander-Stumpel CT, Frijns JP. Rett syndrome and long-term disorder profile. Am J Med Genet Part A 2009: 149A: 199-205.

Smeets E, Schollen E, Moog U, Matthijs G, Herbergs J, Smeets H, Curfs L, Schrander-Stumpel C, Fryns JP. Rett syndrome in adolescent and adult females: Clinical and molecular genetic findings. Am J Med Genet Part A 2003: 122A: 227-233.

Smeets E, Terhal P, Casaer P, Peters A, Midro A, Schollen E, V Van Roozendaal K, Moog U, Matthijs G, Herbergs J, Smeets H, Curfs L, Schrander- Stumpel C, Fryns JP. Rett syndrome in females with CTS hot spot deletions: A disorder profile. Am J Med Genet Part A 2005: 132A: 117-120.

Williamson SL, Christodoulou J. Rett syndrome: New clinical and molecular insights. Eur J Hum Genet 2006: 14: 896-903.

Zappella M, Meloni I, Longo I, Hayek G, Renieri A. Preserved speech variants of the Rett syndrome: Molecular and clinical analysis. Am J Med Genet 2001: 104: 14-22. 


\section{Chapter 3}

\section{Neurophysiology versus clinical genetics in Rett syndrome: A multicenter study}

Halbach NSJ, Smeets EEJ, Julu POO, Witt Engerström I, Pini G, Bigoni S, Hansen S, Apartopoulos F, Delamont RS, Van Roozendaal KEP, Scusa MF, Borelli P, Candel MJJM, Curfs LMG.

\section{Submitted}




\begin{abstract}
Objective Many studies have attempted to establish the genotype-phenotype correlation in Rett syndrome (RTT). Cardio-respiratory measurements provide robust objective data, to correlate with each of the different clinical phenotypes. It has important implications for the management and treatment of this syndrome. The aim of this study was to correlate the genotype with the quantitative cardiorespiratory data obtained by neurophysiological measurement combined with a clinical severity score.
\end{abstract}

Methods This international multicenter study was conducted in four European countries from 1999 to 2012. The study cohort consisted of a group of 132 welldefined RTT females aged between two and 43 years with extended clinical, molecular and neurophysiological assessments. Diagnosis of RTT was based on the consensus criteria for RTT and molecular confirmation. Genotype-phenotype analyses of clinical features and cardiorespiratory data were performed after grouping mutations by the same type and localization or having the same putative biological effect on the MeCP2 protein, and subsequently on eight single recurrent mutations. Results A less severe phenotype was seen in females with CTS, p.R133C and p.R294X mutations. Autonomic disturbances were present in all females, and not restricted to nor influenced by one specific group or any single recurrent mutation.

Interpretation The objective information from non-invasive neurophysiological evaluation of the disturbed central autonomic control is of greater importance in helping to organize the lifelong care for females with RTT. Further research is needed to provide insights into the pathogenesis of autonomic dysfunction, and to develop evidence-based management in RTT. 


\section{Introduction}

Rett syndrome (RTT) is a neurodevelopmental disorder affecting almost exclusively females. It is caused by mutations in the gene encoding the methyl CpG binding protein 2 (MECP2) (Hagberg et al., 1983; Amir et al., 1999). A unique pattern of neurological and behavioral symptoms appears over time (Julu et al., 2008). Most prominent are the abnormal breathing patterns, which is a consequence of developmental brainstem immaturity in this syndrome. Abnormal breathing is the most distressing and underestimated feature in many RTT females. It is a major determinant of the quality of daily life of the female and her family, and has an important secondary socio-economic impact on the community (Julu \& Witt Engerström, 2005; Smeets et al., 2006; Julu et al., 2008). Neurophysiological research has established three cardiorespiratory phenotypes in RTT (forceful, feeble and apneustic breathers), and their clinical relevance (Julu \& Witt Engerström, 2005; Smeets et al., 2006; Julu et al., 2008; Halbach et al., 2011; Julu et al., 2012).

Many genotype-phenotype correlation studies have been published (Huppke et al., 2002; Leonard et al., 2003; Colvin et al., 2004; Schanen et al., 2004; Charman et al., 2005; Kerr \& Prescott, 2005; Leonard et al., 2005; Smeets et al., 2005; Bebbington et al., 2008; Neul et al., 2008; Smeets et al., 2009; Bebbington et al., 2010; Halbach et al., 2012; Bebbington et al., 2012). Some have specific but many have inconclusive results. These studies are based on clinical scoring lists and/or questionnaires and lack objective measurement of the clinical phenotype. Cardiorespiratory variables can be measured objectively in different clinical phenotypes, providing robust quantitative data for research. We believe that this has important implications for life long management and future treatment in RTT (Julu et al., 2008).

The aim of this collaborative multicenter study is to correlate the RTT genotype with the quantitative cardiorespiratory data obtained by neurophysiological measurement combined with a clinical severity score.

\section{Methods}

Ethical approval was obtained from the Medical Ethical Committee at the Maastricht University Medical Center.

\section{Study design and participants}

This was an international multicenter study conducted in four European countries from 1999 to 2012. The six participating centers were: Tuscany Rett Center, Versilia Hospital (Lucca, Italy), Medical Genetic Unit, Ferrara University Hospital (Ferrara, Italy), the National Swedish Rett Center (Frösön, Sweden), the Rett Expertise Center, Maastricht University Medical Center (Maastricht, the Netherlands), Neurodegen- 
eration and Neuroinflamation at Imperial college (London, United Kingdom), and Institute of Neurological Sciences, Southern General Hospital (Glasgow, United Kingdom).

The study cohort consisted of a group of 132 well-defined RTT females with extended clinical, molecular and neurophysiological assessment. These females were referred to one of the participating centers. Neurophysiological assessment was performed in Italy and Sweden, each examining 66 RTT females. Diagnosis of RTT was based on the consensus criteria for RTT (Hagberg et al., 2002; Neul et al., 2010). Only females with molecular confirmation were included. Males with MECP2 related disorders were excluded from this study.

\section{Molecular analysis of MECP2}

DNA analysis of MECP2 was performed by sequencing the coding exons and immediately adjacent intronic regions. Additional Multiplex Ligation-dependent Probe Amplification analysis of MECP2 was done to identify large genomic rearrangements. Nomenclature was according to the MECP2A isoform reference sequence NM_004992.3. Numbering started at the A of the ATG translation initiation codon.

Mutations were classified by type and localization in the gene (Table 1). As to mutation type, they were classified as missense (single amino acid substitutions) and truncating mutations (nonsense mutations, frame shift mutations and large deletions/duplications). The following domains were included for mutation localization: the N-Terminal domain (NT domain), the methyl-CpG- binding domain (MBD), the transcription repression domain (TRD) and the C-terminal segment (CTS). 
Table 1 Mutation type and localization in MECP2

\begin{tabular}{|c|c|c|c|c|c|}
\hline $\begin{array}{l}\text { Type } \\
\text { of mutation } \downarrow\end{array}$ & NT $(n)$ & $\operatorname{MBD}(n)$ & $\operatorname{TRD}(\mathrm{n})$ & CTS (n) & Total \\
\hline Truncating & $p . M 5 f_{s} X(1)$ & $p . D 90 f s X(1)$ & $p . R 168 \times(12)$ & p.T327fsX (1) & 85 \\
\hline (Nonsense, & $p . R 9 f s X(9)$ & $p . R 111 f s X(1)$ & p.G237fsX (1) & $p . K 347 f_{s} X(1)$ & \\
\hline Frame shift, & & p.N126fsX (1) & p.G238fsX (1) & p.A358fsX (1) & \\
\hline \multirow[t]{7}{*}{ Large Deletion) } & & p.Q128X (1) & p.R255X (9) & $p . P 362 f_{s} X(1)$ & \\
\hline & & p.Y141X (2) & p.G269fsX (2) & p.A378fs X (1) & \\
\hline & & $p . K 144 f_{s} X(2)$ & $p . R 270 \times(11)$ & p.L386fsX (11) & \\
\hline & & & $p . R 294 X(10)$ & $p . P 388 f_{s} X(1)$ & \\
\hline & & & & p.P389fsX (2) & \\
\hline & & & & $p . S 401 f s X(1)$ & \\
\hline & & & & $p . R 453 \times(1)$ & \\
\hline \multirow[t]{7}{*}{ Missense } & & p.R106W (5) & p.P225A (1) & & 47 \\
\hline & & $p . R 133 C$ (14) & p.P225R (1) & & \\
\hline & & p.S134C (1) & p.P302L (1) & & \\
\hline & & p.K135G (1) & p.R306C (8) & & \\
\hline & & p.P152R (5) & & & \\
\hline & & p.D156E (2) & & & \\
\hline & & p.T158M (8) & & & \\
\hline Total & 10 & 44 & 57 & 21 & 132 \\
\hline
\end{tabular}

NT: N-Terminal segment, MBD: methyl-CpG-binding domain, TRD: transcription repression domain, CTS: C-terminal segment, $\mathrm{n}$ : number of patients (Nomenclature according to the MECP2A isoform reference sequence NM_004992.3)

\section{ISS scoring list}

In order to evaluate the clinical severity of the common features in RTT, a modified version of the International Scoring System was used (ISS, Table 2) (Kerr et al., 2001). The clinical scoring system originally consisted of 20 items (ranging from A to $\mathrm{T}$ ), which were scored from zero to two; the lower the score, the better the clinical condition. Based on the high prevalence of gastro-intestinal and bladder problems in females with RTT, an additional item concerning these problems was added in the adapted ISS (item U) (Giesbers et al., 2012). These 21 items were grouped into five functional domains: Growth and Development (A-E), Musculoskeletal (F-H), Movement (I-L), Cortical (M-O), and Autonomic features (P-U). The oro-motor disturbances were included in the Autonomic domain, according to Julu and Witt Engerström (2005). 
Table 2 Modified version of the ISS scoring list ( Adapted from Kerr et al., 2001)

\section{International Scoring System}

\section{GROWTH AND DEVELOPMENT}

A Head circumference during the first year

2 Already below the 3rd percentile at birth

1 Normal at birth but decelerating

0 Normal at birth with no deceleration

B Early developmental progress (birth to 12 months)

2 No or virtually no progress

1 Suboptimal progress

0 Normal progress

C Present head circumference - (percentile/standard deviations sd)

2 Below 3rd percentile

1 3rd to10th percentile

0 Above 10th percentile

D Weight $(\mathrm{kg})$

2 Below 3rd percentile

13 rd to10th percentile

0 Above 10th percentile

E Height $(\mathrm{cm})$

2 Below 3rd percentile

13 rd to10th percentile

0 Above 10th percentile

\section{MUSCULOSKELETAL}

F Muscle tone (also describe)

2 Severe hypotonia, dystonia or hypertonia

1 Tone mildly abnormal

0 Normal

G Spine posture

2 Severe scoliosis

1 Mild scoliosis

0 No deviation

$\mathrm{H}$ Joint contractures

2 Severe contractures

1 Minor contractures

0 None

MOVEMENT

I Gross motor function

2 Cannot walk with support

1 Walking impaired

0 Walks normally

J Hand stereotypy (patting, squeezing, wringing, mouthing)

2 Dominating or constant

1 Mild or intermittent

0 None 


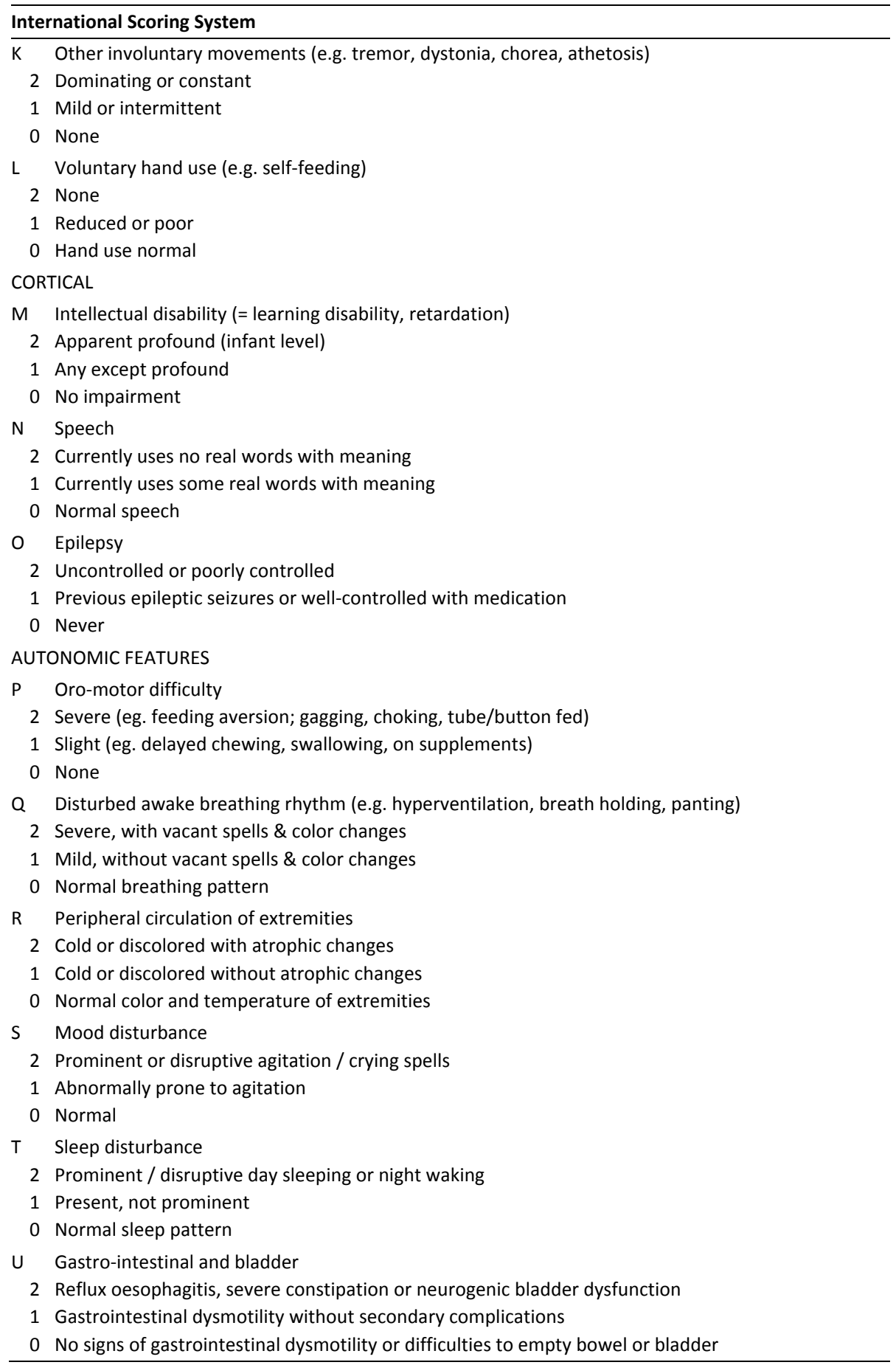




\section{Neurophysiological assessment}

Autonomic monitoring of brainstem function was carried out using the NeuroScope $^{\mathrm{TM}}$ (Medifit Instruments Ltd, London UK). This is a cortico-bulbar neurophysiological method for monitoring brainstem autonomic functions and cortical activity simultaneously in real-time and synchronizing the various autonomic signs. The cardiovascular and respiratory vital signs we quantified and recorded are: cardiac vagal tone (CVT), heart rate (HR) and the rate and rhythms of the breathing movements. Transcutaneous partial pressures of oxygen $\left(\mathrm{pO}_{2}\right)$ and carbon dioxide $\left(\mathrm{pCO}_{2}\right)$ representing blood gases were recorded continuously and synchronized with autonomic function. Cortical activity was monitored using electroencephalography (EEG) and synchronized with autonomic function. A continuous video record time-locked with the physiological data was kept for behavioral analysis.

\section{Data analysis}

Data was collected from all centers into a unified, anonymous database. Clinician experts in RTT made the ISS scoring list. Baseline brainstem functions were measured during normal breathing without agitation, with normal blood gases $\left(\mathrm{pCO}_{2}\right.$ and $\mathrm{pO}_{2}$ ) and in the absence of epileptiform activity on EEG.

The genotype-phenotype analyses were performed after grouping together all mutations of similar types, localizations or putative biological effect on the MeCP2 protein. Consequently, mutations were then subdivided into the following five groups: 1) truncating mutations in the NT and MBD domain, causing loss of function or disruption of the two functional domains MBD and TRD;2) missense mutations in the MBD domain, giving rise to a modified or non-functional MBD; 3) truncating mutations in the Interdomain and TRD, causing a loss of functional TRD; 4) missense mutations in TRD giving rise to a modified or non-functional TRD; 5) small truncations in the CTS leading to protein with an altered C-terminus. A further separate genotype-phenotype analysis was performed on eight recurrent mutations, defined as mutations present in at least $5 \%$ of the RTT females in this cohort (Table 3 ).

We used descriptive statistics to analyses mutation types, ISS scores, and cardiorespiratory data including Valsalva's manoeuvre type of breathing (Valsalva breathing). Linear regression analysis was used to analyze the relationships among ISS scores (total and functional domain scores), CVT, HR, and mutation groups or recurrent mutations. Checks for the normality assumption were done employing Q$Q$ plots. If the normality assumption was in doubt, the analyses were done by ordinal logistic regression. Relationships among cardiorespiratory phenotypes, Valsalva breathing (present or absent) and mutation groups or recurrent mutations, were examined using nominal logistic regression. The mutation groups and the recurrent mutations were used as predictor variables through dummy coding in the regression analyses. Since age may be a confounding factor for the ISS scores and HR, this vari- 
able was included as an extra predictor for these outcomes. First a statistical test was done to check whether there was a relation between mutation groups or recurrent mutations and the outcome in question. If present, it was re-examined in a pairwise fashion to determine which groups differed from each other with respect to the outcome variable. The level of statistical significance for all tests was set to a probability value of $\leq 0.05$, and all analyses were carried out using SPSS18.

Table 3 Recurrent mutations including number and percentage of RTT females

\begin{tabular}{lcc}
\hline Recurrent mutation & Number of RTT females & Percentage of RTT females \\
\hline p.R133C & 14 & $11 \%$ \\
p.T158M & 8 & $6 \%$ \\
p.R168X & 12 & $9 \%$ \\
p.R255X & 9 & $7 \%$ \\
p.R270X & 11 & $8 \%$ \\
p.R294X & 10 & $8 \%$ \\
p.R306C & 8 & $6 \%$ \\
C-terminal deletions & 21 & $16 \%$ \\
Total & 93 & $70 \%$ \\
\hline
\end{tabular}

\section{Results}

The age of the RTT females ranged between two and 43 years (mean age: 12.46 years, $s d=9.36)$. According to the clinical criteria, $74 \%(n=98)$ of the females were typical RTT and $26 \%(n=34)$ atypical RTT.

\section{Mutation analysis}

MECP2 mutations were classified by mutation type, localization and putative protein function, as shown in Table 1. Truncating mutations were present in $64 \%(n=85)$ and missense mutations in $36 \%(n=47) .43 \%$ had a mutation affecting the TRD $(n=57)$, whereas $41 \%(n=54)$ had a mutation affecting the MBD. The mutations localized in the MBD were predominantly missense mutations (82\%), while those affecting in the TRD were mostly truncating (81\%). Half of the truncating mutations, affecting both the MBD and TRD, were due to a large deletion of both exon 3 and most of the coding part of exon $4.16 \%(n=21)$ displayed a truncating mutation in the CTS leading to an extensive replacement of the C-terminus, which is likely to have an unfavorable effect on the natural protein function due to its putative effect on protein structure.

Table 3 shows the recurrent mutations included in this study, together comprising $70 \%$ of the pathogenic mutations in this cohort. 


\section{ISS scoring list}

The mean severity score on the ISS scoring list was 20.7 points (range 2-36, $s d=7.59$ ). Separating the scores into the functional domains, the mean scores were: Growth and Development, 3.79 points (range 0-8, sd=2.42); Musculoskeletal, 2.54 points (range 0-6, sd=1.84); Movement, 4.76 points (range 1-8, sd=1.59); Cortical, 4.10 points (range $1-6, \mathrm{sd}=1.37$ ); Autonomic, 5.53 points (range $0-12$, sd=2.59) respectively.

\section{Cardiorespiratory status of the RTT cohort}

$49 \%$ were diagnosed as feeble breathers $(n=65), 41 \%$ as forceful $(n=54)$, and $10 \%$ as apneustic $(n=13)$. Valsalva breathing was present in $62 \%(n=82)$, and occurred in all three cardiorespiratory phenotypes. We assessed both sympathetic and parasympathetic functions of the autonomic nervous system by measuring HR and CVT of these females. HR varied between 66 and 172 beats/min (mean rate=99.2, sd=17.4). Mean CVT was 4.50 (range 0.9-13.9, sd=2.53).

\section{Genotype-phenotype analysis}

\section{Clinical severity}

\section{Total ISS score}

The total ISS score did differ significantly between the different mutation groups $(F(d f 1=4, d f 2=126)=3.02, p=0.02)$. Females with a CTS mutation scored significantly lower than females with a mutation in the NT domain or nonsense mutation in the $\operatorname{MBD}(t=2.53, p=0.01)$, and with a nonsense or missense mutation in the TRD (respectively $\mathrm{t}=3.22, \mathrm{p}<0.01$ and $\mathrm{t}=2.31, \mathrm{p}=0.02$ ).

The total ISS score also differed significantly between the different recurrent mutations $(F(d f 1=7, d f 2=83)=4.47, p<0.001)$. Females with a p.R133C, p.R294X or CTS mutation scored significantly lower than females with a p.T158M ( $t=2.32-2.57$, $p=0.01-0.02), p . R 168 X(t=2.70-2.92, p<0.01), p . R 255 X(t=3.54-3.70, p<0.001-0.01)$, p.R270X ( $t=2.55-2.79, p=0.01)$, or $p . R 306 C$ mutation $(t=2.05-2.35, p=0.02-0.04)$.

\section{Growth and Development domain}

The ISS score in the Growth and Development domain did differ significantly between the different mutation groups $(F(d f 1=4, d f 2=126)=3.22, p=0.02)$. Females with a CTS mutation scored significantly lower than females with a mutation in the NT domain or nonsense mutation in the $\operatorname{MBD}(t=3.00, p<0.01)$, missense mutation in the $\operatorname{MBD}(t=2.53, p=0.01)$, and nonsense or missense mutation in the TRD (respectively $\mathrm{t}=2.92, \mathrm{p}<0.01$ and $\mathrm{t}=2.76, \mathrm{p}<0.01$ ). 
The ISS score also differed significantly between the different recurrent mutations $(F(d f 1=7, d f 2=83)=4.57, p<0.001)$. Females with a p.R294X or CTS mutation scored significantly lower than females with a p.T158M $(t=3.08, p<0.01$ and $t=2.89, p<0.01$ respectively); $p . R 168 X(t=2.31, p=0.02$ and $t=2.03, p=0.05$ respectively), $p . R 255 X$ $(\mathrm{t}=3.88, \mathrm{p}<0.001$ and $\mathrm{t}=3.84, \mathrm{p}<0.001$ respectively), $\mathrm{p} . \mathrm{R} 270 \mathrm{X}(\mathrm{t}=3.10, \mathrm{p}<0.01$ and $t=2.93, p<0.01$ respectively) or $p . R 306 C$ mutation ( $t=3.00, p<0.01$ and $t=2.78, p<0.01$ respectively). Also females with a $\mathrm{p} . \mathrm{R} 133 \mathrm{C}$ mutation scored significantly lower than females with a p.T158M mutation $(t=2.00, p=0.05)$ or p.R255X mutation $(t=2.84$, $p=0.01)$.

\section{Musculoskeletal domain}

The ISS score in the Musculoskeletal domain did not differ significantly among the different mutation groups $(F(d f=4)=9.42, p=0.051)$, but did differ significantly among the different recurrent mutations $(F(d f=7)=15.00, p=0.04)$. Females with a $p . R 133 C$ or p.R294X mutation scored significantly lower than females with a p.T158M $(F(d f=1)=12.23, \quad p<0.001$ and $F(d f=1)=9.39, \quad p<0.01$ respectively), $\quad$. $R 168 X$ $(F(d f=1)=13.44, \quad p<0.001$ and $F(d f=1)=10.00, \quad p<0.01$ respectively), $\quad$. $R 255 X$ $(F(d f=1)=14.83, \quad p<0.001$ and $F(d f=1)=11.47, \quad p=0.001$ respectively), $\quad$. $R 270 X$ $(F(d f=1)=9.19, p<0.01$ and $F(d f=1)=6.64, p=0.01$ respectively) or $p . R 306 C$ mutation $(F(d f=1)=5.86, p=0.02$ and $F(d f=1)=4.11, p=0.04$ respectively). Also females with a CTS mutation scored significantly lower than females with a p.T158M ( $F(d f=1)=5.84$, $p=0.02), p . R 168 X \quad(F(d f=1)=6.38, p=0.01)$ or $p . R 255 X$ mutation $(F(d f=1)=7.89$, $p=0.01)$.

\section{Movement domain}

The ISS score in the Movement domain did not differ significantly among the different mutation groups $(F(d f 1=4, d f 2=126)=1.27, p=0.29)$ or recurrent mutations $(F(d f 1=7, d f 2=83)=1.55, p=0.16)$.

\section{Cortical domain}

The ISS score in the Cortical domain did not differ significantly among the different mutation groups $(F(d f 1=1, d f 2=5)=12.78, p=0.21)$ or recurrent mutations $(F(d f 1=1, d f 2=8)=14.83, p=0.34)$.

\section{Autonomic domain}

The ISS score in the Autonomic domain did not differ significantly among the different mutation groups $(F(d f 1=4, d f 2=126)=2.11, p=0.08)$ or recurrent mutations $(F(d f 1=7, d f 2=83)=1.93, p=0.08)$. 


\section{Autonomic assessment}

\section{Cardiorespiratory phenotype}

There was no significant correlation between cardiorespiratory phenotype and groups of mutations $\left(\chi^{2}(d f=8)=4.77, p=0.78\right)$. Excluding the apneustic breathers for the analysis did not change these results $\left(\chi^{2}(d f=4)=3.37, p=0.50\right)$.

Also no significant correlation was seen among the cardiorespiratory phenotypes and recurrent mutations $\left(\chi^{2}(d f=14)=13.42, p=0.49\right)$. Excluding the apneustic breathers for this analysis also did not change these results $\left(\chi^{2}(d f=7)=8.91, p=0.26\right)$.

\section{Valsalva manoeuvre type of breathing}

There was no significant correlation among the presence and absence of Valsalva breathing and the groups of mutations $\left(\chi^{2}(d f=4)=2.50, p=0.64\right)$ or recurrent mutations $\left(\chi^{2}(d f=7)=10.81, p=0.15\right)$.

\section{Cardiac Vagal Tone (CVT)}

There was no significant correlation between CVT and the groups of mutations $(F(d f 1=4, d f 2=126)=2.40, p=0.06)$ or recurrent mutations $(F(d f 1=7, d f 2=83)=1.17$, $\mathrm{p}=0.33)$.

\section{Heart rate (HR)}

There was no significant correlation between $\mathrm{HR}$ and the groups of mutations $(F(d f 1=4, d f 2=126)=0.29, p=0.88)$ or recurrent mutations $(F(d f 1=7, d f 2=83)=0.31$, $p=0.95)$.

\section{Discussion}

This multicenter study was the result of an international collaborative network set up to create a database with sufficient numbers of robust clinical, molecular and neurophysiological data for further analyses. The grouping of the mutations in MECP2 was based on the putative biological effects of these mutations on the MeCP2 protein as explained in our Methods. Despite the minor methodological differences, the clinical severity and general genotype-phenotype results were similar to those in previous studies. We used a modified version of the internationally accepted clinical scoring system (Kerr et al., 2001) to quantify the effects of RTT on growth, development and other bodily dysfunctions in our genotype-phenotype analyses. The ISS provided us with a form of quantifiable clinical severity of the various bodily dysfunctions in this RTT cohort, which indeed is comparable with previous research (Bebbington et al., 2008; Halbach et al., 2012). We have elucidated a less severe clinical phenotype in females with CTS, p.R133C or p.R294X mutations (Huppke et al., 2002; Leonard et al., 2003; Colvin et al., 2004; Charman et al., 
2005; Kerr \& Prescott, 2005; Leonard et al., 2005; Smeets et al., 2005; Bebbington et al., 2008; Neul et al., 2008; Smeets et al., 2009; Bebbington et al., 2010; Halbach et al., 2012; Bebbington et al., 2012). However, clinical severity varies even within one specific type or group of mutations (Halbach et al., 2012). It means genotypes have very limited use for clinical management in RTT.

The main reason for conducting this study was to evaluate the influence of MECP2 mutation on brainstem instability, which includes breathing dysrhythmia, so characteristic of RTT. Breathing dysrhythmia is a major reason for seeking medical attention and for secondary referral of persons with RTT (Julu \& Witt Engerström, 2005; Smeets et al., 2006; Julu et al., 2008). Cardiorespiratory data must be obtained using objective and quantitative neurophysiological measurements of brainstem functions, because clinical management of brainstem autonomic dysfunction in RTT is a profound challenge. Each cardiorespiratory phenotype requires a unique and specific clinical approach (Julu et al., 2008). In this cohort of RTT females, up to $49 \%$ were feeble breathers, $41 \%$ were forceful breathers and $10 \%$ were apneustic breathers. There is some but little difference in the distribution of the three cardiorespiratory phenotypes in this cohort compared with that previously reported (Julu \& Witt Engerström, 2005). This cohort of RTT confirms that Valsalva breathing is a common complication of breathing dysrhythmia in RTT, affecting all three cardiorespiratory phenotypes as previously reported (Julu \& Witt Engerström, 2005). The wildcat excitatory effects of Valsalva's manoeuvres on the autonomic nervous system in general and other brainstem functions can cause clinical deterioration in RTT (Julu \& Witt Engerström, 2005). Detailed correlation analyses of the cardiorespiratory data showed that the cardiorespiratory phenotypes in RTT are not influenced by genetic mutations. This provides further proof that cardiorespiratory phenotypes are more important for clinical management in RTT than the genetic mutations.

The baseline brainstem functions were severely affected in all RTT females similar to the results in previous studies (Julu et al., 1997; Julu et al., 2001; Julu \& Witt Engerström, 2005). The mean CVT in this cohort was lower than the normal mean value in young adults (Julu, 1992). Since CVT is the only central inhibitory output to the heart, it is very important in brainstem cardiorespiratory integration (Guyenet et al., 1996). Its role in rapid cardiovascular responses is very important and it is a major contributor to integrative inhibition within the cardiovascular system (Guyenet et al., 1996). The HR values in this cohort were within the normal limits for the age group. It implies that the resting sympathetic tone is within normal limits (Julu et al., 1997), and not exaggerated above normal as previously thought (Naidu et al., 1987). This normal but unrestrained sympathetic tone due to little or no parasympathetic negative feedback is the cause of a type of sympatho-vagal imbalance unique to RTT. This may contribute to the increased sudden deaths of up to $26 \%$ of females with RTT, compared with only $2.3 \%$ in the general population of the same age range (Kerr et al., 1997; Hagberg et al., 2001). The discussion above and the 
high ISS score in the Autonomic domain both reflect the great impact of brainstem dysfunction on the clinical severity in RTT. We provide here sufficient reasons for carers of persons with RTT to seek medical attention starting early in childhood. This is because "bedside" clinical evaluation including ISS scoring cannot determine the contributions of autonomic dysfunction to the clinical severity in individual cases (Halbach et al., 2012). In persons with RTT, objective quantitative clinical and neurophysiological assessment must be done early after diagnosis or promptly following the onset of brainstem autonomic symptoms. This is necessary in order to plan a better and effective clinical management strategy for the RTT person (Julu et al., 2005; Julu et al., 2008)

In conclusion, this is the first study to use objective and robust data of cardiorespiratory variables in the investigation of genotype-phenotype correlation in RTT. All females with RTT had dysautonomia, and this was not restricted to nor influenced by one specific group or single recurrent mutation. The clinical variability within a specific genetic mutation or within a similar group of mutations makes genotype-phenotype correlations impossible and renders the genetic mutations of limited use in clinical management of RTT. The robust and objective information obtained from non-invasive neurophysiological evaluation of the brainstem autonomic functions is of much greater importance and it helps to organize the lifelong care for persons with RTT. Although considerable progress is being made in understanding the mechanisms of autonomic dysfunction in RTT (Weese-Mayer et al., 2006; Rohdin et al., 2007; Julu et al., 2008; Katz et al., 2009), further research is needed for a better understanding of the pathogenesis of autonomic dysfunctions in this syndrome. This will facilitate future development of evidence-based management strategies in RTT. 


\section{References}

Amir RE, Van den Veyver IB, Wan M, Tran CQ, Francke U, Zoghbi HY. Rett syndrome is caused by mutations in X-linked MECP2, encoding methyl-CpG-binding protein 2. Nat Genet 1999: 23: 185-188.

Bebbington A, Anderson A, Ravine D, Fyfe S, Pineda M, De Klerk N, Ben-Zeev B, Yatawara N, Percy A, Kaufmann WE, Leonard $\mathrm{H}$. Investigating genotype-phenotype relationships in Rett syndrome using an international data set. Neurology 2008: 70: 868-875.

Bebbington A, Downs J, Percy A, Pineda M, Zeev BB, Bahi-Buisson N, Leonard H. The phenotype associated with a large deletion on MECP2. Eur J Hum Genet 2012: Epub ahead of print.

Bebbington A, Percy A, Christodoulou J, Ravine D, Ho G, Jacoby P, Anderson A, Pineda M, Ben Zeev B, Bahi-Buisson N, Smeets E, Leonard H. Updating the profile of C-terminal MECP2 deletions in Rett syndrome. J Med Genet 2010: 47: 242-248.

Charman T, Neilson TC, Mash V, Archer H, Gardiner MT, Knudsen GP, McDonnell A, Perry J, Whatley SD, Bunyan DJ, Ravn K, Mount RH, Hastings RP, Hulten M, Orstavik KH, Reilly S, Cass H, Clarke A, Kerr AM, Bailey ME. Dimensional phenotypic analysis and functional categorisation of mutations reveal novel genotype-phenotype associations in Rett syndrome. Eur J Hum Genet 2005: 13: 1121-1130.

Colvin L, Leonard H, de Klerk N, Davis M, Weaving L, Williamson S, Christodoulou J. Refining the phenotype of common mutations in Rett syndrome. J Med Genet 2004: 41: 25-30.

Giesbers S, Didden R, Radstaake M, Korzilius H, Von Gontard A, Lang R, Smeets E, Curfs LM. Incontinence in individuals with Rett syndrome: a comparative study. J Dev Phys Disabil 2012: 24: 287-300.

Guyenet PG, Koshiya N, Huangfu D, Baraban SC, Stornetta RL, Li YW. Role of medulla oblongata in generation of sympathetic and vagal outflows. Prog Brain Res 1996: 107: 127-44.

Hagberg B, Aicardi J, Dias K, Ramos O. A progressive syndrome of autism, dementia, ataxia and loss of purposeful handuse in girls: Rett's syndrome: report of 35 cases. Ann Neurol 1983: 14: 471-479.

Hagberg B, Berg M, Steffenburg U. Three decades of sociomedical experiences from West Swedish Rett females 4-60 years of age. Brain Dev 2001: 23: S28-31.

Hagberg B, Hanefeld F, Percy A, Skjeldal O. An update on clinically applicable diagnostic criteria in Rett syndrome. Eur J Peadiatr Neurol 2002: 6: 293-297.

Halbach NSJ, Smeets EEJ, Bierau J, Keularts IMLW, Plasqui G, Julu POO, Witt Engerström I, Bakker JA, Curfs LMG. Altered carbon dioxide metabolism and creatine abnormalities in Rett Syndrome. JIMD Rep 2012: 3: 117-124.

Halbach NSJ, Smeets EEJ, Van den Braak N, Van Roozendaal KEP, Blok RMJ, Schrander-Stumpel CTRM, Frijns JP, Maaskant MA, Curfs LMG. Genotype-Phenotype Relationships as Prognosticators in Rett Syndrome Should be Handled With Care in Clinical Practice. Am J Med Genet Part A 2012: 158A: 340-350.

Huppke P, Held M, Handefeld F, Engel W, Laccone F. Influence of mutation type and location on phenotype in 123 patients with Rett syndrome. Neuropediatrics 2002: 33: 63-68.

Julu POO. A linear scale for measuring vagal tone in man. J Auton Pharmacol 1992: 12: 109-115.

Julu PO, Engerström IW, Hansen S, Apartopoulos F, Engerström B, Pini G, Delamont RS, Smeets EE. Cardiorespiratory challenges in Rett's syndrome. Lancet 2008: 371: 1981-1983.

Julu PO, Kerr AM, Apartopoulos F, Al-Rawas S, Engerström I, Engerström L, Jamal G, Hansen S. Characterisation of breathing and associated central autonomic dysfunction in the Rett disorder. Arch Dis Child 2001: 85: 29-37.

Julu POO, Kerr AM, Hansen S, Apartopoulos F, Jamal GA. Functional evidence of brain stem immaturity in Rett syndrome. Arch Dis Child 1997: 77(5): 464-465.

Julu PO, Witt Engerström I. Assessment of the maturity-related brainstem functions reveals the heterogeneous phenotypes and facilitates clinical management of Rett syndrome. Brain Dev 2005: 27(suppl 1): S43-S53.

Julu PO, Witt Engerström I, Hansen S, Apartopoulos F, Engerström B; The ESSRA group. Treating hypoxia in a feeble breather with Rett syndrome. Brain Dev 2012: Epub ahead of print. 
Katz DM, Dutschmann M, Ramirez JM, Hilaire G. Breathing disorders in Rett syndrome: progressive neurochemical dysfunction in the respiratory network after birth. Respir Physiol Neurobiol 2009: 168: 101-108.

Kerr AM, Armstrong DD, Prescott RJ, Doyle D, Kearney DL. Rett syndrome: analysis of deaths in the British survey. Eur Child Adolesc Psychiatry 1997: 6(Suppl1): 71-74.

Kerr AM, Nomura Y, Armstrong D, Anvret M, Belichenko PV, Budden S, Cass H, Christodoulou J, Clarke A, Ellaway C, d'Esposito M, Francke U, Hulten M, Julu P, Leonard H, Naidu S, Schanen C, Webb T, Witt Engerstr€om I, Yamashita $Y$, Segawa M. Guidelines for reporting clinical features in cases with MECP2 mutations. Brain Dev 2001: 23: 208-211.

Kerr AM, Prescott RJ. Predictive value of the early clinical signs in Rett disorder. Brain Dev 2005: 27: S20S24.

Leonard H, Colvin L, Christodoulou J, Schiavello T, Williamson S, Davis M, Ravine D, Fyfe S, de Klerk N, Matsuishi T, Kondo I, Clarke A, Hackwell S, Yamashita Y. Patients with the R133C mutation: is their phenotype different from Rett syndrome patients with other mutations? J Med Genet 2003: 40: e52.

Leonard H, Moore H, Carey M, Fyfe S, Hall S, Robertson L, Wu XR, Bao X, Pan H, Christodoulou J, Williamson S, Klerk Nd. Genotype and early development in Rett syndrome: The value of international data. Brain Dev 2005: 27: S59-S68.

Lioy DT, Wu WW, Bissonnette JM. Autonomic dysfunction with mutations in the gene that encodes methyl-CpG-binding protein 2: insights into Rett syndrome. Auton Neurosci 2011: 161: 55-62.

Naidu S, Chatterjee S, Murphy M, Uematsu S, Phillapart M, Moser H. Rett syndrome: new observations. Brain Dev 1987: 9(5): 525-8.

Neul JL, Fang P, Barrish J, Lane J, Caeg EB, Smith EO, Zoghbi H, Percy A, Glaze DG. Specific mutations in methyl-CpG-binding protein 2 confer different severity in Rett syndrome. Neurology 2008; 70: 13131321.

Neul JL, Kaufmann WE, Glaze DG, Christodoulou J, Clarke AJ, Bahi-Buisson N, Leonard H, Bailey ME, Schanen NC, Zappella M, Renieri A, Huppke P, Percy AK, RettSearch Consortium. Rett syndrome: revised diagnostic criteria and nomenclature. Ann Neurol 2010: 68: 944-950.

Rohdin M, Fernell E, Eriksson M, Albåge M, Lagercrantz H, Katz-Salamon M. Disturbances in cardiorespiratory function during day and night in Rett syndrome. Pediatr Neurol 2007: 37: 338-344.

Schanen C, Houwink EJ, Dorrani N, Lane J, Everett R, Feng A, Cantor RM, Percy A. Phenotypic manifestations of MECP2 mutations in classical and atypical Rett syndrome. Am J Med Genet 2004: 126A: 129140.

Smeets EE, Chenault M, Curfs LM, Schrander-Stumpel CT, Frijns JP. Rett syndrome and long-term disorder profile. Am J Med Genet Part A 2009: 149A: 199-205.

Smeets EE, Julu PO, Van Waardenburg D, Engerström IW, Hansen S, Apartopoulos F, Curfs LM, SchranderStumpel CT. Management of a severe forceful breather with Rett syndrome using carbogen. Brain Dev 2006: 28(10): 625-632.

Smeets E, Terhal P, Casaer P, Peters A, Midro A, Schollen E, Van Roozendaal K, Moog U, Matthijs G, Herbergs J, Smeets H, Curfs L, Schrander-Stumpel C, Fryns JP. Rett syndrome in females with CTS hot spot deletions: a disorder profile. Am J Med Genet 2005: 132: 117-120.

Weese-Mayer DE, Lieske SP, Boothby CM, Kenny AS, Bennett HL, Silvestri JM, Ramirez JM. Autonomic nervous system dysregulation: breathing and heart rate perturbation during wakefulness in young girls with Rett syndrome. Pediatr Res 2006: 60: 443-449. 
Chapter 4

\section{Altered carbon dioxide metabolism and creatine abnormalities in Rett syndrome}

Halbach NSJ, Smeets EEJ, Bierau J, Keularts IMLW, Plasqui G, Julu POO, Witt Engerström I, Bakker JA, Curfs LMG.

JIMD Reports 2012: 3: 117-124. 


\begin{abstract}
Despite their good appetite, many females with Rett syndrome (RTT) meet the criteria for moderate to severe malnutrition. Although feeding difficulties may play a part in this, other constitutional factors such as altered metabolic processes are suspected. Irregular breathing is a common clinical feature, leading to chronic respiratory alkalosis or acidosis. We assumed that these changes in intracellular $\mathrm{pH}$ cause disturbances in the metabolic equilibrium, with important nutritional consequences. The study population consisted of a group of thirteen well-defined RTT girls with extended clinical, molecular and neurophysiological assessments. Despite normal levels of total dietary energy and protein intakes, malnutrition was confirmed based on significantly low fat-free mass index (FFMI) values. Biochemical screening of multiple metabolic pathways showed significantly elevated plasma creatine concentrations and increased urinary creatine/creatinine ratio in five RTT girls. Four girls, 10 years and older, were forceful breathers, one 13-year-old girl had an undetermined cardiorespiratory phenotype. An isolated increase of the urinary creatine/creatinine ratio was seen in two girls, a 9-year-old forceful and a 4-year-old feeble breather. Given that the young girls are feeble breathers and the older girls are forceful breathers, it is impossible to determine whether the elevated creatine concentrations are due to increasing age or cardiorespiratory phenotype. Furthermore, MeCP2 deficiency may cause epigenetic aberrations affecting the expression of the creatine-transporter gene, which is located at Xq28. Further studies are required to confirm these findings and to provide greater insight into the pathogenesis of the abnormal creatine metabolism in RTT.
\end{abstract}




\section{Introduction}

Rett syndrome (RTT; OMIM 312750) is a unique X-linked neurodevelopmental disorder. Affecting 1 in 10,000 females, RTT is a common genetic cause of severe intellectual disability in females (Smeets \& Schrander-Stumpel, 2005; Williamson \& Christodoulou, 2006). In up to $95 \%$ of all classical cases, RTT is caused by a mutation in the methyl-CpG-binding protein 2 gene (MECP2) located on the long arm of the $X$ chromosome (Xq28) (Amir et al., 1999; Williamson \& Christodoulou, 2006).

Despite their good appetite, the majority of the females with RTT meet the criteria for moderate to severe malnutrition. However, not all RTT females present in this manner (Rice \& Haas, 1988). The true prevalence of malnutrition in RTT is unknown, and the pathological mechanism underlying is barely understood. Although feeding difficulties may play a role, other constitutional factors such as altered metabolic processes are suspected (Motil et al., 1998; Oddy et al., 2007; Reilly \& Cass, 2001).

Irregular breathing is a common clinical feature of RTT, reflecting the immaturity of the brainstem in these females. The underlying pathophysiology involves a defective control mechanism of carbon dioxide exhalation, leading to chronic respiratory alkalosis or acidosis (Julu et al., 2008a; Julu et al., 2001; Smeets \& Schrander-Stumpel, 2005). This change in $\mathrm{pH}$ might cause disturbance of the metabolic equilibrium in RTT females, with potential consequences for their nutritional status.

Hitherto, no systematic studies on altered metabolic processes as a cause of impaired nutritional status in RTT have been carried out. The objective of this study was to examine whether chronic respiratory acidosis or alkalosis leads to disturbed metabolic profiles and enzyme activities in multiple metabolic pathways.

\section{Patients and methods}

Ethical approval was obtained from the Medical Ethical Committee at the Maastricht University Medical Centre, and all parents provided informed written consent. The study was registered at clinicaltrials.gov.

\section{Patient population}

The patient population consisted of a group of thirteen well-defined RTT girls with extended clinical, molecular and neurophysiological assessment. This assessment consisted of:

1. Clinical examination comprising a full physical examination including measurement of height, weight and Body Mass Index (BMI). In addition, clinical features were scored uniformly using the International Scoring System (ISS) (Kerr et al., 2001). The ISS is used to determine clinical severity concerning 20 items (maxi- 
mum score being 40), grouped into five functional domains (growth and development, musculoskeletal, movement, cortical and autonomic features).

2. Mutation analysis of $M E C P 2$ by $P C R$, sequencing the coding regions and multiplex ligation-dependent probe amplification analysis (nomenclature according to the MECP2A isoform reference sequence AF158180, numbering starting at the $A$ of the ATG translation initiation codon).

3. Detailed neurophysiological assessment using the Neuroscope, a technique for continuous and real-time assessment of brainstem function to define the cardiorespiratory phenotype (Julu \& Engerström, 2005). The different cardiorespiratory phenotypes (Apneustic, Feeble, and Forceful breathers) in RTT have been described in detail elsewhere (Julu et al., 2008a, b).

Diagnosis of RTT was based on the consensus diagnostic criteria for RTT and confirmed by mutation finding in MECP2 (Hagberg et al., 2002). All girls were diagnosed as classical RTT.

\section{Study design}

The RTT girls were recruited at the Clinical Genetics outpatient clinic at the Maastricht University Medical Centre, the Netherlands. All participants were clinically assessed by the same experienced clinician (Dr. E. Smeets). The nutritional status was assessed by a complete nutrition assessment and measurement of body composition. Blood and urine samples were collected for biochemical analysis and stored at $-20^{\circ} \mathrm{C}$ until analysis after the appropriate workup.

\section{Nutritional status}

Dietary intake was assessed using a standardized format including two 3-day food records. Parents were instructed to record all foods and beverages consumed on three subsequent days, including one weekend day. The timing of the first 3-day record period was prior to the blood sampling, and the second period was recorded approximately 6 months later. The amount of liquid and the size of food portions offered and actually consumed at each meal were reported in household measures. Energy and nutrient intake was calculated using the Dutch food composition table (NeVo, version 06) and the software Komeet ${ }^{\circledR}$ (BaS Nutrition Software, Arnhem).

In addition to the food records, a semistructured interview was administered to the parents to specify usual dietary intakes, eating abilities, and food preferences.

Body composition was measured using the Deuterium dilution method according to the Maastricht protocol (Westerterp et al., 1995). A random urine sample was used to determine the background isotope level before the administration of $a D_{2} O$ mixture. At least $6 \mathrm{~h}$ after administration of a $\mathrm{D}_{2} \mathrm{O}$ dose (per oz or through a PEG catheter), a urine sample was taken from the second voiding. Fat-free mass (FFM) 
was then calculated from total body water (TBW) using the child-specific hydration factors published by Lohman (Lohman, 1989). Subsequently, FFM was divided by squared height to calculate the fat-free mass index (FFMI; $\mathrm{kg} /$ height $\left.(\mathrm{m})^{2}\right)$. Malnutrition was defined as an FFMI below the fifth percentile (or -2 SD) for age and gender (Vanltallie et al., 1990; Schutz et al., 2002).

\section{Metabolic measurements}

Routine chemistry and hematology were carried out, as proposed by the Frösö Declaration and included full blood count, total protein, albumin, protein electrophoresis, urea, creatinine, electrolytes such as $\mathrm{Na}^{+} / \mathrm{K}^{+} / \mathrm{Ca}^{2+} / \mathrm{Cl}^{-} / \mathrm{PO}_{4}$. Liver function tests were only done if specifically indicated (Julu et al., 2008b).

In addition, the metabolic screening program as shown in Table 1 was carried out to identify markers pointing toward possible consequences of an altered carbon dioxide metabolism. In view of the specific breathing irregularities in combination with feeding problems, one would expect changes in the "intermediate metabolism" including metabolism of glucose, glycogen, amino acids/proteins, and fatty acids. Short- and long-term changes due to, for example, a specific nutritional status are reflected in amino acid profiles in urine and plasma, acylcarnitine profiles in plasma (to also exclude a fatty acid oxidation defect or organic acidurias) and excretion of metabolites (organic acids) in urine (organic acid excretion profile). 
Table 1 General overview of selective metabolic screening including matrix and methodology

\begin{tabular}{lll}
\hline Analysis & Matrix & Methodology \\
\hline Amino acid analysis & Urine, plasma & LC-MS/MS \\
Organic acid analysis & Urine, plasma & GC-MS, silylated \\
Purines and pyrimidines & Urine, plasma & LC-MS/MS \\
Guanidinoacetate and creatine & Urine, plasma & LC-MS/MS \\
Phenolic compounds & Urine & HPLC-fluorescence \\
Acylcarnitine profiling & Plasma & MS/MS \\
Very-long chain fatty acids & Plasma & LC-MS/MS \\
Sialotransferrines & Plasma & Isoelectric focusing \\
Methylmalonate & Plasma & LC-MS/MS \\
Homocysteine & Plasma & LC-MS/MS \\
Adenosine Deaminase activity & Erythrocytes & HPLC-UV \\
Adenine Phosphoribosyltransferase activity & Erythrocytes & HPLC-UV \\
Hypoxanthine Phosphoribosyltransferase activity & Erythrocytes & HPLC-UV \\
Inosine triphosphatase activity & Erythrocytes & HPLC-UV \\
Nucleotide profile & Erythrocytes & HPLC-UV \\
$\alpha$-Galactosidase A activity & Leukocytes & Fluorescence \\
\hline
\end{tabular}

LC-MS/MS Liquid Chromatography with Tandem Mass Spectrometry, GC-MS Gas chromatography-mass spectrometry, HPLC High-performance liquid chromatography, MS/MS Tandem mass spectrometers, HPLC-UV High-Pressure Liquid Chromatography with UV Detector

\section{Statistical analysis}

Using SPSS version 15.0, frequency tables including percentages were obtained for the variables "MECP2-mutation", "cardiorespiratory phenotype", and "anthropometry data". Concerning age, mean values and standard deviation were calculated. Regarding ISS scores, both frequency tables and mean scores were calculated.

\section{Results}

\section{Patient characteristics}

Patient characteristics are presented in Table 2. 
Table 2 The clinical characteristics of the RTT girls

\begin{tabular}{|c|c|c|c|c|c|c|c|c|c|}
\hline $\begin{array}{l}\text { RTT } \\
\text { girl }\end{array}$ & $\begin{array}{l}\text { Age } \\
\text { (yr.month) }\end{array}$ & $\begin{array}{l}\text { Height } \\
(\mathrm{cm}+\mathrm{p})\end{array}$ & $\begin{array}{l}\text { Weight } \\
(k g+p)\end{array}$ & $\begin{array}{l}\text { Head } \\
\text { circumference } \\
(\mathrm{cm}+\mathrm{p})\end{array}$ & $\begin{array}{l}\text { BMI } \\
(\mathrm{kg} / \mathrm{m} 2+\mathrm{p})\end{array}$ & ISS & $\begin{array}{l}\text { MECP2 } \\
\text { mutationa }\end{array}$ & CRPh & $\begin{array}{l}\operatorname{tcpCO}_{2} \\
(\mathrm{mmHg})\end{array}$ \\
\hline 1 & 2.4 & $85(p 2)$ & 11.3 (p10) & 45 (p2) & $15.6(\mathrm{p} 25)$ & 14 & p.R255X & $\mathrm{FeB}$ & 43.3 \\
\hline 2 & 3.11 & 98 (p50) & $16(p 25)$ & 48.5 (p25) & 16.7 (p50) & 8 & p.T158M & $\mathrm{FeB}$ & 48.2 \\
\hline 3 & 4.0 & 107 (p70) & 14.5 (p10) & $50.5(p 50)$ & $12.7(\mathrm{p} 2)$ & 8 & p.R294X & $\mathrm{FeB}$ & 52.3 \\
\hline 4 & 4.3 & 103 (p50) & 20.5 (p98) & $47(\mathrm{p} 2)$ & 19.3 (p98) & 21 & fs710dupG & $\mathrm{FeB}$ & 50.6 \\
\hline 5 & 5.3 & $112(p 50)$ & $19(p 50)$ & 49 (p25) & $15.2(p 50)$ & 20 & p.R270X & $\mathrm{FeB}$ & 40.9 \\
\hline 6 & 6.2 & $113(\mathrm{p} 25)$ & $18(p 25)$ & 49 (p25) & $14.3(\mathrm{p} 25)$ & 9 & p.R306C & FoB & 22.3 \\
\hline 7 & 9.8 & $120(<p 2)$ & $20.5(p 2)$ & $51(p 25)$ & $14.2(p 10)$ & 20 & fs705delG & FoB & 15.5 \\
\hline 8 & 9.8 & $132(p 2)$ & 26.4 (p10) & $49.5(\mathrm{p} 2)$ & $15.2(\mathrm{p} 25)$ & 20 & p.P152R & FoB & $25.8-42.0$ \\
\hline 9 & 10.11 & $127(<p 2)$ & $24.5(\mathrm{p} 2)$ & $50.5(p 25)$ & $15.2(<p 2)$ & 26 & p.R106W & FoB & 15.5 \\
\hline 10 & 13.3 & $148(\mathrm{p} 2)$ & $31.7(p 2)$ & $50(<p 2)$ & $14.5(\mathrm{p} 2)$ & 23 & p.R294X & FoB & $10.5-22.5$ \\
\hline 11 & 13.11 & $148(<p 2)$ & $54(p 75)$ & $54(p 50)$ & 24.7 (p98) & 27 & c.1158del55 & Und & 35.2 \\
\hline 12 & 19.3 & $171(p 50)$ & 65 (p75) & $52(\mathrm{p} 3)$ & $22.3(p 50)$ & 24 & p.R306C & FoB & 20.8 \\
\hline 13 & 20.3 & $150(<p 2)$ & $43(p 2)$ & $53(p 25)$ & $19.1(p 2)$ & 24 & p.R168X & FoB & N.A. \\
\hline
\end{tabular}

$p$ percentile, ISS total ISS score, CRPh Cardiorespiratory phenotype, FeB Feeble breather, FoB Forceful breather, Und Undetermined, $t c p C \mathrm{O}_{2}$ transcutaneous $\mathrm{pCO}_{2}$ (reference values $38-44 \mathrm{mmHg}$ ), N.A. Not acquired ${ }^{\text {a }}$ Nomenclature according to the MECP2A isoform reference sequence AF158180, numbering starting at the $A$ of the ATG translation initiation codon

\section{Age}

The ages of RTT girls ranged from 2 years and 4 months to 20 years and 3 months (mean age 9 years and 5 months, $s d=5$ years and 11 months).

\section{Anthropometry}

Mean height, weight, BMI, and head circumference scores of RTT girls were below that of their age group. The height of $54 \%$ of the RTT girls was below the fifth percentile, of which $86 \%$ were 9 years or older. Regarding BMI, $31 \%$ of the girls were below the fifth percentile and two girls had a BMI over the 50th percentile. Regarding age, low BMI was present in $75 \%$ of those 9 years and older.

\section{ISS score}

Mean ISS scores for the RTT girls was 18.8 (range: 8-27, sd=6.78). Severe RTT (score 25-29) was present in two girls, mild to less severe RTT (score 10-24) in eight and very mild RTT (score below 10) in three girls. Severe RTT was only seen in girls 9 years and older and very mild scores only in those younger than 9 years. Mean 
score of the girls younger than 9 years was 13.3 (range: $8-21$, sd=5.99), compared to 23.4 (range: $20-27, \mathrm{sd}=2.70$ ) in those 9 years and older.

\section{Mutation analysis}

Both missense and nonsense mutations in MECP2 were each observed in five girls. Of these mutations, four were located in the methyl-CpG binding domain and six in the transcription repression domain. Two girls had a frameshift mutation and only one girl had a CTS deletion. In view of the variety in mutations, no differences concerning other patient characteristics could be observed.

\section{Cardiorespiratory phenotype}

Of the 13 girls included in this study, five girls were feeble breathers, seven girls were forceful breathers, and one girl had an undetermined cardiorespiratory phenotype. Remarkably, all feeble breathers were below 5 years of age and all forceful breathers were 6 years and older. Furthermore, Table 2 shows the $\mathrm{tcpCO}_{2}$ values measured during the Neuroscope assessment. As one can see, overall feeble breathers show high tcp $\mathrm{CO}_{2}$ levels in contrast to forceful breathers who show low tcpCO $\mathrm{C}_{2}$ levels.

\section{Nutritional status}

Results on dietary intakes and body composition are presented in Table 3 
Table 3 Nutritional status of the RTT girls including age-specific and lifestyle adjusted recommended / reference values

\begin{tabular}{|c|c|c|c|}
\hline RTT girl & $\begin{array}{l}\text { Dietary energy } \\
\text { (kcal/day) }\end{array}$ & $\begin{array}{l}\text { Protein } \\
(\mathrm{gm} / \mathrm{kg} / \text { day) }\end{array}$ & $\begin{array}{l}\text { FFMI } \\
(\mathrm{kg} / \mathrm{l} 2)\end{array}$ \\
\hline 1 & $1,179(800)$ & $3.0(>0.9)$ & 11.94 (unknown) \\
\hline 2 & $1,222(800)$ & $2.4(>0.9)$ & 12.71 (unknown) \\
\hline 3 & $1,920(1,120)$ & $4.5(>0.9)$ & N.A. \\
\hline 4 & $1,150(1,120)$ & $2.3(>0.9)$ & 9.62 (unknown) \\
\hline 5 & $1,189(1,120)$ & $2.1(>0.9)$ & $9.12^{\mathrm{b}}(11.7-15.7)$ \\
\hline 6 & $1,010^{\mathrm{a}}(1,120)$ & $1.3(>0.9)$ & $11.48^{\mathrm{b}}(11.7-15.7)$ \\
\hline 7 & $1,137(1,120)$ & $2.4(>0.9)$ & $11.60^{\mathrm{b}}(11.7-15.7)$ \\
\hline 8 & $1,222(1,120)$ & $1.9(>0.9)$ & $10.34^{b}(11.7-15.7)$ \\
\hline 9 & $1,710(1,680)$ & $2.2(>0.9)$ & $12.05^{b}(11.7-15.7)$ \\
\hline 10 & $1,828(1,680)$ & $1.6(>0.9)$ & $10.46^{b}(13.2-17.2)$ \\
\hline 11 & $895^{\mathrm{a}}(1,680)$ & $1.2(>0.9)$ & $11.23^{\mathrm{b}}(13.2-17.2)$ \\
\hline 12 & $1,893(1,680)$ & $0.9(>0.8)$ & $12.29^{\mathrm{b}}(13.8-17.6)$ \\
\hline 13 & $1,630^{\mathrm{a}}(1,680)$ & $1.5(>0.8)$ & $12.18^{\mathrm{b}}(13.8-17.6)$ \\
\hline
\end{tabular}

FFMI Fat-free mass index, N.A. Not acquired

${ }^{a}$ Low dietary energy compared to the recommended values

${ }^{b}$ FFMI value < 2 SD or p5 (Freedman et al., 2005; Schutz et al., 2002)

\section{Dietary intakes}

Dietary intakes were evaluated and compared to age-specific standards for an inactive lifestyle, by which the normal values were adjusted to $80 \%$ of the recommended values for healthy girls. Overall, the total daily dietary energy was reasonably normal in the RTT girls, as the mean dietary intake was $117 \%$ of the adjusted recommended values. Almost $77 \%$ of the RTT girls met these adjusted recommended values. Only three girls had a dietary energy intake below these values, respectively, of $90 \%, 53 \%$, and $97 \%$ of the recommended values. The RTT girl having a dietary energy intake of only $53 \%$ of the recommended values had a BMI at the 98th percentile and she was on a strict diet.Protein intake in all patients was above the agespecific recommended values.

Prior to blood and urine sampling, no specific nutrients were consumed which could influence the metabolic investigations as has been described by Arias and colleagues (Arias et al., 2007).

\section{Body composition}

As one can see in Table 3, 9 RTT girls confirm the definition of malnutrition, defined as an FFMI below the fifth percentile (or -2 SD) for age and gender. Since reference 
values for girls younger than 5 years of age are not available, one cannot confirm malnutrition in these younger girls.

\section{Metabolic investigations}

As shown in Table 4, significantly elevated plasma creatine concentrations and increased urinary creatine/creatinine ratios were observed in five RTT girls. An isolated increase of the urinary creatine/creatinine ratio was seen in two girls. The creatinine plasma concentrations were relatively low in all RTT girls. The slightly elevated guanidinoacetate concentrations observed in three females are not clinically relevant, since they do not meet the criteria of a guanidinoacetate methyltransferase deficiency (Stromberger et al., 2003). An elevated CK concentration was seen in a girl with normal creatine concentrations. Other metabolic investigations (Table 1) showed no abnormalities.

Table 4 Creatine metabolism in RTT girls including age-specific reference values

\begin{tabular}{|c|c|c|c|c|c|c|}
\hline RTT girl & $\begin{array}{l}\text { Cr plasma } \\
(\mu \mathrm{mol} / \mathrm{l})\end{array}$ & $\begin{array}{l}\mathrm{Cr} / \mathrm{Crn} \text { urine } \\
\text { (mmol/mol) }\end{array}$ & $\begin{array}{l}\text { Crn plasma } \\
(\mu \mathrm{mol} / \mathrm{I})\end{array}$ & CK (U/L) & $\begin{array}{l}\text { GAA plasma } \\
(\mu \mathrm{mol} / \mathrm{l})\end{array}$ & $\begin{array}{l}\text { GAA/Crn urine } \\
\text { (mmol/mol) }\end{array}$ \\
\hline 1 & $75.7(17-109)$ & $490.6(6-1,200)$ & $29.7^{b}(35-62)$ & $73(<140)$ & $1.1(0.35-1.8)$ & $116.2(4-220)$ \\
\hline 2 & 79.5 (17-109) & $421.3(6-1,200)$ & $27.0^{b}(35-62)$ & $79(<140)$ & $2.1^{\mathrm{a}}(0.35-1.8)$ & $102.3(4-220)$ \\
\hline 3 & $88.1(17-109)$ & N.A. & $30.7^{b}(44-71)$ & $77(<140)$ & $1.6(0.35-1.8)$ & N.A. \\
\hline 4 & 81.0 (17-109) & $828.8^{a}(17-720)$ & $28.0^{b}(44-71)$ & $49(<140)$ & $1.2(0.35-1.8)$ & $76.8(4-220)$ \\
\hline 5 & 83.5 (17-109) & $28.6(17-720)$ & $34.4^{b}(44-71)$ & $44(<140)$ & $1.4(0.35-1.8)$ & $26.8(4-220)$ \\
\hline 6 & $63.0(17-109)$ & $629.7(17-720)$ & $28.8^{b}(44-71)$ & $285^{\mathrm{a}}(<140)$ & $1.2(0.35-1.8)$ & $56.7(4-220)$ \\
\hline 7 & 52.9 (17-109) & $756.2^{a}(17-720)$ & $43.6^{b}(44-80)$ & $104(<140)$ & $1.4(0.35-1.8)$ & $73.2(4-220)$ \\
\hline 8 & $68.7(17-109)$ & $124.3(17-720)$ & $29.2^{b}(44-80)$ & $66(<140)$ & $0.8(0.35-1.8)$ & $45.0(4-220)$ \\
\hline 9 & $70.4^{a}(6-50)$ & $1,305.3^{a}(17-720)$ & $31.7^{b}(53-88)$ & $65(<140)$ & $1.6(0.35-1.8)$ & $72.7(4-220)$ \\
\hline 10 & $73.5^{a}(6-50)$ & $448.0^{a}(11-240)$ & $42.3^{b}(62-97)$ & $64(<140)$ & $1.6(0.35-1.8)$ & $64.4(4-220)$ \\
\hline 11 & $101.5^{\mathrm{a}}(6-50)$ & $1,040.3^{a}(11-240)$ & $40.3^{b}(62-97)$ & $26(<140)$ & $1.4(0.35-1.8)$ & $59.2(4-220)$ \\
\hline 12 & $88.5^{a}(6-50)$ & $403.7^{a}(11-240)$ & $36.7^{b}(50-100)$ & $53(<140)$ & $1.3(1.0-3.8)$ & $106.7^{\mathrm{a}}(3-78)$ \\
\hline 13 & $65.0^{a}(6-50)$ & $538.3^{a}(11-240)$ & $38.3^{b}(50-100)$ & $19(<140)$ & $1.9(1.0-3.8)$ & $82.7^{a}(3-78)$ \\
\hline
\end{tabular}

Cr Creatine, Crn Creatinine, $C K$ Creatine kinase, GAA Guanidinoacetate, N.A. Not acquired

${ }^{a}$ Elevated value

${ }^{\mathrm{b}}$ Low value of Creatinine

Elevated creatine concentrations were only seen in those 9 years and older, except for one 4-year-old girl with an isolated increased urinary creatine/creatinine ratio. Mean age of the girls having an elevated plasma creatine was 14.54 years (range: 9.6-20.3, sd=4.33), compared to 5.09 years (range: $2.3-9.7, \mathrm{sd}=2.34$ ) of the girls having a normal plasma creatine. Mean age of the girls having an increased urinary creatine/creatinine ratio was 13.07 years (range: $4.3-20.3, \mathrm{sd}=2.34$ ), compared to 
5.47 years (range: $2.3-9.7, \mathrm{sd}=2.75$ ) in the normal urinary creatine/creatinine ratio group.

Anthropometric characteristics between the two groups were roughly equal, except for height. Height was below the fifth percentile in $83 \%$ of the girls with elevated creatine concentrations, and greater than the 50th percentile in $57 \%$ of the girls with normal creatine concentrations.

Furthermore, only the girls with an elevated creatine concentration in plasma and urine had a severe ISS score, and the girls with a normal creatine concentration in plasma and urine had a very mild ISS score. The mean score of the girls in the elevated plasma creatine group was 24.0 (range: $20-27$, sd=2.45) versus 14.3 (range: $8-21, \mathrm{sd}=6.02$ ) in the normal plasma creatine group. The mean score of the girls in the increased urinary creatine/creatinine ratio group was 23.6 (range: 20-27, $s d=2.51$ ) compared to 14.2 (range: $8-20, s d=5.76$ ) in the normal urinary creatine/creatinine ratio group. Except for ISS domain four (mental/ cortical function), in which the scores were equally distributed in both groups, girls with an elevated creatine showed high scores in all domains.

In view of the variety in mutations, no differences concerning other patient characteristics could be observed.

Concerning the cardiorespiratory phenotype, in the elevated creatine group, four girls were forceful breathers and one girl had an undetermined cardiorespiratory phenotype. The girls with an isolated increased urinary creatine/creatinine ratio were a forceful and a feeble breather.

Finally, all RTT girls wherefore reference values of FFMI were available met the criteria for malnutrition. Therefore, a possible relationship between elevated creatine concentrations and an impaired nutritional status could not be investigated.

\section{Discussion}

This study is the first attempt to correlate metabolic alterations as a possible explanation of impaired nutritional status in RTT. Despite normal levels of total dietary energy and protein intakes, malnutrition was confirmed in all RTT girls wherefore reference values of FFMI were available. Although the loss of skeletal muscle mass could be partly due to physical inactivity, these low values are certainly an indication for impaired nutritional status in these RTT girls.

Blood and urine samples were collected for biochemical screening of multiple metabolic pathways. We observed significantly elevated plasma creatine concentrations and increased urinary creatine/creatinine ratios in half of the RTT girls. The creatinine plasma concentrations were relatively low, as one would expect in view of the low FFMI values. Nonetheless, the elevated creatine/creatinine ratios are most likely primarily due to the elevated creatine concentrations, considering the high plasma creatine concentrations at the same time. 
Given that in this study the young girls were feeble breathers and the older girls were forceful breathers, it is impossible to determine whether the elevated creatine concentrations are age related or associated with the cardiorespiratory phenotype. This age distribution is likely coincidental since previous studies showed no significant age difference between the different cardiorespiratory phenotypes (Julu \& Engerström, 2005). At present, it is uncertain whether an altered carbon dioxide metabolism affects the creatine metabolism in females with RTT.

It is difficult to explain why creatine concentrations should increase with age in the RTT cohort. According to the reference values for creatine, creatine concentrations normally decrease with increasing age (Salomons et al., 2003). Furthermore, Horská and colleagues reported stable creatine concentrations with increasing age in RTT girls using proton magnetic resonance spectroscopy (Horská et al., 2009). Consequently, it seems highly unlikely that the altered creatine concentrations can be explained by age.

Regarding the cardiorespiratory phenotype, two possible explanations can be given. First of all, as has been described by Julu and colleagues, a major difference in the cardiorespiratory phenotypes is the blood pH value (Julu et al., 2008a, b). Females with a forceful breathing type tend to be alkalotic due to excessive loss of $\mathrm{CO}_{2}$ via respiration, in contrast to females with a feeble breathing pattern who tend to be acidotic. The $\mathrm{pH}$ differences between these phenotypes can be as much as 0.4$0.5 \mathrm{pH}$-units (personal observation Dr. P.O.O. Julu). This $\mathrm{pH}$ difference may affect the creatine metabolism in RTT girls. Second, it can be speculated that the elevated creatine concentrations might be due to the increased energy expenditure as described in forceful breathers (Julu et al., 2008b). Phospho-creatine (P-creatine) together with ATP makes up the phosphagen energy system. P-creatine contains the high-energy phosphate bond, which is 3-8 times as abundant as ATP. As soon as more ATP is needed, P-creatine transfers its high energy phosphate to ATP (Guyton \& Hall 2000). Following this suggestion, it may be speculated that in forceful breathers, the elevated creatine concentrations are indirectly caused by higher $\mathrm{P}$ creatine needs.

Furthermore, as the creatine-transporter gene (SLC6A8) is located adjacent to MECP2 at Xq28, MeCP2 deficiency may cause epigenetic aberrations affecting the expression of the SLC6A8. The clinical phenotypes of RTT and an X-linked creatine transporter deficiency overlap regarding mental retardation, epilepsy, and language delay (Salomons et al., 2001). However, few studies have examined the brain metabolites of RTT females using proton magnetic resonance spectroscopy (Gökcay et al., 2002; Hashimoto et al., 1998; Horská et al., 2000, 2009; Khong et al., 2002; Pan et al., 1999). Overall, $\mathrm{N}$-acetylaspartate/total creatine was significantly decreased compared with age-matched controls, primarily reflecting reduced $\mathrm{N}$-acetylaspartate levels. Even so, an $8 \%$ greater mean creatine concentration was previously found in the frontal white matter in the RTT group. This difference was not signifi- 
cantly different, because of a high variability in creatine levels in both RTT and control groups (Horská et al., 2000, 2009). Nevertheless, in case of a decreased expression of SLC6A8, less creatine would be present in the brain, making this diagnosis highly unlikely in our patients (Salomons et al., 2001).

Clinically, the girls with an elevated creatine concentration differed from girls with a normal creatine concentration regarding height and ISS score. Girls with an elevated creatine concentration were substantially shorter and a more severe phenotype was observed. This severe phenotype reflected several functional domains, that is growth and development, musculoskeletal, movement, and autonomic features.

In summary, this is the first study to report abnormalities in creatine concentrations in RTT girls. Hitherto, only Freilinger and colleagues performed metabolic screening including urinary creatine/creatinine ratio (Freilinger et al., 2007). They did not report any abnormalities in creatine/ creatinine ratios in 29 Rett females with a mean age of 13 years. Reference values were not defined. However, as can clearly be seen in that article, three females have a highly elevated creatine/creatinine ratio. Furthermore, an MECP2 mutation was identified in $76 \%$ of the females, which is rather low compared to previously published data (Williamson \& Christodoulou, 2006). Cardiorespiratory data were not available. So, the discrepancy may be because of difference in reference values or patient populations, as the diagnosis of RTT in the previous study was mainly based on clinical criteria alone and a possibly lower percentage of forceful breathers. The strength of our study was the use of a well-defined group of RTT girls. Only due to these strict inclusion criteria, our study is hampered by the small sample size, which does not allow us to understand the observed creatine abnormalities fully. At this moment, we are not able to confirm our hypothesis regarding metabolic alterations as a possible explanation of impaired nutritional status in RTT, since impaired nutritional status was seen in all RTT girls wherefore reference values of FFMI were available. Different etiologies can explain the observed elevated creatine concentrations in the RTT girls. Except for creatine transporter defects, no other neurological disease ever showed elevated creatine values. Further studies concerning the creatine metabolism in relation to the nutritional requirements and cardiorespiratory status or phenotype of RTT girls are important in order to provide appropriate and effective management.

\section{Conclusions}

Despite normal levels of total dietary energy and protein intakes, malnutrition was confirmed in all RTT girls wherefore reference values of FFMI were available. An important percentage of RTT girls showed creatine concentrations above the reference values. Currently, it is undetermined how the creatine metabolism is affected 
in females with RTT, and how this may affect their nutritional status. Further studies are required to confirm these findings and to provide greater insight into the pathogenesis of the abnormal creatine metabolism in RTT. 


\section{References}

Amir RE, Van den Veyver IB, Wan M, Tran CQ, Francke U, Zoghbi HY. Rett syndrome is caused by mutations in X-linked MECP2, encoding methyl-CpG-binding protein 2. Nat Genet 1999: 23: 185-188.

Arias A, Corbella M, Fons C, Sempere A, García-Villoria J, Ormazabal A, Poo P, Pineda M, Vilaseca MA, Campistol J, Briones P, Pàmpols T, Salomons GS, Ribes A, Artuch R. Creatine transporter deficiency: prevalence among patients with mental retardation and pitfalls in metabolite screening. Clin Biochem 2007: 40: 1328-1331.

Freedman DS, Wang J, Maynard LM, Thornton JC, Mei Z, Pierson RN, Dietz WH, Horlick M. Relation of BMI to fat and fat-free mass among children and adolescents. Int J Obes 2005: 29(1): 1-8.

Freilinger M, Kalisch D, Muehl A, Haas O, Moritz A, Bodamer O. Methylation status in females with Rett syndrome. J Child Neurol 2007: 22: 635-638.

Gökcay A, Kitis O, Ekmekci O, Karasoy H, Sener RN. Proton MR spectroscopy in Rett syndrome. Comput Med Imaging Graph 2002: 26: 271-275.

Guyton AC, Hall JE. Energetics and metabolic rate. In: Guyton AC, Hall JE, editors. Textbook of medical physiology. Philadelphia: Elsevier Saunders 2000: 815-821.

Hagberg B, Hanefeld F, Percy A, Skjeldal O. An update on clinically applicable diagnostic criteria in Rett syndrome. Comments to Rett syndrome Clinical Criteria Consensus Panel Satellite to European Paediatric Neurology Society Meeting, Baden Baden, Germany, 11 September 2001. Eur J Paediatr Neurol 2002: 6: 293-297.

Hashimoto T, Kawano N, Fukuda K, Endo S, Mori K, Yoneda Y, Yamaue T, Harada M, Miyoshi K. Proton magnetic resonance spectroscopy of the brain in three cases of Rett syndrome: comparison with autism and normal controls. Acta Neurol Scand 1998: 98: 8-14.

Horská A, Naidu S, Herskovits EH, Wang PY, Kaufmann WE, Barker PB. Quantitative 1 H MR spectroscopic imaging in early Rett syndrome. Neurology 2000: 54(3): 715-722.

Horská A, Farage L, Bibat G, Nagae LM, Kaufmann WE, Barker PB, Naidu S. Brain metabolism in Rett syndrome: age, clinical, and genotype correlations. Ann Neurol 2009: 65:90-97.

Julu POO, Engerström IW. Assessment of the maturity-related brainstem functions reveals the heterogeneous phenotypes and facilitates clinical management of Rett syndrome. Brain Dev 2005: 27: S43S53.

Julu PO, Kerr AM, Apartopoulos F, Al-Rawas S, Engerström I, Engerström L, Jamal G, Hansen S. Characterisation of breathing and associated central autonomic dysfunction in the Rett disorder. Arch Dis Child 2001: 85: 29-37.

Julu PO, Engerström IW, Hansen S, Apartopoulos F, Engerström B, Pini G, Delamont RS, Smeets EE. Cardiorespiratory challenges in Rett's syndrome. Lancet 2008a: 371: 1981-1983.

Julu PO, Engerström IW, Hansen S, Apartopoulos F, Engerström B, Pini G, Delamont RS, Smeets EE. Clinical update: addressing the cardiorespiratory challenges posed by Rett syndrome in medicine. The Frösö decleration. 2008b.

Kerr AM, Nomura Y, Armstrong D, Anvret M, Belichenko PV, Budden S, Cass H, Christodoulou J, Clarke A, Ellaway C, d'Esposito M, Francke U, Hulten M, Julu P, Leonard H, Naidu S, Schanen C, Webb T, Witt Engerstr€om I, Yamashita $Y$, Segawa M. Guidelines for reporting clinical features in cases with MECP2 mutations. Brain Dev 2001: 23: 208-211.

Khong P, Lam C, Ooi CGC, Ko C, Wong VCN. Magnetic resonance spectroscopy and analysis of MECP2 in Rett syndrome. Pediatr Neurol 2002: 26: 205-209.

Lohman TG. Assessment of body composition in children. Pediatr Exerc Sci 1989: 1:19-30.

Motil KJ, Schultz RJ, Wong WW, Glaze DG. Increased energy expenditure associated with repetitive involuntary movement does not contribute to growth failure in girls with Rett syndrome. J Pediatr 1998: 132(2): 228-233.

Oddy WH, Webb KG, Baikie G, Thompson SM, Reilly S, Fyfe SD, Young D, Anderson AM, Leonard H. Feeding experiences and growth status in a Rett syndrome population. J Pediatr Gastroenterol Nutr 2007: 45(5): 582-590. 
Pan JW, Lane JB, Hetherington H, Percy AK. Rett syndrome: $1 \mathrm{H}$ spectroscopic imaging at 4.1 Tesla. J Child Neurol 1999: 14: 524-528.

Reilly S, Cass H. Growth and nutrition in Rett syndrome. Disabil Rehabil 2001: 23: 118-128.

Rice MA, Haas RH. The nutritional aspects of Rett syndrome. J Child Neurol 1988: 3: S35-S42.

Salomons GS, Van Dooren SJ, Verhoeven NM, Cecil KM, Ball WS, Degrauw TJ, Jakobs C. X-linked creatinetransporter gene (SLC6A8) defect: a new creatine-deficiency syndrome. Am J Hum Genet 2001: 68: 1497-1500.

Salomons GS, Van Dooren SJ, Verhoeven NM, Marsden D, Schwartz C, Cecil KM, DeGrauw TJ, Jakobs C. Xlinked creatine-transporter defect: an overview. J Inherit Metab Dis 2003: 26: 309-318.

Schutz Y, Kyle UU, Pichard C. Fat-free mass index and fat mass index percentiles in Caucasians aged 1898 y. Int J Obes Relat Metab Disord 2002: 26(7): 953-960.

Smeets EE, Schrander-Stumpel CTRM Rett syndrome. In: Cassidy SB, Allanson JE, editors. Management of genetic syndromes. New York: Wiley-Liss 2005: 457-468.

Stromberger C, Bodamer OA, Stöckler-Ipsiroglu S. Clinical characteristics and diagnostic clues in inborn errors of creatine metabolism. J Inherit Metab Dis 2003: 26: 299-308.

Vanltallie TB, Yang MU, Heymsfield SB, Funk RC, Boileau RA. Height normalized indices of the body's fatfree mass and fat mass: potentially useful indicators of nutritional status. Am J Clin Nutr 1990: 52(6): 953-959.

Westerterp KR, Wouters L, Van Marken - Lichtenbelt W. The Maastricht protocol for the measurement of body composition and energy expenditure with labelled water. Obes Res 1995: 3: 49-57.

Williamson SL, Christodoulou J. Rett syndrome: new clinical and molecular insights. Eur J Hum Genet 2006: 14: 896-903. 


\section{Chapter 5 \\ Aging in people with specific genetic syndromes: Rett syndrome}

Halbach NSJ, Smeets EEJ, Schrander-Stumpel CTRM, Van Schrojenstein Lantman de Valk HHJ, Maaskant MA, Curfs LMG.

Am J Med Genet Part A 2008: 146A: 1925-32. 


\begin{abstract}
The aging process of people with intellectual disabilities has been a topic of interest in recent years. Good knowledge of the specific healthcare problems in adults with intellectual disabilities and anticipating on these problems are important issues in providing support and healthcare for these persons. Nevertheless little is known about the aging process of people with specific syndromes, like Rett syndrome. In association with the Dutch Rett syndrome parent association, 70 postal questionnaires were sent to the contact persons of the females aged at least 16 years with a clinical diagnosis of Rett syndrome. The questionnaire consisted of general questions, questions about living conditions, skills, physical and psychiatric morbidity. The response rate was $76 \%(n=53)$. In general adults with Rett syndrome seemed to be reasonably healthy, whereas neurological, respiratory and behavioral morbidity appeared to be of great influence. High care dependency was confirmed. In contrast with underweight, overweight showed to be an under-ascertained feature. The general disorder profile was confirmed, considering the increase with age regarding kyphosis and the better communication and autonomic dysfunction in the oldest age group compared to the younger age groups. Features of autonomic dysfunction deserve more medical attention, especially the interrelation between quality of sleep, respiration and behavior in Rett syndrome. Longitudinal studies including genotype-phenotype analyses are needed for insight in individual changes in support needs and health.
\end{abstract}




\section{Introduction}

Thanks to better life circumstances and major advances in medical care and technology, the life expectancy of persons with childhood onset diseases and/or genetic syndromes has increased (Patja et al., 2000; Donckerwolcke \& Van Zeben-Van der Aa, 2002; Maaskant et al., 2002; Fisher \& Kettl, 2005). Consequently, the number of adults with intellectual disabilities (ID) has increased substantially during the last decades and will continue to increase in the next years (Janicki \& Breitenbrach, 2000; Bernard et al., 2002). Compared to persons without ID, age specific conditions occur more often and earlier in life (Maaskant et al., 1996; Van Schrojenstein Lantman-de Valk et al., 1997). Nevertheless little is known about aging in people with specific syndromes, except for Down syndrome (Roeden \& Zitman, 1995; Torr \& Davis, 2007; Jervis and Prinsloo, 2008). In this study we focus on Rett syndrome (RTT), a neurodevelopmental disorder affecting almost exclusively females. The prevalence is $1: 10,000$ girls at 11 years and therefore a common genetic cause of severe ID in females (Hagberg et al., 1983; Smeets \& Schrander-Stumpel, 2005; Williamson \& Christodoulou, 2006). In spite of the molecular confirmation of a MECP2 mutation, diagnosis of RTT remains mainly clinically based on internationally accepted criteria (Amir et al., 1999; Hagberg et al., 2002). RTT manifests particular symptoms at certain ages, including a wide variability in clinical evolution and severity (Smeets et al., 2003; Williamson \& Christodoulou, 2006). Hagberg and WittEngerström (1986) devised a staging system that divides the natural history of RTT into four stages: early stagnation, rapid regression, pseudo stabilization and late motor deterioration. The general RTT profile is that of a slowly continuing deterioration of gross motor performance over the years in contrast with a relatively better preserved cognitive ability to communicate, mainly with the eyes. An inactive, small and thin woman with trophic skin changes is the general long-term clinical disorder profile, suggesting a kind of "pre-aging" in RTT (Hagberg, 2002; Cass et al., 2003). The aim of the present study is to gain insight into age-related features in RTT. The research question is: what physical, behavioral and psychiatric conditions are present in adults with RTT and which of these conditions are age-related?

\section{Materials and methods}

Prior to the start of this study, ethical approval was obtained from the Medical Ethical Committee at the academic hospital of Maastricht.

\section{Subjects}

Subjects were recruited through the Dutch RTT parent association. Questionnaires were developed and sent to 70 contact persons (mainly parents), of which $76 \%$ 
were returned. In total, data were derived from 53 Dutch females aged 16 years and older with a clinical diagnosis of RTT, confirmed by experienced clinicians. The parents answered in 47 cases, parents together with a professional career in 3 cases, a professional career in 1 case and a physician in 1 case. Those who completed the questionnaires are further referred to as "parents".

\section{Questionnaire}

The questionnaire consisted of four major subdivisions. The first part included questions about demographic characteristics, including height, weight and abdominal circumference. The second part comprised questions about living conditions and use of care facilities. In the third part the Observational Questionnaire Elderly Residents with Intellectual Disabilities (Observatielijst Ouderwordende Bewoners, OOB) was inserted. The $O O B$ is an instrument that assesses functioning, behavior and care dependency; it has to be completed by a care-provider familiar with the client. The OOB has four subscales: (1) activities of daily living (ADL), (2) psychological functioning, (3) (inappropriate) reactions, and (4) physical functions and care dependence. The questionnaire was supplemented with questions addressing RTT specific features. The range for the scale is 0 or 1-4: the higher the score the better the functioning. The reliability and validity of the OOB has been demonstrated to be satisfactory to good (Hoefnagel, 1989). Questions on the medical history, medication use, genetic diagnosis, physical and psychiatric morbidity were inserted in the fourth part of the questionnaire. Ultimately, the view of parents regarding significant changes in skills and morbidity from the age of 10 years was rated on a 3points scale (no change, improvement, or decline). All data were processed anonymously.

\section{Response}

Table 1 shows the characteristics of the respondents. The mean age was 26.9 years. Among the 53 persons with clinical RTT, mutation analyses were performed in $70 \%$, of which $84 \%$ were molecularly confirmed. Forty percent of the RTT persons had a normal weight, $49 \%$ were underweight and $11 \%$ were overweight. Seventeen contact persons did not return the questionnaire. The mean ages of non-respondents and respondents were 25.7 and 26.9 years, respectively $(p=0.17)$. There are no indications that the non-response was selective and affected the results. 
Table 1 Characteristics of the respondents according to age, genotype and BMI

\begin{tabular}{lrr}
\hline & $\mathbf{N}$ & $\%$ \\
\hline Age & 11 & $21 \%$ \\
16 - 20 years & 24 & $45 \%$ \\
20 - 30 years & 18 & $34 \%$ \\
30 + years & & \\
Mean age: 26.9 years, range 16-53, sd=7.85 & & \\
Genotype & 37 & $70 \%$ \\
Mutation analyses performed & 31 & $58 \%$ \\
$\quad$ MECP2 positive & 4 & $8 \%$ \\
$\quad$ MECP2 negative & 2 & $4 \%$ \\
$\quad$ Results unknown & 12 & $8 \%$ \\
Mutation analyses not performed & 4 & \\
Unknown & & $42 \%$ \\
BMI category & 22 & $34 \%$ \\
< 18,5 (underweight) & 18 & $9 \%$ \\
18,5 - 25 (normal weight) & 5 & \\
$>$ 25 (overweight) & 8 & \\
Unknown & & \\
Mean BMI: 20.0, range 13.0-38.1, sd=4.51 & & \\
\hline
\end{tabular}

\section{Data analyses}

Questionnaires were reviewed before data were correlated; in case of two answers the best answer was consistently chosen. SPSS version 14.0 was used for analyzing the data. Three age groups (16-20, 20-30, 30+) were to analyze possible age-related conditions. Prevalence rates were calculated for morbidity and mean scores were calculated for BMI and perceived health. Concerning skills and behavior, frequencies and mean scores were calculated. The following statistical tests were performed: Chi-square (for nominal and ordinal data) and Kendall's tau-b (for ordinal data), independent $t$ tests (means of two groups) or ANOVA (means of more than two groups).

\section{Results}

\section{Living conditions and use of care facilities}

Approximately one third (36\%) of the RTT persons lived full-time or part-time with their parents. About two thirds (71\%) lived in residential facilities, of whom $13 \%$ still spent some (weekend) days a week with their parents. Three RTT persons (6\%) lived in apartments with $24 \mathrm{~h}$ daily support. Significantly more young adults lived with their parents and older adults lived in residential facilities (Kendall's tau-b: $p<0.01$ respectively $p<0.05)$. Analyses regarding age at entering residential facilities showed an ordinal relation with age (Kendall's tau-b: $p<0.01$ ). 
Most RTT persons (67\%) spent their days in day care facilities. Respite care facilities were used by $12 \%$, specifically and non-specifically for persons with ID (10\% respectively $2 \%)$.

\section{Health}

Health of the individuals was assessed on a 5-point scale ranging from very good (1) to very bad (5). In general, the respondents valued the health of the RTT persons as good (mean 2.15, range 1-4). Perceived health was not related to age (Kendall's tau$b: p=0.86$ ) with mean scores in the different age groups of 2.0, 2.2, and 2.1. Further analyses showed a significant relation between health and apnea (Kendall's tau-b: $p<0.01$ ), breath holding spells (Kendall's tau-b: $p<0.05$ ), mood changes (Kendall's tau-b: $p<0.01$ ), spasticity (Kendall's tau-b: $p<0.01$ ) and joint deformities (Kendall's tau-b: $p<0.001)$. Care dependence and physical complaints had a negative relation with health (Kendall's tau-b: $p<0.01$ and $p<0.001$ ).

\section{Weight status and eating behavior}

Discarding the missing values in some respondents, prevalence of underweight RTT persons was $49 \% ; 40 \%$ had a normal weight and $11 \%$ were overweight. Comparing $\mathrm{BMI}$ and eating behavior a positive relation was shown (Kendall's tau-b: $p<0.01$ ). No relation between $B M I$ and perceived health or age was found (ANOVA: $p=0.95$ respectively $\mathrm{p}=0.78$ ).

\section{Communication}

Only one third of the RTT persons were at least sometimes able to express themselves by spoken language and/or signals, of which $13 \%$ through eye pinpointing behavior. Concerning this group, the communication was considerably better in the older age groups (Kendall's tau-b: $p=0.10$ ). Changes in communication skills were experienced by parents: 10 parents considered improvement in their children's communication from the age of 10 years, whereas 3 parents experienced a decline (Chi-square: $p=0.01$ ).

\section{Morbidity}

Table 2 shows the morbidity and behavioral problems of RTT persons per age group. Arranged by subject, explanatory remarks are made below. Skin problems, sleep abnormalities, respiratory problems and behavioral problems are considered as manifestations of autonomic dysfunction. To investigate potential relations between the different items further analyses were performed. 
Table 2 Prevalence of morbidity in RTT persons per age-group and significance level

\begin{tabular}{|c|c|c|c|c|c|c|}
\hline Morbidity by age group & $\begin{array}{l}16-20 \\
(n=11) \\
(\%)\end{array}$ & $\begin{array}{l}20-30 \\
(n=24) \\
(\%)\end{array}$ & $\begin{array}{l}30+ \\
(n=18) \\
(\%)\end{array}$ & $\begin{array}{l}\text { Total } \\
(n=53) \\
(\%)\end{array}$ & $\begin{array}{l}\text { Kendall's } \\
\text { tau-b }\end{array}$ & Chi-square \\
\hline \multicolumn{7}{|l|}{ Skin problems } \\
\hline Cold feet & $100 \%$ & $96 \%$ & $94 \%$ & $96 \%$ & $p=0.41$ & $p=0.56$ \\
\hline Pressure sores and vesicles & $40 \%$ & $54 \%$ & $39 \%$ & $46 \%$ & $p=0.73$ & $p=0.56$ \\
\hline Trophic skin and nail changes & $33 \%$ & $39 \%$ & $18 \%$ & $30 \%$ & $p=0.16$ & $\mathrm{p}=0.05^{*}$ \\
\hline \multicolumn{7}{|l|}{ Sleep abnormalities } \\
\hline Nightly unrest & $64 \%$ & $79 \%$ & $83 \%$ & $77 \%$ & $p=0.16$ & $p=0.16$ \\
\hline \multicolumn{7}{|l|}{ Prolonged wakefulness and / } \\
\hline or early morning awakening & $36 \%$ & $58 \%$ & $50 \%$ & $51 \%$ & $p=0.54$ & $p=0.66$ \\
\hline Sleepy during the day & $80 \%$ & $83 \%$ & $89 \%$ & $85 \%$ & $p=0.59$ & $p=0.59$ \\
\hline \multicolumn{7}{|l|}{ Respiratory problems } \\
\hline Apnea & $44 \%$ & $46 \%$ & $23 \%$ & $38 \%$ & $p=0.13$ & $p=0.01^{*}$ \\
\hline Hyperventilation & $30 \%$ & $42 \%$ & $39 \%$ & $39 \%$ & $p=0.65$ & $p=0.76$ \\
\hline Breath holding spells & $80 \%$ & $83 \%$ & $56 \%$ & $73 \%$ & $p=0.24$ & $p=0.30$ \\
\hline Air swallowing & $40 \%$ & $44 \%$ & $39 \%$ & $41 \%$ & $p=0.83$ & $p=0.96$ \\
\hline \multicolumn{7}{|l|}{ Behavioral problems } \\
\hline Nightly screaming & $33 \%$ & $46 \%$ & $33 \%$ & $39 \%$ & $p=0.56$ & $p=0.96$ \\
\hline Mood changes & $67 \%$ & $61 \%$ & $72 \%$ & $66 \%$ & $p=0.32$ & $p=0.82$ \\
\hline Agitation & $22 \%$ & $65 \%$ & $56 \%$ & $54 \%$ & $p=0.27$ & $p=0.25$ \\
\hline Anxious impression & $50 \%$ & $79 \%$ & $62 \%$ & $68 \%$ & $p=0.89$ & $p=0.49$ \\
\hline \multicolumn{7}{|l|}{ Musculoskeletal } \\
\hline Scoliosis & $90 \%$ & $88 \%$ & $94 \%$ & $90 \%$ & $p=0.43$ & $p=0.41$ \\
\hline Kyphosis & $0 \%$ & $24 \%$ & $19 \%$ & $16 \%$ & $p=0.05^{*}$ & $p=0.21$ \\
\hline Spasticity & $60 \%$ & $41 \%$ & $61 \%$ & $52 \%$ & $p=0.51$ & $p=0.37$ \\
\hline Joint deformities & $44 \%$ & $65 \%$ & $61 \%$ & $60 \%$ & $p=0.77$ & $p=0.70$ \\
\hline Epilepsy & $82 \%$ & $62 \%$ & $83 \%$ & $74 \%$ & $p=0.93$ & $p=0.51$ \\
\hline
\end{tabular}

$* p \leq 0.05$

\section{Autonomic manifestations}

Skin problems. Cold feet were notified in $96 \%$ of the RTT persons, $50 \%$ with blue discoloration, and $50 \%$ without. Pressure sores and vesicles occurred in $46 \%$. The prevalence of trophic skin and nail changes was 30\%, whereas the occurrence was significantly lower in the oldest age group ( $18 \%$, Chi-square: $p=0.05)$. According to the parents, in 7 of their children's a decline in skin problems was observed from the age of 10 years.

Sleep abnormalities. Half of the RTT persons sometimes had nightly unrest, whereas $20 \%$ had nightly unrest at least once a week up to daily. The prevalence of nightly unrest was higher in the two older age groups, although these differences were awakening not statistically significant (64\% to $79 \%$ to $83 \%$, Kendall's tau-b: $\mathrm{p}=0.16$ ). Prolonged wakefulness and/or early morning awakening was more or less pronounced in $51 \%$. Daytime sleeping was reported in $85 \%$, ranging from some- 
times in $50 \%$ to constantly in $8 \%$. No statistically significant relationships with age were found (Kendall's tau-b: $p>0.16$ ).

Respiratory problems. Apnea was reported in 38\% of the RTT persons, ranging from $16 \%$ once a month up to $14 \%$ daily. The prevalence was significantly lower in the oldest age group ( $23 \%$, Chi-square: $p=0.01)$. Thirty-nine percent of the RTT persons had hyperventilation and $73 \%$ had breath holding spells. Air swallowing was present in 41\%. Except for apnea, the differences between the age groups and respiratory problems were not statistically significant.

Behavioral problems. Nightly screaming was reported in 39\%, two thirds less than once a week. Prevalence of mood changes was $66 \%$, one third at least once a week. Abnormal agitation was more or less pronounced in $54 \%$. Whereas the occurrence was lower in the younger age group, this was not significant $(22 \%$, Chi-square: $p=0.25$ ). Two thirds of the RTT persons showed anxiety, of which $4 \%$ was constantly agitated. No statistically significant relationships with age were found (Kendall's taub: $p>0.27$.

\section{Interrelationships}

Further analyses regarding autonomic manifestations showed a relation between behavioral problems and sleep abnormalities (Kendall's tau-b: $p<0.01-0.019$ ), and respiratory problems and sleep abnormalities (Kendall's tau-b: $p<0.001-0.03$ ).

\section{Musculoskeletal}

The prevalence of scoliosis in our study was $90 \%$. Thirty-six percent had undergone surgery and $40 \%$ had not been operated. For the remaining $24 \%$, scoliosis operation was not mentioned by parents in the medical history.

The overall prevalence of kyphosis was $16 \%$, whereas the occurrence was significantly higher in the older age groups ( $0 \%$ to $24 \%$ to $19 \%$ respectively, Kendall's tau$b: p=0.05$ ). Analyses regarding osteoporosis and kyphosis showed $25 \%$ occurrence of osteoporosis in the kyphosis group in contrast to $0 \%$ occurrence in the remaining group (Chi-square: $\mathrm{p}<0.01$ ). Hereby, the occurrence of osteoporosis was unknown with $50 \%$ of the kyphosis group and $60 \%$ of the remaining group. Ambulation and mobility were very limited in all age-groups, and no relationship with age was found (Kendall's tau-b: $p=0.72$ respectively $p=0.82$ ). Anticonvulsive treatment was used by $100 \%$ of the osteoporosis group, $75 \%$ of the kyphosis group and $70 \%$ of the remaining group (Chi-square: $p=0.66$ ). Since our statistical power to investigate explicit anticonvulsive treatment was limited, we were not able to perform these analyses.

The prevalence of spasticity was $52 \%$, mainly affecting the arms and legs. Sixty percent of the RTT persons had joint deformities, mainly affecting the feet.

Except for kyphosis, the differences between the age-groups and muskoskeletal morbidity were not statistically significant (Kendall's tau-b: $p>0.43$ ). 


\section{Epilepsy}

A history of epilepsy was present in $74 \%$, of whom $95 \%$ used anticonvulsive treatment. The occurrence of epilepsy was significantly higher with combination therapy compared to monotherapy (Kendall's tau-b: $p<0.01$ ). The differences in prevalence of epilepsy between the age-groups were not statistically significant (Kendal's tau: $p=0.93)$.

\section{Observational questionnaire elderly residents with ID}

In general RTT persons scored low on the subscale "ADL" (mean score: 1.15, $s d=0.2$ ), meaning they have limited ADL-skills. Regarding "psychological functioning" they also scored low (mean score: 1.63, sd=0.6), meaning limited abilities on this subject. Concerning "(inappropriate) reactions" they scored reasonable (mean score $2.9, \mathrm{sd}=0.7$ ), meaning occasionally appearance of these reactions. Regarding "physical functions" they also scored reasonable (mean score $2.8, \mathrm{sd}=0.5$ ), meaning moderate physical limitations.

No relationship with age was found (Table 3). Further analyses on item-level showed no relation regarding age and ambulation and mobility (Kendall's tau-b: $p=0.72$ respectively $p=0.82$ ), which is in accordance with the view of the parents. In conclusion, care dependence was lower in the older age groups (Kendall's tau-b: $p=0.08)$. 
Table 3 OOB-scores in relation to age

\begin{tabular}{lllll}
\hline OOB subscales & $\mathbf{1 6 - 2 0}$ years & $\mathbf{2 0 - 3 0}$ years & $\mathbf{3 0 +}$ years & ANOVA \\
\hline $\begin{array}{l}\text { Daily activity } \\
\text { Mean score }\end{array}$ & 1.11 & 1.17 & 1.15 & $\mathrm{p}=0.76$ \\
$\quad$ Range & $1.0-1.5$ & $1.0-1.5$ & $1.0-1.63$ & \\
$\quad$ sd & 0.20 & 0.22 & 0.23 & \\
Psychological functioning & & & & \\
$\quad$ Mean score & 1.52 & 1.74 & 1.55 & $\mathrm{p}=0.52$ \\
$\quad$ Range & $0.67-2.5$ & $0.9-3.5$ & $0.53-4.0$ & \\
sd & 0.47 & 0.57 & 0.77 & \\
(Inappropriate) reactions & & & & \\
$\quad$ Mean score & 3.12 & 2.85 & 3.00 & $\mathrm{p}=0.80$ \\
$\quad$ Range & $1.0-3.83$ & $1.5-3.83$ & $1.33-4.0$ & \\
sd & 0.83 & 0.61 & 0.72 & \\
Physical functioning & & & & \\
$\quad$ Mean score & 2.69 & 2.84 & 2.80 & \\
$\quad$ Range & $1.0-3.38$ & $1.88-3.63$ & $2.13-3.71$ & \\
sd & 0.66 & 0.45 & 0.53 & \\
\hline
\end{tabular}

\section{Genotype-phenotype analyses}

Genotype-phenotype analyses have not been performed, since our statistical power to investigate the effect of genotype was limited.

Among the 53 persons with clinical RTT, mutation analyses was performed in $70 \%$, of which $84 \%$ were molecularly confirmed. As a result, we had 31 confirmed MECP2 mutations and $22 \mathrm{RTT}$ persons with a negative or unknown mutation status. The mean ages of the molecularly confirmed RTT persons and those with a negative or unknown mutation status were respectively 27.1 and 26.6 years $(p=0.82)$. There are no indications that the negative or unknown mutation status is due to selection bias and would affect the results.

\section{Discussion}

Anticipating on specific health problems in adults with ID is important in providing long-term healthcare for these persons (Schrander-Stumpel et al., 2007). Concerning RTT, a cross-sectional study was performed. Owing to the high response rate of $76 \%$, we gathered data on 53 Dutch RTT individuals aged 16 years or older with a clinical diagnosis of RTT with a broad range of clinical symptoms. Our data represent almost exclusively the parental view. Since parents are closest to their children in everyday life, they have the opportunity to experience their lack or change of development early on. The medical background of parents may be limited although.

In general the parents valued the health of the RTT persons as good, irrespective of age, whereas neurological, respiratory and behavioral morbidity appeared to 
be of great influence. This is important for professionals in considering the significant impact of these features on quality of life of the RTT person and her family.

Although care dependency was lower in the older age groups, the required therapeutic services remained high. This is in accordance with the conception of a stable condition with high dependency needs at adult age (Smeets et al., 2003; Williamson \& Christodoulou, 2006). Reported underweight in half of the subjects is in line with previous reports (Williamson \& Christodoulou, 2006). Overweight on the contrary is an under-ascertained feature in RTT. Some RTT girls will have a tendency to become overweight if they are allowed to eat what they want (Smeets \& Schrander-Stumpel, 2005). A positive relation was shown between eating behavior and BMI. Therefore, nutritional factors and energy expenditure play an important role in weight control and general health at adult age.

Although speech is absent in most RTT persons, in our study non-verbal communication was considerably better in the older age groups. This in accordance with the view of parents and previous observations that comprehension, contact behavior and non-verbal communication improve with age (Hagberg, 2002; Williamson \& Christodoulou, 2006). Given the importance of mutual understanding, active management of communication is required in RTT.

Contrary to the better preserved communication abilities, gross motor performance in RTT slowly but continuously declines over the years (Steffenburg et al., 2001; Hagberg, 2002; Kerr, 2002; Williamson \& Christodoulou, 2006). Nonetheless, we demonstrated no relationship between musculoskeletal problems and age, except for kyphosis. Kyphosis is present in $16 \%$ of the respondents and the occurrence was significantly higher in the older age groups. Information about prevalence and age dependency for kyphosis in both RTT and the female Dutch population is extremely limited, making comparison impossible. In this study, analyses showed a significantly high occurrence of osteoporosis in the kyphosis group (25\%) compared with the remaining RTT persons (0\%). The occurrence of osteoporosis in the female Dutch population at the age of $20-24$ years is $0.013 \%$ and at the age of $50-54$ years $0.74 \%$ (Poos \& Gijsen, 2003). Besides, in three quarters of the RTT persons the occurrence of osteoporosis was unknown. Active management and future study regarding diagnostics of osteoporosis and kyphosis is therefore advisable. Scoliosis is seen in $90 \%$ of the subjects in our study. This is in accordance with the results of a study in the UK with a prevalence of $87 \%$ at the age of 25 years (Kerr et al., 2003). Scoliosis in RTT is typically noted between 8 and 11 years, whereas the progress usually occurs in early adolescence and close to the growth spurt (Keret et al., 1988; Percy, 2002). The RTT persons in our study are at least 16 years old; therefore the increase with age has already taken place. In our study scoliosis necessitated surgery in $36 \%$, which is in accordance with approximately $28 \%$ in the age-group $16-20$ years (Kerr et al., 2003). As scoliosis is a major clinical manifestation that has detri- 
mental effects on health and quality of life, medical attention is highly important (Ager et al., 2006).

Regarding epilepsy, we found no relation with age. However, many paroxysmal events diagnosed in RTT as epileptic have been found to be of non-epileptic origin (Glaze et al., 1998; Smeets et al., 2006). Active management is of great importance, in particular on behalf of the high consumption of anti-epileptic drugs reported in our study.

In line with previous reports, we noted a tendency towards improving autonomic dysfunction in adult RTT (Ellaway \& Christodoulou, 2001; Julu et al., 2001; Williamson \& Christodoulou, 2006). Trophic skin and nail changes are significantly less prevalent in the older age group, which is in contrast with the view of parents who did not report any improvement. However, this is a cross-sectional study and the view of the parents changes with time. Regarding breathing dysfunction, apnea is significantly less prevalent in the older age group. The prevalence of autonomic dysfunction widely differs in the current literature; making comparisons with our results very difficult (Julu et al., 2001; Mount et al., 2001, 2002). Another important finding in this study is the positive relation between both behavioral and respiratory problems with sleep abnormalities, which is in line with previous reports. Autonomic dysfunction reflects the immaturity of the brainstem in RTT resulting from the hyperactive sympathetic system with insufficient or absent parasympathetic control (Kerr \& Julu, 1999; Julu et al., 2001; Smeets et al., 2006). Because of their role in overall health, respiratory and behavioral problems can be seen as the most distressing features in RTT. Therefore, their relationship to quality of sleep is an important target for future study.

Another area that requires more attention in the future is genotype-phenotype analyses. Recent studies show a correlation of disease severity with mutation type and location (Cheadle et al., 2000; Christodoulou \& Weaving, 2003; Charman et al., 2005; Archer et al., 2007). Since our statistical power to investigate the effect of genotype was limited, we unfortunately were not able to perform these analyses. However, there was no indication that this would affect the results.

Finally, since cross-sectional data are used, one has to realize there might be a selection towards survivors, with the most severely affected dying earlier. It is hoped that this information will lead to further longitudinal studies of the natural history of RTT.

\section{Conclusion}

Although the results in this report relate to cross-sectional data, the adult RTT group has a more or less stable condition. The general RTT profile is confirmed, considering the increase with age regarding kyphosis and the better communication and 
autonomic dysfunction in the oldest age group compared to the younger age groups.

Early intervention and preventive management in RTT requires an individualized approach at every age. It is aiming at maintaining or improving motor and communicative skills and trying to find treatment for respiratory health in order to improve the quality of life of the individuals and their families. In order to get a better understanding of the aging process and mortality in RTT, longitudinal studies including genotype-phenotype analyses are of great importance. 


\section{References}

Ager S, Fyfe S, Christodoulou J, Jacoby P, Schmitt L, Leonard H. Predictors of scoliosis in Rett syndrome. J Child Neurol 2006: 21: 809-813.

Amir RE, Van den Veyver IB, Wan M, Tran CQ, Francke U, Zoghbi HY. Rett syndrome is caused by mutations in X-linked MECP2, encoding methyl-CpG-binding protein 2. Nat Genet 1999: 23: 185-188.

Archer H, Evans J, Leonard H, Colvin L, Ravine D, Christodoulou J, Williamson S, Charman T, Bailey MES, Sampson J, De Klerk N, Clarke A. Correlation between clinical severity in patients with Rett syndrome with a p.R168X or p.T158M MECP2 mutation, and the direction and degree of skewing of Xchromosome inactivation. J Med Genet 2007: 44: 148-152.

Bernard S, Maaskant MA, Gevers JPM, Wierda H. Voorspellingen ten aanzien van het aantal oudere mensen met een verstandelijke handicap in algemene woonvoorzieningen 1996-2011. Ned Tijdschr Verst Gehand 2002: 27: 166-177.

Cass H, Reilly S, Owen L, Wisbeach A, Weekes L, Slonims V, Wigram T, Charman T. Findings from a multidisciplinary clinical case series of females with Rett syndrome. Dev Med Child Neurol 2003: 45: 325337.

Charman T, Neilson TCS, Mash V, Archer H, Gardiner MT, Knudsen GPS, McDonnell A, Perry J, Whatley SD, Bunyan DJ, Ravn K, Mount RH, Hastings RP, Hulten M, Ørstavik KH, Reilly S, Cass H, Clarke A, Kerr AM, Bailey MES. Dimensional phenotypic analysis and functional categorisation of mutations reveal novel genotype-phenotype associations in Rett syndrome. Eur J Hum Genet 2005: 13: 1121-1130.

Cheadle JP, Gill H, Fleming N, Maynard J, Kerr A, Leonard H, Krawczak M, Cooper DN, Lynch S, Thomas N, Hughes $H$, Hulten $M$, Ravine D, Sampson JR, Clarke A. Long-read sequence analysis of the MECP2 gene in Rett syndrome patients: Correlation of disease severity with mutation type and location. Hum Mol Genet 2000: 9: 1119-1129.

Christodoulou J, Weaving LS. MECP2 and beyond: Phenotype-genotype correlations in Rett syndrome. $J$ Child Neurol 2003: 18: 669-674.

Donckerwolcke RAMG, Van Zeben-Van der Aa DMCB. Overdracht van de zorg voor adolescenten met chronische ziekten: Van kindergeneeskunde naar specialismen voor volwassenen. Ned Tijdschr Geneeskd 2002: 146: 675-678.

Ellaway C, Christodoulou J. Rett syndrome: Clinical characteristics and recent genetic advances. Disabil Rehabil 2001: 23: 98-106.

Fisher K, Kettl P. Aging with mental retardation: Increasing population of older adults with MR require health interventions and prevention strategies. Geriatrics 2005: 60: 26-29.

Glaze DG, Schultz RJ, Frost JD. Rett syndrome: Characterization of seizures versus non-seizures. Electroencephalogr Clin Neurophysiol 1998: 106: 79-83.

Hagberg B. Clinical manifestations and stages of Rett syndrome. Ment Retard Dev Disabil Res Rev 2002: 8: 61-65.

Hagberg B, Witt-Engerström I. Rett syndrome: A suggested staging system for describing impairment profile with increasing age towards adolescence. Am J Med Genet 1986: 24: 47-59.

Hagberg B, Aicardi J, Dias K, Ramos O. A progressive syndrome of autism, dementia, ataxia, and loss of purposeful hand use in girls: Rett's syndrome: Report of 35 cases. Ann Neurol 1983: 14: 471-479.

Hagberg B, Hanefeld F, Percy A, Skjeldal O. An update on clinically applicable diagnostic criteria in Rett syndrome. Comments to Rett syndrome Clinical Criteria Consensus Panel Satellite to European Paediatric Neurology Society Meeting, Baden Baden, Germany, 11 September 2001. Eur J Paediatr Neurol 2002: 6: 293-297.

Hoefnagel CWM. Oud en zwakzinnig: Mentale retardatie vanuit psychologische optiek. Lisse: Swets en Zeitlinger 1989.

Janicki MP, Breitenbrach N. Veroudering en verstandelijke handicap, verbetering van de levensverwachting en bevordering van gezond oud worden: Eindrapport. Geneva: Wereld Gezondheids Organisatie 2002. 
Jervis N, Prinsloo L. How we developed a multidisciplinary screening project for people with Down's syndrome given the increased prevalence of early onset dementia. Br J Learn Disab 2008: 36: 13-21.

Julu PO, Kerr AM, Apartopoulos F, Al Rawas S, Engerström IW, Engerström L, Jamal GA, Hansen S. Characterisation of breathing and associated central autonomic dysfunction in the Rett disorder. Arch Dis Child 2001: 85: 29-37.

Keret D, Bassett GS, Bunnell WP, Marks HG. Scoliosis in Rett syndrome. J Ped Ortho 1988: 8: 138-142.

Kerr A. Annotation: Rett syndrome: Recent progress and implications for research and clinical practice. $J$ Child Psychol Psychiatry 2002: 43: 277-287.

Kerr AM, Julu PO. Recent insights into hyperventilation from the study of Rett syndrome. Arch Dis Child 1999: 80: 384-387.

Kerr AM, Webb P, Prescott RJ, Milne Y. Results of surgery for scoliosis in Rett syndrome. J Child Neurol 2003: 18: 703-708.

Maaskant MA, Van den Akker M, Kessels AG, Haveman MJ, Van Schrojenstein Lantman de Valk HM, Urlings HF. Care dependence and activities of daily living in relation to aging: Results of a longitudinal study. J Intellect Disabil Res 1996: 40: 535-543.

Maaskant MA, Gevers JPM, Wierda H. Mortality and live expectancy in Dutch residential centres for individuals with intellectual disabilities, 1991- 1995. J Appl Res Int Dis 2002: 15: 200-212.

Mount RH, Hastings RP, Reilly S, Cass H, Charman T. Behavioural and emotional features in Rett syndrome. Disabil Rehabil 2001: 23: 129-138.

Mount RH, Charman T, Hastings RP, Reilly S, Cass H. The Rett syndrome behaviour questionnaire (RSBQ): Refining the behavioural phenotype of Rett syndrome. J Child Psychol Psychiatry 2002: 43: 10991110.

Patja K, livanainen $\mathrm{M}$, Vesala $\mathrm{H}$, Oksanen $\mathrm{H}$, Ruoppila I. Life expectancy of people with intellectual disabilities: A 35-year follow-up study. J Intellect Disabil Res 2000: 44: 591- 599.

Percy AK. Clinical trials and treatment prospects. Ment Retard Dev Disabil Res Rev 2002: 8: $106-111$.

Poos MJJC, Gijsen R. Prevalentie, incidentie en sterfte naar leeftijd en geslacht. In: Volksgezondheid Toekomst Verkenning, Nationaal Kompas Volksgezondheid. Bilthoven: RIVM 2003.

Roeden JM, Zitman FG. Aging in adults with Down's syndrome in institutionally based and communitybased residences. J Intellect Disabil Res 1995: 39: 399-407.

Schrander-Stumpel CTRM, Sinnema M, Van den Hout L, Maaskant MA, Van Schrojenstein Lantman-de Valk HMJ, Wagemans A, Schrander JJP, Curfs LMG. Healthcare transition in persons with intellectual disabilities: General issues, the Maastricht model, and Prader-Willi syndrome. Am J Med Genet Part C Semin Med Genet 2007: 145C: 241-247.

Smeets EE, Schrander-Stumpel CTRM. Rett syndrome. In: Cassidy SB, Allanson JE, editors. Management of genetic syndromes, 2e. New York: Wiley-Liss 2005: 457-468.

Smeets E, Schollen E, Moog U, Matthijs G, Herbergs J, Smeets H, Curfs L, Schrander-Stumpel C, Fryns JP. Rett syndrome in adolescent and adult females: Clinical and molecular genetic findings. Am J Med Genet Part A 2003: 122A: 227-233.

Smeets EEJ, Julu POO, Van Waardenburg D, Witt-Engerström I, Hansen S, Apartopoulos F, Curfs LMG, Schrander-Stumpel CTRM. Management of a severe forceful breather with Rett syndrome using carbogen. Brain Dev 2006: 28: 625-632.

Steffenburg U, Hagberg G, Hagberg B. Epilepsy in a representative series of Rett syndrome. Acta Paediatr 2001: 90: 34- 39.

Torr J, Davis R. Ageing and mental health problems in people with intellectual disability. Curr Opin Psychiatry 2007: 20: 467-471.

Urlings HFJ, Kessels AGH, Crebolder HFJK. Prevalence and incidence of health problems in people with intellectual disabilities. J Intellect Disabil Res 1997: 41: 42-51.

Williamson SL, Christodoulou J. Rett syndrome: New clinical and molecular insights. Eur J Hum Genet 2006: 14: 896- 903. 



\section{Chapter 6}

\section{Aging in Rett syndrome: a longitudinal study}

Halbach NSJ, Smeets EEJ, Steinbusch C, Maaskant MA, Van Waardenburg D, Curfs LMG.

Clinical Genetics: Epub ahead of print. 


\begin{abstract}
Little is known about the aging process of people with specific syndromes, like Rett syndrome (RTT). Recognition of the clinical and behavioral characteristics of the adult RTT is needed in order to improve future management of the RTT girl and counseling of parents. In association with the Dutch RTT parent association, a 5-year longitudinal study was carried out. The study population consisted of 53 adult women with a clinical diagnosis of RTT. Postal questionnaires were sent, including demographic features, skills, physical and psychiatric morbidity. At the time of the second measurement seven women had died. In 2012, $80 \%$ of the questionnaires (37/46) were returned. Mean age of the women was 31.4 years. Molecular confirmation was possible for $83 \%$ of the women for whom analyses were carried out. The adult RTT woman has a more or less stable condition. The general disorder profile is that of a slow on-going deterioration of gross motor functioning in contrast to a better preserved cognitive functioning, less autonomic and epileptic features and good general health. This is the first longitudinal cohort study about aging in RTT. Continuing longitudinal studies are needed to gain more insight into the aging process in RTT.
\end{abstract}




\section{Introduction}

Owing to advances in medical care and technology, persons with childhood onset diseases and/or genetic syndromes are now living to advanced ages (Patja et al., 2000; Maaskant et al., 2002; Fisher \& Kettl, 2005; Tyler \& Noritz, 2009; Haveman et al., 2010). Expectations are that their life expectancy will even continue to increase in the next years (Janicki \& Breitenbach, 2000; Bernard et al., 2002; Tyler \& Noritz, 2009). Therefore, clinicians are increasingly challenged by the care for adults with specific genetic syndromes (Donckerwolcke \& Van Zeben-Van der Aa, 2002; Tyler \& Noritz, 2009; Vignoli et al., 2012). Still little is known about the aging process of people with specific syndromes, like Rett syndrome.

Rett syndrome (RTT, OMIM 312750) is one of the most common causes of severe intellectual disabilities (ID) in girls, with a prevalence of $1: 10,000$ to $1: 15,000$ (Hagberg et al., 1983; Leonard et al., 1997; Bienvenu et al., 2006; Smeets et al., 2012). In spite of the molecular confirmation of a MECP2 mutation, RTT remains a clinical diagnosis based on internationally accepted criteria (Amir et al., 1999; Neul et al., 2010). RTT is characterized by early neurological regression affecting motor, cognitive and communication skills, along with autonomic dysfunction and the development of stereotypic hand movements (Rett, 1966; Hagberg et al., 1983, Smeets et al., 2012). The natural history of RTT is divided into four stages: early stagnation, rapid regression, pseudostabilization and late motor deterioration (Hagberg \& Witt-Engerström, 1986).

Studies on aging in RTT are scarce, counting a few cross-sectional studies and some longitudinal follow-up case studies (Jacobsen et al., 2001; Nielsen et al., 2001; Cass et al., 2003; Hagberg, 2005; Halbach et al., 2008; Lotan et al., 2010; Vignoli et al., 2012). The clinical condition of RTT women tends to stabilize over time, and prolonged survival has recently been showed (Freilinger et al., 2010; Kirby et al., 2010).

A longitudinal study was designed in order to gain better understanding of the aging process and mortality in RTT. Recognition of the clinical and behavioral characteristics of the adults with RTT is needed, in order to improve future management and follow-up of the RTT girl and counseling of parents regarding prognosis, natural course of the disease, and life expectancy.

\section{Materials and methods}

Prior to the start of this study, ethical approval was obtained from the Medical Ethical Committee at the Maastricht University Medical Center. 


\section{Subjects}

In association with the Dutch RTT parent association, a 5-year longitudinal study was carried out including two measurements (2007 - 2012). The initial study population consisted of 53 women above 16 years of age with a clinical diagnosis of RTT, confirmed by experienced clinicians. Results of the first measurement have already been published (Halbach et al., 2008).

Since 2007, seven of these 53 RTT women, aged between 21 and 43 years (mean age: 26.7 years), had died. Exact cause of death was known for two women: pneumonia and status epilepticus. For the remaining five women cause of death was not registered, the possibility of sudden death was sometimes mentioned. Postal questionnaires were sent to the remaining 46 contact persons.

\section{Questionnaire}

The questionnaire consisted of four major subdivisions (Halbach et al., 2008). The first two parts included demographic features including living conditions (living at home or in residential facilities) and use of care facilities (day care or respite care facilities). In the third part the Observational Questionnaire Elderly Residents with Intellectual Disabilities (OOB) was inserted. This instrument assesses functioning, behavior and care dependency. It has four subscales: (1) activities of daily living (ADL), (2) psychological functioning, (3) (inappropriate) reactions, and (4) physical functions and care dependence. The range for the scale is 0 or $1-4$ : the higher the score, the better the functioning. The reliability and validity of the OOB has been showed to be satisfactory to good (Hoefnagel, 1989). Questions on the medical history (hospital admission and surgery), medication use (type and dose of medication including duration of use), genetic diagnosis (presence and specific type of MECP2 mutation), physical (e.g. epilepsy, scoliosis, breathing problems and osteoporosis) and psychiatric morbidity (e.g. mood changes, screaming spells and abnormal agitation) were inserted in the fourth part of the questionnaire. Finally, the view of parents regarding significant changes in skills and morbidity from the age of 10 years was recorded on a 3-point scale (no change, improvement or decline). The age of 10 years was selected because by this age most affected girls, even the atypical ones, have emerged from the regression stage (stage 2). Parents were asked to evaluate changes in each of the RTT features. Parents' responses that had been provided in 2007 were compared with those provided in 2012, allowing changes over these 5 years to be appreciated. All data were processed anonymously.

\section{Response}

Eighty percent of the questionnaires sent were returned $(n=37)$. The parents answered in 30 cases, parents together with a professional carer/physician in six cases 
and a professional carer in one case. Those who completed the questionnaires are further referred to as 'parents'. Reasons for non-responding were mainly unknown address and lack of time of parents and/or professional carer, despite two reminders.

Table 1 shows the characteristics of the respondents in 2007 and 2012. The mean age in 2012 was 31.4 years (range: 21 - 46 years, sd=7.37). Eighty-three percent of the women in whom mutation analyses were performed, diagnosis was molecularly confirmed. In four women mutation analyses were not performed, and in four women it was unknown whether analyses were performed. Forty-six percent of the RTT women in 2012 had a normal weight, 35\% were underweight, 9\% were overweight and in $11 \% \mathrm{BMI}$ status was unknown.

Those who died and those for whom the questionnaire was not completed did not differ significantly from the rest of the cohort, concerning age, general health, skills, physical and psychiatric morbidity.

Table 1 Characteristics of the respondents in 2007 and 2012 according to age, genotype and BMI

\begin{tabular}{|c|c|c|}
\hline & 2007, n (\%) & 2012, n (\%) \\
\hline \multicolumn{3}{|l|}{ Age } \\
\hline $16-20$ years & $11(21 \%)$ & $11(30 \%)$ \\
\hline 20 - 30 years & $24(45 \%)$ & $15(41 \%)$ \\
\hline \multirow[t]{2}{*}{$30+$ years } & $18(34 \%)$ & $11(30 \%)$ \\
\hline & $\begin{array}{l}\text { Mean age: } 26.9 \text { years, } \\
\text { range } 16-53, s d=7.85\end{array}$ & $\begin{array}{l}\text { Mean age: } 31.4 \text { years, } \\
\text { range } 21-46, s d=7.37\end{array}$ \\
\hline \multicolumn{3}{|l|}{ Genotype } \\
\hline Mutation analyses performed & $37(70 \%)$ & $29(78 \%)$ \\
\hline MECP2 positive & $31(84 \%)$ & $24(83 \%)$ \\
\hline$M E C P 2$ negative & $4(11 \%)$ & $5(17 \%)$ \\
\hline Unknown & $2(5 \%)$ & $0(0 \%)$ \\
\hline Mutation analyses not performed & $12(23 \%)$ & $4(11 \%)$ \\
\hline Unknown & $4(8 \%)$ & $4(11 \%)$ \\
\hline \multicolumn{3}{|l|}{ BMI category } \\
\hline$<18,5$ (underweight) & $22(42 \%)$ & $13(35 \%)$ \\
\hline 18,5 - 25 (normal weight) & $18(34 \%)$ & 17 (46\%) \\
\hline > 25 (overweight) & $5(9 \%)$ & $3(8 \%)$ \\
\hline \multirow[t]{3}{*}{ Unknown } & $8(15 \%)$ & $4(11 \%)$ \\
\hline & Mean BMI: 20.0, & Mean BMI: 20.4, \\
\hline & range $13.0-38.1, s d=4.51$ & range $13.0-34.85, s d=4.78$ \\
\hline
\end{tabular}

$\mathrm{n}=$ number of RTT women

\section{Data analyses}

SPSS version 18 was used for analyzing the data.

The main aim was to compare data of 2007 and 2012 regarding several variables for the whole group $(n=37)$. The variables were: demographic features includ- 
ing living conditions and use of care facilities, data on functioning via OOB (total, subscales and individual item scores), physical and psychiatric morbidity and view of parents regarding changes in skills and morbidity. For ordinal data $\chi^{2}$ tests were used. In case data were on ratio level and normally distributed, the t-test for related groups was used. However, in case these data were not normally distributed, Wilcoxon signed-rank test (nonparametric tests for related groups) was used.

For each age group (16 - 19 years, 20 - 29 years and 30+ years), the scores for 2007 and 2012 were compared. On the basis of the number of respondents per agegroups, the nonparametric Kruskall - Wallis test (nonparametric tests for more than two unrelated groups) rather than a parametric test was used for analyzing the data.

For all tests, a p-value of 0.05 or less was used for statistical significance.

\section{Results}

The ages given in this section are those of 2007.

\section{Living conditions and use of care facilities}

Approximately one-third ( $n=12$ ) of the RTT women lived full time or part time with their parents. Eighty-two percent lived in residential facilities, of whom $14 \%$ still spent some (weekend) days a week with their parents. Two RTT women lived in apartments with $24 \mathrm{~h}$ daily support. Compared to 2007, eight RTT women now spent less time living with their parents and four women spent more time with their parents. More young women lived in residential facilities, in contrast to the oldest age group with no changes in living conditions $(p=0.005)$. In the oldest age group only one woman still lived at home.

Sixty percent of the RTT women spent their days in day care facilities. The use of these facilities increased in four women, of whom three were between 16 and 20 years of age. Respite care facilities were used by three RTT women.

\section{Health}

General health of the individuals was assessed on a 5-point scale ranging from very good (1) to very bad (5). In general, the respondents reported the health of RTT women as good (mean: 2.24, range: $1-4$, and $s d=0.86$ ). Health had improved the most in the oldest age group ( $p=0.007)$. Concerning physical complaints a significant improvement was shown in the total RTT population $(p=0.03)$.

During the last 5 years 10 women were hospitalized. Main reason was pneumonia (three women), followed by seven different indications: respiratory distress, status epilepticus, rectal bleeding, PEG probe, bladder inspection, decline in walking 
and refusal to eat and/or drink. Surgery was performed in five women; three women had an orthopedic surgery because of contractures, and two women had a dental surgery for extraction of wisdom teeth.

\section{Weight status and eating behavior}

Discarding the missing values in some respondents, the prevalence of underweight RTT women was $39 \%$, 52\% had a normal weight and $9 \%$ were overweight. Compared to 2007 the mean BMI decreased by only 0.21 points $(p=0.70)$. Concerning the different age groups, BMI only slightly increased in the youngest age group (0.29) and decreased the most in the oldest age group ( $-0.93 ; p=0.44)$.

The majority of the RTT women are oral feeders needing assistance, only four females used a G-tube.

\section{Communication}

Only $22 \%$ of the RTT women were at least sometimes able to express themselves by spoken language and/or signals. Since 2007, three women had improved their ability to express themselves and three had shown deterioration in self-expression. Improvement was especially seen in the oldest group $(p=0.16)$. Parents reported a deterioration in two women and improvement in three women ( $p=0.17)$.

\section{Morbidity}

Table 2 shows the morbidity of the total RTT cohort in $2007(n=53)$ and the longitudinal data of 2007 and 2012 ( $n=37$ ). Arranged by subject, explanatory remarks are made below. Skin problems, sleep abnormalities, respiratory problems, behavioral problems and drooling are considered as manifestations of autonomic dysfunction. 
Table 2 Prevalence of morbidity of total RTT cohort in $2007^{a}(n=53), 2007(n=37)$ and 2012 ( $\left.n=37\right)$

\begin{tabular}{|c|c|c|c|}
\hline Morbidity & $\begin{array}{l}2007 a \\
(n=53)\end{array}$ & $\begin{array}{l}2007 \\
(n=37)\end{array}$ & $\begin{array}{l}2012 \\
(n=37)\end{array}$ \\
\hline \multicolumn{4}{|l|}{ Skin problems } \\
\hline Cold feet & $96 \%$ & $97 \%$ & $92 \%$ \\
\hline Trophic skin changes & $46 \%$ & $54 \%$ & $31 \%$ \\
\hline \multicolumn{4}{|l|}{ Sleep abnormalities } \\
\hline Nightly unrest & $77 \%$ & $81 \%$ & $78 \%$ \\
\hline $\begin{array}{l}\text { Prolonged wakefulness and / } \\
\text { or early morning awakening }\end{array}$ & $51 \%$ & $56 \%$ & $54 \%$ \\
\hline Sleepy during the day & $85 \%$ & $81 \%$ & $87 \%$ \\
\hline \multicolumn{4}{|l|}{ Respiratory problems } \\
\hline Apnea during daytime & $38 \%$ & $37 \%$ & $32 \%$ \\
\hline Apnea during night & $41 \%$ & $40 \%$ & $30 \%$ \\
\hline Hyperventilation & $39 \%$ & $40 \%$ & $26 \%$ \\
\hline Breath holding spells & $73 \%$ & $72 \%$ & $60 \%$ \\
\hline Air swallowing & $41 \%$ & $47 \%$ & $46 \%$ \\
\hline Bloating & $54 \%$ & $65 \%$ & $60 \%$ \\
\hline \multicolumn{4}{|l|}{ Behavioral problems } \\
\hline Nightly screaming & $39 \%$ & $43 \%$ & $35 \%$ \\
\hline Mood changes & $66 \%$ & $71 \%$ & $70 \%$ \\
\hline Abnormal agitation & $54 \%$ & $51 \%$ & $65 \%$ \\
\hline Anxiety & $68 \%$ & $72 \%$ & $65 \%$ \\
\hline Drooling & $80 \%$ & $83 \%$ & $65 \%$ \\
\hline \multicolumn{4}{|l|}{ Musculoskeletal } \\
\hline Scoliosis & $90 \%$ & $89 \%$ & $89 \%$ \\
\hline Kyphosis & $16 \%$ & $15 \%$ & $29 \%$ \\
\hline Spasticity & $52 \%$ & $50 \%$ & $49 \%$ \\
\hline Joint deformities & $60 \%$ & $57 \%$ & $64 \%$ \\
\hline Epilepsy & $74 \%$ & $68 \%$ & $76 \%$ \\
\hline
\end{tabular}

${ }^{a}$ Halbach et al., 2008

\section{Autonomic manifestations}

\section{Skin problems}

The prevalence of cold feet was nearly the same as in 2007 , occurring in $92 \%$ of the RTT women. Trophic skin changes, including sores and vesicles occurred in $31 \%$, whereas improvement was seen in 11 women and deterioration was seen in three women $(p=0.03)$.

\section{Sleep abnormalities}

The prevalence of nightly unrest was nearly the same as in 2007, occurring in $78 \%$ of the RTT women. Prolonged wakefulness and/or early morning awakening was more or less pronounced in 54\%, with a significant improvement in RTT women aged 
between 16 and 20 years ( $p=0.04$ ). Daytime sleeping was reported in $87 \%$, which is in line with previous results in 2007.

\section{Respiratory problems}

Apnea during daytime was reported in $32 \%$ of the RTT women, whereas improvement was mainly seen in women aged between 16 and 20 years $(p=0.08)$. During night the prevalence was $30 \%$, compared to $40 \%$ in 2007 . Significant improvements were seen in the total RTT group, but especially in women aged between 20 and 30 years ( $p=0.03$ and $p=0.04$, respectively). Hyperventilation was reported in $26 \%$ of the women, significant improvement was seen for the total RTT group $(p=0.02)$. This is in line with the view of parents, reporting mainly improvement. The prevalence of breath holding spells was $60 \%$, compared to $72 \%$ in 2007 . Improvement was seen in six women and deterioration in two women $(p=0.03)$. Air swallowing was present in $46 \%$ of the RTT women and bloating in $60 \%$. Both for air swallowing and bloating, no significant changes were seen in the last 5 years.

\section{Behavioral problems}

Nightly screaming was reported in $35 \%$, whereas improvement was mainly seen in the women aged between 16 and 20 years and deterioration in women aged 30 years and older $(p=0.05)$. Prevalence of mood changes was $70 \%, 13$ women improved and six women deteriorated $(\mathrm{p}=0.19)$. Abnormal agitation was more or less pronounced in $65 \%$, whereas improvement was mainly seen in the women aged between 20 and 30 years and deterioration in women aged 30 years and older $(p=0.06)$. Two thirds of the RTT women showed anxiety, whereas improvements were mainly seen in women aged 30 years and older $(p=0.07)$.

\section{Remaining autonomic problems}

Drooling was reported in $65 \%$ of the women. Nine had improved and two had deteriorated $(p=0.03)$. Improvement was especially seen in women aged 30 years and older $(p=0.04)$.

\section{Musculoskeletal}

The prevalence of scoliosis was $89 \%$, with no changes in the last 5 years. The overall prevalence of kyphosis had increased to $29 \%(p=0.06)$. Three women had deteriorated, all between 16 and 20 years, and one had improved $(p=0.33$ ). Ambulation and mobility were still very limited, whereas mobility mainly deteriorated in the last 5 years $(p=0.08)$. This is in line with the view of parents, who mainly report deterioration of mobility $(p=0.02)$. However, some elderly women improved regarding to ambulation and mobility.

The prevalence of rigidity was $49 \%$, whereas improvement was reported in five of the seven women aged 30 years and older $(p=0.008)$. Joint deformities were seen 
in $64 \%$ of the RTT women, with improvement in three women and deterioration in five women $(p=0.49)$.

\section{Epilepsy}

A history of epilepsy was present in $76 \%$ of the RTT women, of whom $54 \%$ was seizure free for at least 3 months. Anticonvulsive treatment was used by $93 \%$ of the RTT females with a history of epilepsy, of whom $64 \%$ received combination therapy.

Compared to 2007, improvement was reported in four women mainly aged 30 years and older, deterioration was seen in five women mainly between 16 and 20 years of age $(p=0.17)$. Parents indicated stabilization and/or improvement of epilepsy in women aged between 20 and 30 years $(p=0.01)$.

\section{Age related morbidity}

Both hypertension and diabetes were not reported in any of the RTT women. Osteoporosis was only reported in two women.

\section{Observational questionnaire elderly residents with ID}

\section{$A D L$}

In general, RTT women scored low on the subscale 'ADL' (mean score: 1.14, $s d=0.21$ ), meaning they have limited ADL-skills. In the last 5 years no significant changes were seen in this subscale and/or the individual items.

\section{Psychological functioning}

Regarding 'psychological functioning' the scores were remarkably higher than in 2007 (mean score: 1.85 vs 1.63), which was significant in the elderly RTT women $(p=0.01)$. On item level three items showed significant differences compared to 2007: memory, alertness and purposeful behavior. Memory improved in women aged 16 to 20 years $(p=0.02)$. Alertness improved in the whole RTT group, especially women aged 30 years and older (both $p=0.045$ ). Purposeful behavior also improved in the whole RTT group ( $p=0.009)$.

\section{(Inappropriate) reactions}

Concerning '(inappropriate) reactions' the RTT women still scored reasonable (mean score: $2.98, \mathrm{sd}=0.59)$, meaning occasionally appearance of these reactions. Compared to 2007, no significant changes were seen in this subscale, besides the sleep abnormalities as already described in the autonomic section.

\section{Physical functions}

Regarding 'physical functions' the women scored slightly better compared to 2007 (mean score 2.98 vs 2.87 ), meaning moderate physical limitations. Improvement 
was mainly seen in the elderly women $(p=0.15)$. On item level, two items showed significant differences compared to 2007. First, physical complaints, as already described in the health section. Second, constipation improved in the whole RTT group, especially women aged 20 years and older $(p=0.01$ and $p=0.009)$.

\section{Care dependency}

Care dependence remained high, with a mean score of $1.86(\mathrm{sd}=0.35)$. No significant changes were seen in the last 5 years $(p=0.66)$.

\section{Genotype-phenotype analyses}

Genotype-phenotype analyses have not been performed, as the statistical power to investigate the effect of genotype was limited. Among the 37 women with clinical $\mathrm{RTT}$, mutation analyses were performed in $78 \%$, of which $83 \%$ were molecularly confirmed. As a result, 24 RTT women had a confirmed MECP2 mutation and 13 RTT women had a negative or unknown mutation status. Besides, in the past results of mutation analyses were limited to a positive MECP2 mutation, no specific details were given. In this cohort only in seven RTT women a specific MECP2 mutation is known, respectively one p.R133C mutation, one p.D156E mutation, one p.R270X mutation, one p.R306C mutation, two large deletions and one CTS deletion. The mean perceived health of the molecularly confirmed RTT women and those with a negative or unknown mutation status were respectively 2.20 and $2.00 \quad(p=0.48)$. There are no indications that the negative or unknown mutation status is due to selection bias and would affect the results.

\section{Discussion}

This is the first longitudinal cohort study on aging in RTT. It provides longitudinal data of a 5 -year follow-up. A high response rate of $80 \%$ resulted in obtained data on 37 Dutch RTT individuals aged 21 years or more, reporting a broad range of clinical symptoms. This is a reasonably large cohort for a relatively recently defined disorder, infrequently diagnosed in adults (Nielsen et al., 2001). Molecular confirmation was possible for $83 \%$ of the women for whom analyses were carried out. This is reasonable, as not all analyses had access to the Multiplex Ligation-dependent Probe Amplification (MLPA) of MECP2 required for the detection of large deletions (Erlandson et al., 2003). Mutation results were not available for eight women. In spite of the molecular confirmation of a MECP2 mutation, RTT remains a clinical diagnosis based on internationally accepted criteria (Amir et al., 1999; Neul et al., 2010). Molecular confirmation is not always necessary or desirable in older people who exhibit the clearly defined clinical characteristics. 
Our results indicate improvement in the general health of the adult with RTT, with a reduction in physical complaints. However there remains a high level of care dependency, as a result of many RTT women living in residential facilities. Hospitalization in the adult RTT women is mainly due to pneumonia, also an important cause of death in RTT (Freilinger et al., 2010). Therefore pneumonia should clearly be considered when such a woman is unwell. In this study few operations had been performed, mainly for orthopedic or dental conditions, confirming the overall good health.

We confirmed the previously reported high mortality in RTT as compared with the general population (Kerr et al., 1997). During the 5-years of follow-up seven women died at a mean age of 27 years. The exact cause of death was not registered in most cases. As previously shown, there was a high incidence of sudden death in RTT, which makes it difficult to compile the exact causes of death in RTT (Kerr et al., 1997; Ellaway \& Christodoulou, 2001; Byard, 2006). In the initial records we found no significant health differences between those in the cohort who survived and those who later died or for whom the second questionnaire was not returned. In the earlier literature, the clinical picture in adult RTT has been reported to stabilize over time, with a high level of dependency. It is characterized by severe neurological impairment with a decline in motor function. In contrast to the surprisingly wellpreserved cognitive functions, reduced seizure activity and improved autonomic function (Witt Engerström \& Hagberg, 1990; Ellaway \& Christodoulou, 2001; Hagberg, 2002; Cass et al., 2003; Hagberg, 2005; Halbach et al., 2008; Smeets et al., 2012; Vignoli et al., 2012).

In this study there was only slight deterioration in gross motor function, based mainly on the parental view (Hagberg, 2002; Kerr, 2002; Cass et al., 2003; Hagberg, 2005; Williamson \& Christodoulou, 2006; Vignoli et al., 2012). However some elderly women actually improved on these aspects (Jacobsen et al., 2001; Cass et al., 2003; Hagberg, 2005). Emphasizing that therapy in the adult RTT women is still of great importance, in which the need to be adjusted to the characteristics of RTT (Jacobsen et al., 2001). Musculoskeletal problems were relatively stable during the 5 -year follow-up. However the prevalence of kyphosis increased with age, as previously reported by us, although the data on that change did not reach significance (Halbach et al., 2008). It is note-worthy that kyphosis has not been so far researched in RTT and guidelines for its management are lacking. Our study found less increase in rigidity and contractures as compared to other reports for adults with RTT and we suggest that this observation merits further investigation (Witt Engerström \& Hagberg, 1990; Ellaway \& Christodoulou, 2001; Hagberg, 2002; Cass et al., 2003; Hagberg, 2005; Smeets et al., 2012; Vignoli et al., 2012). It is possible that in our study the favorable reports reflected the overall improvement in psychological functioning. Giving a global picture of a more comforting RTT woman, parents could report a decreased level of rigidity. 
Improvement in psychological functioning was mainly based on an improved memory, alertness and purposeful behavior in the adult RTT women (Hagberg, 2002; Hagberg, 2005). Improved communication was reported in those over 30 but this did not reach statistical significance (Fontanesi \& Haas, 1988; Budden et al., 1990; Hagberg, 2002; Cass et al., 2003; Hagberg, 2005; Williamson \& Christodoulou, 2006; Halbach et al., 2008; Smeets et al., 2012; Vignoli et al., 2012). Given the importance of mutual understanding, it is clear that active intervention with provision of alternative communication is justified throughout life in RTT (Halbach et al., 2012).

Our study confirmed the previously reported decrease in epilepsy in the older person with RTT (Steffenburg et al., 2001; Hagberg, 2002; Cass et al., 2003; Hagberg, 2005; Vignoli et al., 2012). Nevertheless, the prescription of anticonvulsant medication remained high, indicating a need for regular review. Also the autonomic problems appeared to improve in the adults (Engerström, 1990; Kerr \& Julu, 1999; Ellaway \& Christodoulou, 2001; Julu et al., 2001; Cass et al., 2003; Williamson \& Christodoulou, 2006; Halbach et al., 2008). Arguing the potential survival effect, reported as a possible explanation in our previous study (Halbach et al., 2008). Improvement was seen in several areas of autonomic function: skin problems, sleep disturbances, respiratory irregularities and digestive difficulties. However, nightly screaming had increased in women aged over 30 years (Hagberg, 2002; Hagberg, 2005; Smeets et al., 2012).

Age related morbidity appeared uncommon. Hypertension and diabetes were reported to be absent, in contrast to the Dutch age and sex matched prevalence of hypertension of 7.5 - 15\% (www.rivm.nl). Osteoporosis was reported in only two RTT women in our study, contrasting with the reports from other studies (Haas et al., 1997; Budden \& Gunness, 2003; Zysman et al., 2006). Under reporting due to absence of screening may be responsible for these unexpectedly low figures. Screening for these age related conditions may be advisable as a routine element in the care for adult RTT women.

In conclusion, many of our findings confirm earlier reports. The general disorder profile of the adult RTT woman in this study is that of a slow on-going deterioration of gross motor functioning in contrast to a better preserved cognitive functioning, less autonomic and epileptic features and overall good general health. Clinical provision should include the maintenance of gross motor skills and communication, awareness of the risk of pneumonia, regular review of anticonvulsant medication and screening for such age related disorders as hypertension, diabetes, osteoporosis and kyphosis. Differences in results with most published RTT studies could be explained by several reasons. First, this study analyzed changes longitudinally rather than in a single cross-sectional review at one time. Comparing results in the same individual excludes the possible survivor effect in cross sectional studies. However, this longitudinal study has only a follow-up period of 5 years. Extending the follow- 
up period will probably give better and more reliable results. At last, the data are almost exclusively based on the parental view. Especially in the fourth section of the questionnaire with the vision of parents specifically requested. Our model for investigating the views of parents regarding their aging daughters has not been formally tested. However we consider that, in spite of their lack of medical training, parents are likely to be the first to notice changes in their daughters because they are so close to them in everyday life. The clinical data provided in this study offer insight in the natural course and prognosis of RTT in adults. It holds potential for continuing longitudinal review and the development of guidelines for early intervention and life-long individualized multidisciplinary provision that can improve the quality of life and health for the RTT woman and her family. 


\section{References}

Amir RE, Van den Veyver IB, Wan M, Tran CQ, Francke U, Zoghbi HY. Rett syndrome is caused by mutations in X-linked MECP2, encoding methyl-CpG-binding protein 2. Nat Genet 1999: 23: 185-188.

Bernard S, Maaskant MA, Gevers JPM, Wierda H. Voorspellingen ten aanzien van het aantal oudere mensen met een verstandelijke handicap in algemene woonvoorzieningen, $1996-2011$. Ned Tijdschr Verst Gehand 2002: 27: 166-177.

Bienvenu T, Philippe C, De Roux N, Raynaud M, Bonnefond JP, Pasquier L, Lesca G, Mancini J, Jonveaux P, Moncla A, Feingold J, Chelly J, Villard L. The incidence of Rett syndrome in France. Pediatr Neurol 2006: 34(5): 372-375.

Budden SS, Gunness ME. Possible mechanisms of osteopenia in Rett syndrome: bone histomorphometric studies. J Child Neurol 2003: 18(10): 698-702.

Budden S, Meek M, Henighan C. Communication and oral-motor function in Rett syndrome. Dev Med Child Neurol 1990: 32 (1): 51-55.

Byard RW. Forensic issues and possible mechanisms of sudden death in Rett syndrome. $J$ Clin Forensic Med 2006: 13 (2): 96-99.

Cass H, Reilly S, Owen L, Wisbeach A, Weekes L, Slonims V, Wigram T, Charman T. Findings from a multidisciplinary clinical case series of females with Rett syndrome. Dev Med Child Neurol 2003: 45: 325337.

Donckerwolcke RAMG, Van Zeben-Van der Aa DMCB. Overdracht van de zorg voor adolescenten met chronische ziekten: Van kindergeneeskunde naar specialismen voor volwassenen. Ned Tijdschr Geneeskd 2002: 146: 675-678.

Ellaway C, Christodoulou J. Rett syndrome: clinical characteristics and recent genetic advances. Disabil Rehabil 2001: 23: 98-106.

Engerström IW. Rett Syndrome in Sweden. Neurodevelopment - disability - pathophysiology. Acta Paediatr Scand 1990: 369(Suppl): 1-60.

Erlandson A, Samuelsson L, Hagberg B, Kyllerman M, Vujic M, Wahlstro“m J. Multiplex ligationdependent probe amplification (MLPA) detects large deletions in the MECP2 gene of Swedish Rett syndrome patients. Genet Test 2003: 7 (4): 329-332.

Fisher K, Kettl P. Aging with mental retardation: increasing population of older adults with MR require health interventions and prevention strategies. Geriatrics 2005: 60: 26-29.

Fontanesi J, Haas RH. Cognitive profile of Rett syndrome. J Child Neurol 1988: 3(Suppl): S20-S24.

Freilinger M, Bebbington A, Lanator I, De Klerk N, Dunkler D, Seidl R, Leonard H, Ronen GM. Survival with Rett syndrome:comparing Rett's original sample with data from the Australian Rett Syndrome Database. Dev Med Child Neurol 2010: 52: 962-965.

Haas RH, Dixon SD, Sartoris DJ, Hennessy MJ. Osteopenia in Rett syndrome. J Pediatr 1997: 131(5): 771774.

Hagberg B. Clinical manifestations and stages of Rett syndrome. Ment Retard Dev Disabil Res Rev 2002: 8 : 61-65.

Hagberg B. Rett syndrome. Long-term clinical follow-up experiences over four decades. J Child Neurol 2005: 20 (9): 722-726.

Hagberg B, Aicardi J, Dias K, Ramos O. A progressive syndrome of autism, dementia, ataxia, and loss of purposeful hand use in girls: Rett's syndrome: report of 35 cases. Ann Neurol 1983: 14: 471-479.

Hagberg B, Witt-Engerström I. Rett syndrome: a suggested staging system for describing impairment profile with increasing age towards adolescence. Am J Med Genet 1986: 24: 47-59.

Halbach NSJ, Smeets EEJ, Schrander-Stumpel CTRM, Van Schrojenstein Lantman de Valk HHJ, Maaskant MA, Curfs LMG. Aging in people with specific genetic syndromes: Rett syndrome. Am J Med Genet Part A 2008: 146A: 1925-1932.

Haveman M, Heller T, Lee L, Maaskant M, Shooshtari S, Strydom A. Major health risks in aging persons with intellectual disabilities: an overview of recent studies. J Intellect Disabil Res 2010: 7: 59-69. 
Hoefnagel CWM. Oud en zwakzinnig: Mentale retardatie vanuit psychologische optiek. Lisse: Swets en Zeitlinger, 1989.

Jacobsen K, Viken A, von Tetzchner S. Rett syndrome and ageing: a case study. Disabil Rehabil 2001: 23 (3-4): 160-166.

Janicki MP and Breitenbach N. Aging and intellectual disabilities - improving longevity and promoting healthy aging: summative report. Geneva, Switzerland: World Health Organization 2000.

Julu PO, Kerr AM, Apartopoulos F, Al-Rawas S, Engerström I, Engerström L, Jamal G, Hansen S. Characterisation of breathing and associated central autonomic dysfunction in the Rett disorder. Arch Dis Child 2001: 85: 29-37.

Kerr A. Annotation: Rett syndrome: recent progress and implications for research and clinical practice. $J$ Child Psychol Psychiatry 2002: 43: 277-287.

Kerr AM, Armstrong DD, Prescott RJ, Doyle D, Kearney DL. Rett syndrome: analysis of deaths in the British survey. Eur Child Adolesc Psychiatry 1997: 6(Suppl. 1): 71-74.

Kerr AM, Julu PO. Recent insights into hyperventilation from the study of Rett syndrome. Arch Dis Child 1999: 80: 384-387.

Kirby RS, Lane JB, Childers J, Skinner SA, Annese F, Barrish JO, Glaze DG, Macleod P, Percy AK. Longevity in Rett syndrome: analysis of the North American database. J Pediatr 2010: 156: 135-138.

Leonard H, Bower C, English D. The prevalence and incidence of Rett syndrome in Australia. Eur Child Adolesc Psychiatry 1997: 6(Suppl. 1): 8-10.

Lotan M, Merrick J, Kandel I, Morad M. Aging in persons with Rett syndrome: an updated review. Scientific World J 2010: 10: 778-787.

Maaskant MA, Gevers JPM, Wierda H. Mortality and live expectancy in Dutch residential centres for individuals with intellectual disabilities, 1991 - 1995. J Appl Res Intellect Disabil 2002: 15: 200-212.

Neul JL, Kaufmann WE, Glaze DG, Christodoulou J, Clarke AJ, Bahi-Buisson N, Leonard H, Bailey ME, Schanen NC, Zappella M, Renieri A, Huppke P, Percy AK, RettSearch Consortium. Rett syndrome: revised diagnostic criteria and nomenclature. Ann Neurol 2010: 68: 944-950.

Nielsen JB, Ravn K, Schwartz M. A 77-year-old woman and a preserved speech variant among Danish Rett patients with mutations in MECP2. Brain Dev 2001: 23: S230-S232.

Patja K, livanainen M, Vesala H, Oksanen H, Ruoppila I. Life expectancy of people with intellectual disabilities: a 35-year follow-up study. J Intellect Disabil Res 2000: 44: 591-599.

Rett A. Über ein eigenartiges hirnatrophisches Syndrom bei Hyperammonämie im Kindesalter. Wien Med Wochenschr 1966: 116: 723-728.

Smeets EE, Pelc K, Dan B. Rett syndrome. Mol Syndromol 2012: 2(3-5): 113-127.

Steffenburg U, Hagberg G, Hagberg B. Epilepsy in a representative series of Rett syndrome. Acta Paediatr 2001: 90: 34-39.

Tyler CV Jr, Noritz G. Healthcare issues in aging adults with intellectual and other developmental disabilities. Clin Geriatr 2009: 17(8): 30-35.

Vignoli A, La Briola F, Peron A, Turner K, Savini M, Cogliati F, Russo S, Canevini MP. Medical care of adolescents and women with Rett syndrome: An Italian study. Am J Med Genet Part A 2012: 158A: 1318.

Williamson SL, Christodoulou J. Rett syndrome: new clinical and molecular insights. Eur J Hum Genet 2006: 14: 896-903.

Witt-Engerström I, Hagberg B. The Rett syndrome: gross motor disability and neural impairment in adults. Brain Dev 1990: 12 (1): 23-26.

Zysman L, Lotan M, Ben-Zeev B. Osteoporosis in Rett syndrome: a study on normal values. Scientific World J 2006: 6: 1619-1630. 
Chapter 7

General discussion 


\section{General discussion}

Thirty years have passed since RTT was revealed to the world as a unique and puzzling disorder in girls (Hagberg et al., 1983). There has been hope of developing a targeted therapy, especially since its reversibility was demonstrated in mouse models (Guy et al., 2007). However for the present there is still no specific treatment that can arrest the disorder's evolution or rescue the loss of acquired abilities. Hence the need for clinicians of advice on the clinical management of these females and support for their families.

The aim of this thesis is to contribute to improved clinical management of RTT. Various aspects of the syndrome were evaluated, including the role of the genotype in clinical management, the pathophysiology of the impaired nutritional status and the ageing process of the RTT women. In this general discussion, the results will be discussed in a broader perspective and methodological considerations and clinical challenges will be addressed. Directions for future research in RTT are given.

\section{Results in perspective}

\section{What is the role of the genotype in clinical management of the RTT female?}

Since the discovery in 1999 that RTT is caused by mutations in MECP2, large retrospective genotype-phenotype correlation studies have been performed and yielded often conflicting results (Amir et al., 1999; Amir et al., 2000; Cheadle et al., 2000; Huppke et al., 2000; Auranen et al., 2001; Hoffbuhr et al., 2001; Monros et al., 2001; Nielsen et al., 2001; Yamashita et al., 2001; Hoffbuhr et al., 2002; Huppke et al., 2002; Leonard et al., 2003; Smeets et al., 2003; Weaving et al., 2003; Schanen et al., 2004; Colvin et al., 2004; Charman et al., 2005; Fukuda et al., 2005; Kerr \& Prescott, 2005; Leonard et al., 2005; Smeets et al., 2005; Bebbington et al., 2008; Neul et al., 2008; Smeets et al., 2009; Bebbington et al., 2010; Temudo et al., 2011). The limited correlation might be due to several reasons, including the subjectivity among different clinicians or researchers completing the scoring lists. In chapter $\mathbf{2}$, a study is described in which one experienced clinician compared the clinical observations with the specific MECP2 mutations identified in a series of 137 cases. This in contrast to parental reports or questionnaires as used in other studies, making data more reliable and useful for counselling. Although general genotype-phenotype relationships could be confirmed, individual clinical variation in RTT females with the same mutation was generally very wide. Prognosis is a very important issue for parents. It determines their attitudes to planning their own and the planning of provision for their daughters. But due to the clinical variability of single mutations, genotype-phenotype relationships have only limited value in advising parents of newly diagnosed RTT females regarding her future outcome. However, the clinical 
data presented in this study are of great value for the guidance of these parents during regular review of their daughters. The scoring lists include all common features in RTT and the range of scores for these individual items is helpful in advising the parents about the expected clinical evolution. It is concluded that the limited genotype-phenotype correlation is not due to the subjectivity of different clinicians or researchers who fill in the scoring lists. It is more likely to arise from other factors, including methodological differences, for example in classification of mutations, assessment tools and structure of datasets (Ham et al., 2005; Grillo et al., 2012). Other genetic and epigenetic mechanisms, including variations in $X$ inactivation patterns, may also modify the clinical presentation and these require further investigation (Ogier \& Katz, 2008; Takahashi et al., 2008; Xinhua et al., 2008; Matjievic et al., 2009). In addition "jumping genes" may also contribute to the phenotype. These genes, also known as retrotransposons, were first discovered by McClintock in 1948, wherefore she earned her Nobel Prize in 1983. Such genes can insert copies of so-called transposable elements of themselves into other parts of the genetic code, making one neuron function differently from its neighbour. In the absence of MeCP2 increased numbers of retrotransposons in the neurons of both mice and humans were found (Muotri et al., 2010). This could be an explanation for the clinical variety in RTT, even within females with the same mutation.

In our collaborative multicentre study described in chapter 3 , the effect of the genotype on brainstem instability was evaluated. Autonomic features are a major reason for seeking medical attention in RTT and this study is the first to use objective and robust data of brainstem cardiorespiratory variables in the study of genotypephenotype correlation in RTT. Baseline brainstem functions were severely affected in all RTT females investigated, reflecting the important impact of brainstem dysfunction on clinical severity in RTT as described in previous studies (Julu et al., 1997; Julu et al., 2001; Julu \& Witt Engerström, 2005; Julu et al., 2012). These autonomic disturbances were not restricted to nor influenced by one specific group or single recurrent mutation. Although objective data were used, no constant relationship was found with the genotype.

On the basis of the above-described studies, we concluded that the role of the genotype in clinical management of RTT females is limited. The clinical variability within a specific genetic mutation or mutation group makes genotype-phenotype correlations impossible. Autonomic dysfunction (dysautonomia) was present in all RTT females and no relation with the genotype could be found. Therefore we concluded that, from the clinical point of view, the cardiorespiratory phenotype is more important for clinical management than the genetic mutation. Neurophysiological assessment is recommended early after diagnosis or promptly after the onset of brainstem autonomic symptoms. This is advisable in order to plan an effective man- 
agement strategy for RTT females, since each of the three distinguishable cardiorespiratory phenotypes requires a different management strategy (Julu, 2001; Julu et al., 2005; Julu et al., 2008; Julu et al., 2012). Of course mutation in MECP2 should be determined on clinical suspicion of RTT in an infant girl with developmental delay. Such early diagnosis is important in order to avoid prolonged uncertainty for the parents, to allow genetic counselling for the family and so that clinical management strategies may be initiated at the earliest possible age.

\section{Malnutrition in RTT: could altered metabolic processes be a cause?}

Although malnutrition is a prevalent problem in RTT females, the pathophysiology is still unknown and probably complex. In chapter 4 , we investigated whether acidbase imbalance due to the breathing irregularities causes disturbances in the metabolic equilibrium, so contributing to malnutrition. Despite normal levels of total dietary energy and protein intake, all RTT females had significantly low fat-free mass index (FFMI) values. Although the loss of skeletal muscle mass may be partly due to physical inactivity, these low values were certainly an indication for impaired nutritional status in these RTT females. A systematic metabolic screening was performed and showed significantly elevated creatine concentrations in plasma and/or urine in half of the RTT females. Different aetiologies might explain these creatine abnormalities, including age, cardiorespiratory phenotype and epigenetic influences affecting the creatine transporter gene SLC6A8. The relevance of these creatine abnormalities to malnutrition remained unclear. Further research is continuing and described in appendix 1.

In this follow-up study, the functionality of the creatine transporter has been investigated in fibroblasts under different $\mathrm{CO}_{2}$ circumstances. Firstly, previous findings were confirmed in 12 of the 13 females. In three of the females elevated creatine values were found in at least one body fluid on each occasion. However, the respective body fluid in which the increased values were found was different on each occasion. Here it is important to realize that these measurements are snapshots. One female had normal creatine concentrations in both plasma and urine in 2009, however elevated creatine concentrations in plasma in 2010 . This can be explained by change of reference values of creatine concentrations in plasma at the age of 10 years. In 2009 this female was 9 years and 8 months old, so reference values of the younger age group were applied and values were within the normal range. Secondly, intracellular creatine concentrations were measured in the fibroblasts cultured in the presence of $5 \% \mathrm{CO}_{2}$ and in $\mathrm{CO}_{2}$-independent medium and atmospheric $\mathrm{CO}_{2}$ pressure in the RTT population and three controls. In the controls practically equal intracellular creatine concentrations were found under both growth conditions studied. However, in the total RTT population intracellular creatine concentrations were significantly elevated in the fibroblasts when cultured at 
$5 \% \mathrm{CO}_{2}$ compared to the $\mathrm{CO}_{2}$-independent medium in the RTT females and both culture media in controls. Only slight differences were seen in the different subgroups of RTT females, with higher intracellular creatine concentrations in fibroblasts of the forceful breathers and females with elevated creatine concentrations in plasma and/or urine. There is an overlap, since in particular forceful breathers have increased levels of creatine concentrations in plasma and/or urine. Thirdly, measurements were performed in a muscle biopsy of a 15-year-old forceful breather with elevated creatine concentrations in plasma and urine. Significantly low concentrations of creatine, creatine phosphate and ATP were found. Concluding, the fibroblasts data strongly suggest that there is no primary creatine transporter defect. Though there may very well be an alteration in the creatine transport regulation. Given the differences in intracellular creatine concentrations in the fibroblasts of both culture media, $\mathrm{CO}_{2}$ seems to influence the creatine metabolism and/or transport in RTT females. $\mathrm{pH}$ dependency of the equilibrium of the alteration of creatine to form creatinine has previously been described (Wyss \& Kaddurah-Daouk, 2000). Creatine formation is favoured at high $\mathrm{pH}$, which is in line with our observations of high creatine concentrations in plasma and/or urine of the forceful breathers. Furthermore, low creatine, creatine phosphate and ATP concentrations were seen in the myocytes of one RTT female. A possible explanation could be increased energy requirement, which cannot be fulfilled in this RTT female. However, this might also be an expression of an abnormality in creatine transport regulation, leading to difficulty in transport of creatine into the myocyte. Another possible factor affecting intracellular concentrations of creatine might be an alternation in the composition of the plasma membrane. During the metabolic measurements it was noticed that the erythrocytes were very difficult to lyse. In Duchenne Muscular Dystrophy patients, increased plasma membrane fragility and subsequent leakage of cytosolic components are described, leading to low muscle concentrations of creatine, creatine phosphate and ATP in contrast to high serum creatine (Wyss \& Kaddurah-Daouk, 2000). Finally, MeCP2 binds to the promoter region of the gene encoding guanidinoacetate methyltransferase (GAMT), involved in the creatine biosynthesis (Chahrour et al., 2008). However, a decreased expression of GAMT will impair the ability of the guanidinoacetate methyltransferase enzyme to participate in the creatine synthesis and lower creatine concentrations would be expected. Further research using classical transporter studies with labelled creatine will be needed to provide greater insight into the pathogenesis of the abnormal creatine metabolism and/or transport of different cell types, and its possible association with malnutrition in RTT. 


\section{What is the phenotype of adult RTT women?}

Due to the prolonged survival of RTT females, clinicians are increasingly challenged by the provision of care for adults with RTT (Donckerwolcke \& Van Zeben-Van der Aa, 2002; Tyler \& Noritz, 2009; Freilinger et al., 2010; Kirby et al., 2010; Vignoli et al., 2012). However, little is known about the ageing process in RTT. To gain insight into the age-related features in RTT, in chapter 5 a cross-sectional questionnaire study was carried out. Data were gathered on 53 Dutch RTT individuals aged 16 years or older with a clinical diagnosis of RTT. The adult RTT group had a more or less stable condition. The general RTT disorder profile indicated deterioration in gross motor function in contrast to surprisingly better preserved cognitive functioning and reduced autonomic dysfunction. However, since cross- sectional data were used, it was considered that there might be a selection bias with the most severely affected dying earlier. Therefore, in chapter 6 a longitudinal ageing study was conducted. The same population was contacted on a second occasion after five years. Many of the findings of this study confirmed earlier reports of ageing in RTT. On the second questionnaire, the adult RTT women were reported to have better general health, with reduction in physical complaints. However a higher mortality rate as compared with the general population was confirmed (Kerr et al., 1997). In RTT a high incidence of sudden death has been reported, to which cardiorespiratory morbidity is suspected to contribute (Kerr et al., 1997; Ellaway \& Christodoulou, 2001; Byard, 2006). In our cross-sectional study neurological, respiratory and behavioural morbidity appeared to have a major influence on the general health of the RTT females. However analysing the initial records of the first ageing study, we did not find any health differences between those in the cohort who survived and those who died during the five years between questionnaires. The general disorder profile of the adult RTT women is that of a slow on-going impairment of motor function, in contrast to a relatively better preserved ability to communicate, mainly through the characteristic eye-pinpointing and visual interactive behaviour. The diminishing autonomic features and lesser to absence of epileptic seizures contribute to an overall good general health.

In order to maximise the clinical outcome of adult RTT women, clinical management must be directed towards maintaining motor function and skills. Learning ability persists to older ages (Piazza et al., 1993; Jacobsen et al., 2001; Nielsen et al., 2001; Cass et al., 2003; Hagberg, 2005). Continuation of physical therapy at later ages is of great importance to maintain motor function and to prevent orthopaedic malformations. Given the importance of mutual understanding, it is clear that active intervention with provision of alternative and supportive communication is justified throughout life in RTT. Special medical attention is needed for the prevention and diagnosis of pneumonia, since pneumonia was the main reason for hospital admission and also an important cause of death in RTT. Therefore the possibility of pneumonia should be considered when a RTT woman is unwell. Age-related morbidities 
such as hypertension, diabetes type II and osteoporosis were rarely reported, in contrast to previous reports, in which osteoporosis was prevalent in RTT (Haas et al., 1997; Budden \& Gunness, 2003; Zysman et al., 2006). Under reporting due to absence of screening is likely to be responsible for our unexpectedly low figures. Therefore, we advise screening for these age related conditions as a routine element in the care for adult RTT women. Kyphosis is a common age-related orthopaedic malformation in RTT. Surprisingly, little is known about the clinical management of kyphosis. Given the increasing prevalence of kyphosis with age, future research is therefore needed. Reports of epileptic seizures reduced with increasing age. Nevertheless, the prescription of anticonvulsant medication remained high. Reduction of in antiepileptic drugs should be seriously considered when a RTT female is seizure free for 2 years.

In conclusion, the clinical data provided in our ageing studies give more insight into the natural course and prognosis of RTT in adult women. Overall, clinical severity evolves over time and not always for the worse. Although the follow-up period in our cohort of RTT woman thus far is relatively short, the findings are interesting and consistent with previous research. Extending the follow-up period will give better and more stable results. These studies hold great potential for continuing longitudinal review that will enable the development of guidelines for early intervention and a life-long individualised multidisciplinary approach. This can contribute to the quality of life and health of RTT women. The success of this approach needs to be assessed in future studies.

\section{Methodological considerations}

\section{Collaborations}

The majority of our studies have been performed in close association with the RTT parent associations and RTT parental support foundation. Close collaboration between physicians and parents is of great importance in clinical research and ensures that the needs of the RTT females and their families are met. It contributes to awareness, improved knowledge and the development of appropriate information for families and health professionals. The high response rates in the questionnaire studies confirm the success of this collaboration. As well as parental involvement, engagement in international collaborative networking is crucial to effective research in rare disorders. Sharing expertise and creating databases with sufficient numbers of patients improves the methodological quality of research and leads to better understanding of the syndrome. All this is essential in order to facilitate future development of evidence-based management strategies and therapeutic intervention. 


\section{Material and methods}

In the genotype-phenotype studies, the internationally accepted clinical scoring system was used (Kerr et al., 2001). This scoring list was modified in our collaborative multicentre study. Two adjustments were made: adding an item concerning gastro-intestinal and bladder problems and moving the oro-motor disturbances from the movement into the autonomic domain. Gastro-intestinal and bladder problems are in fact very prevalent in RTT females (Giesbers et al., 2012). Previous studies have shown that the oro-motor difficulties are brainstem related in RTT (Julu \& Witt Engerström, 2005). This modified version of the clinical scoring system is more complete and adapted to the pathophysiology of RTT and therefore recommended for use in future studies.

Grouping of mutations was primarily based on the domain in the MECP2 gene in which the mutation was localised. Recurrent mutations were analysed separately. This method is commonly used in genotype-phenotype studies to date, but it only partly accounts for the biological effect of a mutation on the MeCP2 protein. Therefore type and location should be combined as described in the collaborative multicentre study. This method is therefore recommended in future genotype-phenotype studies.

Data in the ageing studies were based on questionnaires mainly completed by parents. Although the medical background of parents may be limited, they are the closest to their daughters in everyday life and are the most able to notice changes in development. One of the disadvantages of using questionnaires, is the occurrence of recall bias. However, especially in exploratory research, the use of questionnaires is a good method for collection of a large amount of information. For follow-up studies it will be preferable to use clinical measurements in order to increase knowledge about ageing in RTT, and to facilitate the development of guidelines for early intervention and evidence-based management strategies.

\section{Clinical challenges}

As RTT is a rare disorder, most clinicians gain experience with only small patient series. RTT is a complex and puzzling disorder presenting some unique clinical manifestations. It therefore requires specific knowledge and specific intervention for proper evaluation and adequate management. In 2011, the Maastricht University Medical Centre established a RTT Expertise Centre, pursuing and advocating an individualised multidisciplinary team approach. Since parents become great experts concerning their own child's history, behaviour and needs, they are critical mem- 
bers of this team. For more information on the RTT Expertise Centre and autonomic assessment in particular please refer to appendix $\mathbf{2}$ in this thesis.

It is hoped that most paediatricians are now familiar with the presentation of classical RTT. However, in clinical practice RTT is frequently still diagnosed at a late stage, although it is one of the leading monogenetic causes of severe intellectual disability in females. Differential diagnoses such as Angelman syndrome, with a lower prevalence of 1:20,000 (Steffenburg et al., 1996), are often excluded at a much earlier age. Given the importance of early diagnosis, clinicians need to consider RTT in any infant girl with a developmental delay. RTT is under-diagnosed in elderly women, for whom diagnostic alertness may be reduced. At older ages the clinical characteristics become less obvious and are readily overlooked, especially when the information about early infancy and childhood is limited (Nielsen et al., 2001).

\section{Conclusions and future perspectives}

In this thesis, information is presented for clinicians and families regarding assessment and clinical management of RTT females. The role of the genotype in clinical management, the pathophysiology of malnutrition and the phenotype of adult RTT women are considered. This information contributes to advice on the clinical management of RTT females and to the development of guidelines for early intervention and evidence-based management strategies. The deviant brain and brainstem development with defective and immature functioning leads to a cascade of clinical features. Particularly striking is the prominent role of the cardiorespiratory phenotype in this syndrome. The breathing irregularities are very distressing to the RTT females and their families. They are a prominent reason for seeking medical advice and they may contribute to sudden death. The clinical relevance of the cardiorespiratory phenotype in RTT is confirmed in this study. Neurophysiological assessment is therefore recommended early in stage three, in order to plan better and effective clinical management strategies. The clinical management of the brainstem autonomic dysfunction in RTT is a major challenge for the clinician. The multi-organ involvement requires multi-disciplinary and cross-professional collaboration to include paediatrician, respiratory physician, neurologist, anaesthetist, cardiologist, orthopaedic surgeon, endocrinologist, physiotherapist, speech therapist, nutritionist and nurse. Further advances in understanding the cardiorespiratory pathophysiology in RTT will be the key to an appropriate and effective clinical management.

The ultimate goal of basic research is to understand the disorder and so to design effective new therapeutic avenues. Although much has been learned about RTT since its first description, the pathogenesis of this unique disorder is still not fully understood despite the identification of the mutations in MECP2 in the vast majori- 
ty of the RTT females. In many ways RTT remains a mystery, with no clear correlations between the gene mutation and abnormal biological markers (like creatine in our study), neuropathology and neurophysiology leading to its unique clinical presentation (Kerr \& Witt Engerström, 2001; Hagberg et al., 2002; Bienvenu \& Chelly, 2006; Chahrour \& Zoghbi, 2007, Matsuishi et al., 2011). Optimism is justified regarding possible therapies, especially since the work of Guy and colleagues, that in the RTT mice the neurological regression may be reversed, in part or in whole (Guy et al., 2007). Lack of understanding its pathogenesis is the major reason for lack of an effective therapy in RTT. Therefore besides concentrating on clinical management, future research will need to focus further on understanding the molecular pathways in RTT, including the identification of further target genes and their interaction with MECP2 and CDKL5. Such research may provide alternative strategies to targeting MeCP2 deficiency directly through gene therapy. Gene therapy is particularly problematic because MeCP2 levels are tightly regulated and over-expression as seen in patients with a MECP2 duplication appears to be even more deleterious than loss of expression. Hopefully the target gene approach will identify specific therapeutic targets, leading to improvement in the health and quality of life of the RTT females. It may also yield insights into normal brain development and function and into mechanism involved in other neurodevelopmental disorders. Another approach in basic science would consist of achieving read through in case of nonsense mutations in MECP2. Pharmacological agents such as aminoglycoside antibiotics may enable read through of these mutations, possibly resulting in the production of a full-length functional protein with virtually preserved activity. Recent research appears promising, but still is inconclusive (Brendel et al., 2009; Popescu et al., 2010; Vecsler et al., 2011; Brendel et al., 2011). In basic research, animal models provide important opportunities to examine the pathophysiological mechanisms involved in various aspects of the syndrome and to evaluate potential therapeutic approaches. They will contribute to the understanding of MECP2 function and the pathobiology of RTT.

In conclusion, treatment of RTT will be a lifelong challenge for clinicians and researchers all over the world. Until a breakthrough in genetic therapy, clinicians will have to rely on conservative medical treatments and preventive management strategies based on clinical evidence. Understanding of the cardiorespiratory neurophysiology in RTT is one of the important goals for research, resulting in an effective treatment that can improve quality of life and long term survival. 


\section{References}

Amir RE, Van den Veyver IB, Schultz R, Malicki DM, Tran CQ, Dahle EJ, Philippi A, Timar L, Percy AK, Motil KJ, Lichtarge O, Smith EO, Glaze DG, Zoghbi HY. Influence of mutation type and X chromosome inactivation on Rett syndrome phenotypes. Ann Neurol 2000: 47: 670-679.

Amir RE, Van den Veyver IB, Wan M, Tran CQ, Francke U, Zoghbi HY. Rett syndrome is caused by mutations in X-linked MECP2, encoding methyl-CpG-binding protein 2. Nat Genet 1999: 23: 185-188.

Auranen M, Vanhala R, Vosman M, Levander M, Varilo T, Hietala M, Riikonen R, Peltonen L, Järvelä I. MECP2 gene analysis in classical Rett syndrome and in patients with Rett-like features. Neurology 2001: 56: 611-617.

Bebbington A, Anderson A, Ravine D, Fyfe S, Pineda M, de Klerk N, Ben-Zeev B, Yatawara N, Percy A, Kaufmann WE, Leonard $\mathrm{H}$. Investigating genotype-phenotype relationships in Rett syndrome using an international data set. Neurology 2008: 70: 868-875.

Bebbington A, Percy A, Christodoulou J, Ravine D, Ho G, Jacoby P, Anderson A, Pineda M, Ben Zeev B, Bahi-Buisson N, Smeets $E$, Leonard $H$. Updating the profile of C-terminal MECP2 deletions in Rett syndrome. J Med Genet 2010: 47: 242-248.

Bienvenu T, Chelly J. Molecular genetics of Rett syndrome: when DNA methylation goes unrecognized. Nat Rev Genet 2006: 7: 415-426.

Brendel C, Belakhov V, Werner H, Wegener E, Gärtner J, Nudelman I, Baasov T, Huppke P. Readthrough of nonsense mutations in Rett syndrome: evaluation of novel aminoglycosides and generation of a new mouse model. J Mol Med 2011: 89(4): 389-398.

Brendel C, Klahold E, Gärtner J, Huppke P. Suppression of nonsense mutations in Rett syndrome by aminoglycoside antibiotics. Pediatr Res 2009: 65(5): 520-523.

Budden SS, Gunness ME. Possible mechanisms of osteopenia in Rett syndrome: bone histomorphometric studies. J Child Neurol 2003: 18 (10): 698-702.

Byard RW. Forensic issues and possible mechanisms of sudden death in Rett syndrome. $J$ Clin Forensic Med 2006: 13: 96-99.

Cass H, Reilly S, Owen L, Wisbeach A, Weekes L, Slonims V, Wigram T, Charman T. Findings from a multidisciplinary clinical case series of females with Rett syndrome. Dev Med Child Neurol 2003: 45: 325337.

Chahrour M, Jung SY, Shaw C, Zhou X, Wong ST, Qin J, Zoghbi HY. MeCP2, a key contributor to neurological disease, activates and represses transcription. Science 2008: 320(5880): 1224-1229.

Chahrour M, Zoghbi HY. The story of Rett syndrome: from clinic to neurobiology. Neuron 2007: 56: 422437.

Charman T, Neilson TC, Mash V, Archer H, Gardiner MT, Knudsen GP, McDonnell A, Perry J, Whatley SD, Bunyan DJ, Ravn K, Mount RH, Hastings RP, Hulten M, Orstavik KH, Reilly S, Cass H, Clarke A, Kerr AM, Bailey ME. Dimensional phenotypic analysis and functional categorisation of mutations reveal novel genotype-phenotype associations in Rett syndrome. Eur J Hum Genet 2005: 13: 1121-1130.

Cheadle JP, Gill H, Fleming N, Maynard J, Kerr A, Leonard H, Krawczak M, Cooper DN, Lynch S, Thomas N, Hughes $H$, Hulten M, Ravine D, Sampson JR, Clarke A. Long-read sequence analysis of the MECP2 gene in Rett syndrome patients: correlation of disease severity with mutation type and location. Hum Mol Genet 2000: 9: 1119-1129.

Colvin L, Leonard H, De Klerk N, Davis M, Weaving L, Williamson S, Christodoulou J. Refining the phenotype of common mutations in Rett syndrome. J Med Genet 2004: 41: 25-30.

Donckerwolcke RAMG, Van Zeben-Van der Aa DMCB. Overdracht van de zorg voor adolescenten met chronische ziekten: Van kindergeneeskunde naar specialismen voor volwassenen. Ned Tijdschr Geneeskd 2002: 146: 675-678.

Ellaway C, Christodoulou J. Rett syndrome: Clinical characteristics and recent genetic advances. Disabil Rehabil 2001: 23: 98-106. 
Freilinger M, Bebbington A, Lanator I, De Klerk N, Dunkler D, Seidl R, Leonard H, Ronen GM. Survival with Rett syndrome:comparing Rett's original sample with data from the Australian Rett Syndrome Database. Dev Med Child Neurol 2010: 52: 962-965.

Fukuda T, Yamashita Y, Nagamitsu S, Miyamoto K, Jin JJ, Ohmori I, Ohtsuka Y, Kuwajima K, Endo S, Iwai T, Yamagata H, Tabara Y, Miki T, Matsuishi T, Kondo I. Methyl- CpG binding protein 2 gene (MECP2) variations in Japanese patients with Rett syndrome: pathological mutations and polymorphisms. Brain Dev 2005: 27: 211-217.

Giesbers S, Didden R, Radstaake M, Korzilius H, Von Gontard A, Lang R, Smeets E, Curfs LM. Incontinence in individuals with Rett syndrome: a comparative study. J Dev Phys Disabil 2012: 24: 287-300.

Grillo E, Villard L, Clarke A, Ben Zeev B, Pineda M, Bahi-Buisson N, Hryniewiecka- Jaworska A, Bienvenu T, Armstrong J, Roche-Martinez A, Mari F, Veneselli E, Russo S, Vignoli A, Pini G, Djuric M, Bisgaard AM, Mejaški Bošnjak V, Polgár N, Cogliati F, Ravn K, Pintaudi M, Melegh B, Craiu D, Djukic A, Renieri A. Rett networked database: an integrated clinical and genetic network of Rett syndrome databases. Hum Mutat 2012: 33(7): 1031-1036.

Guy J, Gan J, Selfridge J, Cobb S, Bird A. Reversal of neurological defects in a mouse model of Rett syndrome. Science 2007: 315: 1143-1147.

Haas RH, Dixon SD, Sartoris DJ, Hennessy MJ. Osteopenia in Rett syndrome. J Pediatr 1997: 131 (5): $771-$ 774.

Hagberg, B. Rett syndrome. Long-term clinical follow-up experiences over four decades. J Child Neurol 2005: 20(9): 722-726.

Hagberg B, Aicardi J, Dias K, Ramos O. A progressive syndrome of autism, dementia, ataxia, and loss of purposeful hand use in girls: Rett's syndrome: Report of 35 cases. Ann Neurol 1983: 14: 471-479.

Hagberg B, Hanefeld F, Percy A, Skjeldal O. An update on clinically applicable diagnostic criteria in Rett syndrome: Comments to Rett Syndrome Clinical Criteria Consensus Panel Satellite to European Paediatric Neurology Society Meeting, Baden Baden, Germany, 11 September 2001. Eur J Paediatr Neurol 2002: 6: 293-297.

Ham AL, Kumar A, Deeter R, Schanen NC. Does genotype predict phenotype in Rett syndrome? J Child Neurol 2005: 20: 768-778.

Hoffbuhr K, Devaney JM, LaFleur B, Sirianni N, Scacheri C, Giron J, Schuette J, Innis J, Marino M, Philippart M, Narayanan V, Umansky R, Kronn D, Hoffman EP, Naidu S. MeCP2 mutations in children with and without the phenotype of Rett syndrome. Neurology 2001: 56: 1486-1495.

Hoffbuhr KC, Moses LM, Jerdonek MA, Naidu S, Hoffman EP. Associations between MECP2 mutations, Xchromosome inactivation, and phenotype. Ment Retard Dev Disabil Res Rev 2002: 8: 99-105.

Huppke P, Held M, Handefeld F, Engel W, Laccone F. Influence of mutation type and location on phenotype in 123 patients with Rett syndrome. Neuropediatrics 2002: 33: 63-68.

Huppke P, Laccone F, Kramer N, Engel W, Hanefeld F. Rett syndrome: analysis of MECP2 and clinical characterization of 31 patients. Hum Mol Genet 2000: 9: 1369-1375.

Jacobsen K, Viken A, Von Tetzchner S. Rett syndrome and ageing: a case study. Disabil Rehabil 2001: 23(3-4): 160-166.

Julu POO. The central autonomic disturbance in Rett syndrome. In: Kerr AM, Witt Engerström I, editors. Rett Disorder and the Developing Brain. Oxford: Oxford University Press 2001: 131-181.

Julu PO, Engerström IW, Hansen S, Apartopoulos F, Engerström B, Pini G, Delamont RS, Smeets EE. Cardiorespiratory challenges in Rett's syndrome. Lancet 2008: 371: 1981- 1983.

Julu PO, Kerr AM, Apartopoulos F, Al-Rawas S, Engerström I, Engerström L, Jamal G, Hansen S. Characterisation of breathing and associated central autonomic dysfunction in the Rett disorder. Arch Dis Child 2001: 85: 29-37.

Julu POO, Kerr AM, Hansen S, Apartopoulos F, Jamal GA. Functional evidence of brain stem immaturity in Rett syndrome. Arch Dis Child 1997: 77(5): 464-465.

Julu PO, Witt Engerström I. Assessment of the maturity-related brainstem functions reveals the heterogeneous phenotypes and facilitates clinical management of Rett syndrome. Brain Dev 2005: 27(Suppl 1): S43-S53. 
Julu PO, Witt Engerström I, Hansen S, Apartopoulos F, Engerström B; The ESSRA group. Treating hypoxia in a feeble breather with Rett syndrome. Brain Dev 2012: Epub ahead of print.

Kerr AM, Armstrong DD, Prescott RJ, Doyle D, Kearney DL. Rett syndrome: analysis of deaths in the British survey. Eur Child Adolesc Psychiatry 1997: 6(Suppl1): 71-74.

Kerr AM, Nomura Y, Armstrong D, Anvret M, Belichenko PV, Budden S, Cass H, Christodoulou J, Clarke A, Ellaway C, d'Esposito M, Francke U, Hulten M, Julu P, Leonard H, Naidu S, Schanen C, Webb T, Witt Engerström I, Yamashita $Y$, Segawa M. Guidelines for reporting clinical features in cases with MECP2 mutations. Brain Dev 2001: 23: 208-211.

Kerr AM, Prescott RJ. Predictive value of the early clinical signs in Rett disorder. Brain Dev 2005: 27: S20S24.

Kerr AM, Witt Engerström I. The clinical background to the Rett disorder. In: Kerr AM, Witt Engerström I, editors. Rett Disorder and the Developing Brain. Oxford: Oxford University Press 2001: 1-26.

Kirby RS, Lane JB, Childers J, Skinner SA, Annese F, Barrish JO, Glaze DG, Macleod P, Percy AK. Longevity in Rett syndrome: analysis of the North American database. J Pediatr 2010: 156: 135-138.

Leonard H, Colvin L, Christodoulou J, Schiavello T, Williamson S, Davis M, Ravine D, Fyfe S, de Klerk N, Matsuishi T, Kondo I, Clarke A, Hackwell S, Yamashita Y. Patients with the R133C mutation: is their phenotype different from Rett syndrome patients with other mutations? J Med Genet 2003: 40: e52.

Leonard H, Moore H, Carey M, Fyfe S, Hall S, Robertson L, Wu XR, Bao X, Pan H, Christodoulou J, Williamson S, Klerk Nd. Genotype and early development in Rett syndrome: The value of international data. Brain Dev 2005: 27: S59-S68.

Matijevic T, Knezevic J, Slavica M, Pavelic J. Rett Syndrome: From the Gene to the Disease. Eur Neurol 2009: 61: 3-10.

Matsuishi T, Yamashita Y, Takahashi T, Nagamitsu S. Rett syndrome: The state of clinical and basic research, and future perspectives. Brain Dev 2011: 33: 627-631.

Monros E, Armstrong J, Aibar E, Poo P, Canos I, Pineda M. Rett syndrome in Spain: mutation analysis and clinical correlations. Brain Dev 2001: 23(suppl 1): S251-S253.

Muotri AR, Marchetto MC, Coufal NG, Oefner R, Yeo G, Nakashima K, Gage FH. L1 retrotransposition in neurons is modulated by MeCP2. Nature 2010: 468(7322): 443-446.

Neul JL, Fang P, Barrish J, Lane J, Caeg EB, Smith EO, Zoghbi H, Percy A, Glaze DG. Specific mutations in methyl-CpG-binding protein 2 confer different severity in Rett syndrome. Neurology 2008: 70: 13131321.

Nielsen JB, Henriksen KF, Hansen C, Silahtaroglu A, Schwartz M, Tommerup N. MECP2 mutations in Danish patients with Rett syndrome: high frequency of mutations but no consistent correlations with clinical severity or with the X chromosome inactivation pattern. Eur J Hum Genet 2001: 9: 178-184.

Nielsen JB, Ravn K, Schwartz M. A 77-year-old woman and a preserved speech variant among Danish Rett patients with mutations in MECP2. Brain Dev 2001: 23: S230- 232.

Ogier M, Katz DM. Breathing dysfunction in Rett syndrome: understanding epigenetic regulation of the respiratory network. Respir Physiol Neurobiol 2008: 164(1-2): 55-63.

Piazza CC, Anderson C, Fisher W. Teaching self-feeding skills to patients with Rett syndrome. Dev Med Child Neurol 1993: 35(11): 991-996.

Popescu AC, Sidorova E, Zhang G, Eubanks JH. Aminoglycoside-mediated partial suppression of MECP2 nonsense mutations responsible for Rett syndrome in vitro. J Neurosci Res 2010: 88(11): 2316-2324.

Schanen C, Houwink EJ, Dorrani N, Lane J, Everett R, Feng A, Cantor RM, Percy A. Phenotypic manifestations of MECP2 mutations in classical and atypical Rett syndrome. Am J Med Genet 2004: 126A: 129140.

Smeets EE, Chenault M, Curfs LM, Schrander-Stumpel CT, Frijns JP. Rett syndrome and long-term disorder profile. Am J Med Genet Part A 2009: 149A: 199-205.

Smeets E, Schollen E, Moog U, Matthijs G, Herbergs J, Smeets H, Curfs L, Schrander-Stumpel C, Fryns JP. Rett syndrome in adolescent and adult females: clinical and molecular genetic findings. Am J Med Genet 2003: 122A: 227-233. 
Smeets E, Terhal P, Casaer P, Peters A, Midro A, Schollen E, Van Roozendaal K, Moog U, Matthijs G, Herbergs J, Smeets H, Curfs L, Schrander-Stumpel C, Fryns JP. Rett syndrome in females with CTS hot spot deletions: a disorder profile. Am J Med Genet 2005: 132: 117-120.

Steffenburg S, Gillberg CL, Steffenburg U, Kyllerman M. Autism in Angelman syndrome: A populationbased study. Pediatr Neurol 1996: 14: 131-136.

Takahashi S, Ohinata J, Makita Y, Suzuki N, Araki A, Sasaki A, Murono K, Tanaka H, Fujieda K. Skewed X chromosome inactivation failed to explain the normal phenotype of a carrier female with MECP2 mutation resulting in Rett syndrome. Clin Genet 2008: 73(3): 257-261.

Temudo T, Santos M, Ramos E, Dias K, Vieira JP, Moreira A, Calado E, Carrilho I, Oliveira G, Levy A, Barbot C, Fonseca M, Cabral A, Cabral P, Monteiro J, Borges L, Gomes R, Mira G, Pereira SA, Santos M, Fernandes A, Epplen JT, Sequeiros J, Maciel P. Rett syndrome with and without detected MECP2 mutations: an attempt to redefine phenotypes. Brain Dev 2011: 33(1): 69-76.

Tyler CV, Garey Noritz G. Healthcare issues in aging adults with intellectual and other developmental disabilities. Clinical Geriatrics 2009: 17(8): 30-35.

Vecsler M, Ben Zeev B, Nudelman I, Anikster Y, Simon AJ, Amariglio N, Rechavi G, Baasov T, Gak E. Ex vivo treatment with a novel synthetic aminoglycoside NB54 in primary fibroblasts from Rett syndrome patients suppresses MECP2 nonsense mutations. PLoS One 2011: 6(6): e20733 (Epub).

Vignoli A, La Briola F, Peron A, Turner K, Savini M, Cogliati F, Russo S, Canevini MP. Medical care of adolescents and women with Rett syndrome: An Italian study. Am J Med Genet Part A 2012: 158A: 1318.

Weaving LS, Williamson SL, Bennetts B, Davis M, Ellaway CJ, Leonard H, Thong MK, Delatycki M, Thompson EM, Laing N, Christodoulou J. Effects of MECP2 mutation type, location and X-inactivation in modulating Rett syndrome phenotype. Am J Med Genet 2003: 118A: 103-114.

Wyss M, Kaddurah-Daouk R. Creatine and creatinine metabolism. Physiol Rev 2000: 80(3): 1107-1213.

Xinhua B, Shengling J, Fuying S, Hong,P, Meirong L, Wu XR. X chromosome inactivation in Rett syndrome and its correlations with MECP2 mutations and phenotype. J Child Neurol 2008: 23: 22-25.

Yamashita Y, Kondo I, Fukuda T, Morishima R, Kusaga A, Iwanaga R, Matsuishi T. Mutation analysis of the methyl-CpG-binding protein 2 gene (MECP2) in Rett patients with preserved speech. Brain Dev 2001: 23(suppl 1): S157-S160.

Zysman L, Lotan M, Ben-Zeev B. Osteoporosis in Rett syndrome: a study on normal values. Scientific World J 2006: 6: 1619-1630. 


\section{Appendix 1}

\section{Altered carbon dioxide metabolism and creatine abnormalities in Rett syndrome: a continuing study}

Reference: Halbach NSJ, Smeets EEJ, Bierau J, Keularts IMLW, Plasqui G, Julu POO, Witt Engerström I, Bakker JA, Curfs LMG. Altered carbon dioxide metabolism and creatine abnormalities in Rett Syndrome. JIMD Reports 2012: 3: 117-124.

Reference: Halbach NSJ, Smeets EEJ, Van Waardenburg DA, Bierau J, Bakker JA, Dagnelie P, Plasqui G, Julu PO, Witt Engerström I, Curfs LMG. Altered carbon dioxide metabolism and creatine abnormalities in Rett Syndrome, a continuing study. New Orleans 2012, 7th World Rett Syndrome Congress, Translational \& Pre-clinical research symposium.

Halbach NSJ, Smeets EEJ, Bierau J, Keularts IMLW, Visser D, Dagnelie P, Plasqui G, Julu POO, Witt Engerström I, Van Loon L, Van Waardenburg DA, Salomons GS, Bakker JA, Curfs LMG. 


\section{Introduction}

The pathophysiology of malnutrition in RTT is largely unknown. Besides feeding difficulties, other constitutional factors such as altered metabolic processes are suspected (Motil et al., 1998; Reilly \& Cass, 2001; Oddy et al., 2007; Motil et al., 2009; Platte et al., 2011; Motil et al., 2012). In preliminary research performed by our research group (Halbach et al., 2012), it was investigated whether acid-base imbalance due to the breathing irregularities causes metabolic disturbances, as a possible explanation for the impaired nutritional status. The systematic metabolic screening that was carried out revealed elevated creatine concentrations in plasma and/or urine in half of the RTT females. Since various etiologies might explain these results, further studies were indicated.

\section{Patients and Methods}

Ethical approval was obtained from the Medical Ethical Committee at the Maastricht University Medical Centre, and all parents provided informed written consent. The study was registered at clinicaltrials.gov.

\section{Patient population}

In this follow-up study the same population was contacted as in preliminary research (Halbach et al., 2012), consisting of 13 well-defined RTT females who had extended clinical, molecular and neurophysiological assessments. All parents of the RTT females agreed to participation.

\section{Study design}

The aim of this study was to confirm previous findings and to examine the function of the creatine transporter in RTT females in different $\mathrm{CO}_{2}$ circumstances. First, for confirmation of the previous study findings, blood and urine samples were collected for creatine measurements. Secondly, a skin biopsy was collected for functional studies of the creatine transporter. In one RTT female there was the opportunity to access a muscle biopsy allowing for creatine measurements to be made.

\section{Metabolic measurements}

\section{Cell culture and creatine uptake}

Skin fibroblast cultures were established from skin biopsies and were routinely maintained in AminoMax II culture medium at $37{ }^{\circ} \mathrm{C}$ and $5 \% \mathrm{CO}_{2}$ in a humidified atmosphere. For creatine uptake experiments, fibroblasts were harvested by trypsi- 
nation, and seeded in 6-well plate wells and allowed to adhere overnight. Medium was then refreshed and experiments were started once cultures reached $70-90 \%$. In an alternative procedure, cells were cultured for two passages in $\mathrm{CO}_{2}$-independent medium at $37{ }^{\circ} \mathrm{C}$ in a humidified atmosphere, without extra $\mathrm{CO}_{2}$ (atmospheric $\mathrm{CO}_{2}$ pressure).

Creatine uptake studies were performed by replacing the medium with a creatine enriched medium, containing 0-1100 $\mu \mathrm{m}$ creatine. The concentration used for the panel of cell lines was $500 \mu \mathrm{m}$ creatine. After $24 \mathrm{~h}$ of incubation, the cells were harvested by trypsination, washed in saline and then disrupted by sonication in water. The supernatant obtained after centrifugation, was used for the determination of creatine and protein content. Creatine was measured on a UPLC-MS/MS system using a stable isotope labeled internal creatine standard for quantification.

In addition to the RTT population, measurements were performed in the same manner for three healthy female controls.

\section{Creatine measurements in muscle biopsy}

For loss of muscle mass and suspected mitochondrial disorder, a muscle biopsy was taken on clinical grounds in RTT female number 10. It was obtained during scoliosis surgery in 2011 from the middle region of the vastus lateralis muscle through the fascia by the percutaneous needle biopsy technique described by Bergström (1975), using a modified needle (Maastricht Instruments). A small incision was made in skin and fascia after which the biopsy needle was introduced in the muscle. Vacuum was applied to the needle and, with the needle kept in situ, several small muscle samples (total \pm 50 -80 $\mathrm{mg}$ ) were taken. Spectrophotometric determination of creatine, creatine phosphate (PCr) and ATP was performed (Harris et al., 1974).

\section{Results}

Table 1 shows the patients' characteristics and creatine concentrations in plasma, urine and fibroblasts. Age of the females relates to the age in 2009. Of the $13 \mathrm{fe}$ males, nine females showed equal results of creatine concentrations in plasma and urine, interpreted as normal and/or elevated. One female had elevated creatine concentrations in plasma in 2009 and in urine in 2010. Two females had elevated creatine concentrations in both plasma and urine in 2009. However in 2010, creatine concentrations were elevated in plasma only. One female had normal creatine concentrations in both plasma and urine in 2009 , and elevated creatine concentrations in plasma in 2010. 
Table 1 Patient characteristics and creatine concentrations in plasma, urine and fibroblasts including agespecific reference values of $13 \mathrm{RTT}$ females

\begin{tabular}{|c|c|c|c|c|c|c|c|c|c|}
\hline $\begin{array}{l}\text { RTT } \\
\text { female }\end{array}$ & $\begin{array}{l}\text { Age } 2009 \\
\text { (yr.months) }\end{array}$ & CRPh & $\begin{array}{l}\mathrm{Cr} P \\
2009\end{array}$ & $\begin{array}{l}\text { Cr U } \\
2009\end{array}$ & $\begin{array}{l}\text { Cr P } \\
2010\end{array}$ & $\begin{array}{l}\mathrm{Cr} \mathrm{U} \\
2010\end{array}$ & $\begin{array}{l}\mathrm{Cr} \\
\text { Total }\end{array}$ & 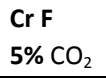 & $\begin{array}{l}\mathrm{Cr} \mathbf{F} \\
\mathbf{0 \% \mathrm { CO } _ { 2 }}\end{array}$ \\
\hline 1 & 2.4 & $\mathrm{FeB}$ & $\begin{array}{l}75.7 \\
(17-109)\end{array}$ & $\begin{array}{l}490.6 \\
(6-1200)\end{array}$ & $\begin{array}{l}61.6 \\
(17-109)\end{array}$ & $\begin{array}{l}650.6 \\
(6-1200)\end{array}$ & $\mathrm{N}$ & 19.1 & 15.03 \\
\hline 2 & 3.11 & $\mathrm{FeB}$ & $\begin{array}{l}79.5 \\
(17-109)\end{array}$ & $\begin{array}{l}421.3 \\
(6-1200)\end{array}$ & $\begin{array}{l}82.6 \\
(17-109)\end{array}$ & $\begin{array}{l}694.8 \\
(17-720)\end{array}$ & $\mathrm{N}$ & 18.5 & 13.3 \\
\hline 3 & 4.0 & $\mathrm{FeB}$ & $\begin{array}{l}88.1 \\
(17-109)\end{array}$ & Und & $\begin{array}{l}86.6 \\
(17-109)\end{array}$ & Und & $N$ & 20.9 & 15.93 \\
\hline 4 & 4.3 & $\mathrm{FeB}$ & $\begin{array}{l}81.0 \\
(17-109)\end{array}$ & $\begin{array}{l}828.8 * \\
(17-720)\end{array}$ & $\begin{array}{l}75.2 \\
(17-109)\end{array}$ & $\begin{array}{l}1456.6 * \\
(17-720)\end{array}$ & $E$ & 21.57 & 7.87 \\
\hline 5 & 5.3 & $\mathrm{FeB}$ & $\begin{array}{l}83.5 \\
(17-109)\end{array}$ & $\begin{array}{l}28.6 \\
(17-720)\end{array}$ & $\begin{array}{l}47.3 \\
(17-109)\end{array}$ & $\begin{array}{l}26.0 \\
(17-720)\end{array}$ & $\mathrm{N}$ & 18.47 & 16.3 \\
\hline 6 & 6.2 & FoB & $\begin{array}{l}63.0 \\
(17-109)\end{array}$ & $\begin{array}{l}629.7 \\
(17-720)\end{array}$ & $\begin{array}{l}95.8 \\
(17-109)\end{array}$ & $\begin{array}{l}512.5 \\
(17-720)\end{array}$ & $N$ & 25 & 13.97 \\
\hline 7 & 9.8 & FoB & $\begin{array}{l}52.9 \\
(17-109)\end{array}$ & $\begin{array}{l}756.2 * \\
(17-720)\end{array}$ & $\begin{array}{l}56.4^{*} \\
(6-50)\end{array}$ & $\begin{array}{l}508.4 \\
(17-720)\end{array}$ & $E$ & 23.77 & 13.47 \\
\hline 8 & 9.8 & FoB & $\begin{array}{l}68.7 \\
(17-109)\end{array}$ & $\begin{array}{l}124.3 \\
(17-720)\end{array}$ & $\begin{array}{l}77.9 * \\
(6-50)\end{array}$ & $\begin{array}{l}98.7 \\
(17-720)\end{array}$ & $E$ & 16.87 & 10.97 \\
\hline 9 & 10.11 & FoB & $\begin{array}{l}70.4^{*} \\
(6-50)\end{array}$ & $\begin{array}{l}1,305.3 * \\
(17-720)\end{array}$ & $\begin{array}{l}55.3 * \\
(6-50)\end{array}$ & $\begin{array}{l}932.1 * \\
(11-240)\end{array}$ & $E$ & 25.73 & 19.07 \\
\hline 10 & 13.3 & FoB & $\begin{array}{l}73.5^{*} \\
(6-50)\end{array}$ & $\begin{array}{l}448.0 * \\
(11-240)\end{array}$ & $\begin{array}{l}71.4 * \\
(6-50)\end{array}$ & $\begin{array}{l}308.0^{*} \\
(11-240)\end{array}$ & $E$ & 20.97 & 10.77 \\
\hline 11 & 13.11 & Und & $\begin{array}{l}101.5 * \\
(6-50)\end{array}$ & $\begin{array}{l}1040.3 * \\
(11-240)\end{array}$ & $\begin{array}{l}81.0 * \\
(6-50)\end{array}$ & $\begin{array}{l}\text { 1041.8* } \\
(11-240)\end{array}$ & $E$ & 24.2 & 16.93 \\
\hline 12 & 19.3 & FoB & $\begin{array}{l}88.5 * \\
(6-50)\end{array}$ & $\begin{array}{l}403.7 * \\
(11-240)\end{array}$ & $\begin{array}{l}54.7^{*} \\
(6-50)\end{array}$ & $\begin{array}{l}117.0 \\
(11-240)\end{array}$ & $E$ & 28.57 & 12.83 \\
\hline 13 & 20.3 & FoB & $\begin{array}{l}65.0^{*} \\
(6-50)\end{array}$ & $\begin{array}{l}\text { 538.3* } \\
(11-240)\end{array}$ & $\begin{array}{l}64.3^{*} \\
(6-50)\end{array}$ & $\begin{array}{l}211.5 \\
(11-240)\end{array}$ & $E$ & 15.57 & 17.03 \\
\hline
\end{tabular}

CRPh Cardiorespiratory phenotype, $\mathrm{FeB}$ Feeble breather, FoB Forceful breather, Und Undetermined, $\mathrm{Cr}$ Creatine, $P$ Plasma, $U$ Urine, $C r F$ Intracellular creatine in fibroblasts in nmol creatine/mg protein, $N$ normal creatine concentrations, $E$ Elevated creatine concentrations, * Elevated value.

Intracellular creatine concentrations were measured in fibroblasts cultured in the presence of $5 \% \mathrm{CO}_{2}$ and in $\mathrm{CO}_{2}$-independent medium and atmospheric $\mathrm{CO}_{2}$ pressure. In Table 2 the mean intracellular creatine concentrations measured under the described conditions are presented for the RTT population and controls, and for different subgroups of the RTT population selected according to cardiorespiratory phenotype and creatine concentrations in plasma and urine. As already stated in our previous study (Halbach et al., 2012), the mean age of the forceful breathers was significantly higher than the mean age of the feeble breathers (14.1 vs. 5.4 years). The mean age of the RTT population was somewhat lower than the controls, 10.8 years and 12.7 years respectively. The intracellular creatine concentrations of the controls were almost identical under both growth conditions studied. In the RTT population, when cultured at $5 \% \mathrm{CO}_{2}$ intracellular creatine concentrations were 
significantly higher than in controls (mean creatine concentration 21.48 compared to 13.04). At atmospheric $\mathrm{CO}_{2}$ intracellular creatine concentrations were almost identical in the RTT population and controls (14.11 compared to 14.15). With respect to subgroups, at $5 \% \mathrm{CO}_{2}$ intracellular creatine concentrations were higher in the forceful breathers (22.35) compared to the feeble breathers (19.71). Females with elevated creatine concentrations in plasma and/or urine also had higher creatine concentrations in fibroblasts at $5 \% \mathrm{CO}_{2}$ compared to females with normal creatine concentrations in plasma and/or urine (22.16 vs. 20.39). At atmospheric $\mathrm{CO}_{2}$ intracellular creatine concentrations were practically identical in all subgroups, with the exception of two RTT females. The lowest intracellular creatine concentration of 7.87 was measured in a 5-year-old feeble breather with elevated creatine concentrations in urine. The highest intracellular creatine concentration of 16.93 was measured in a 15-year-old RTT female with an undetermined cardiorespiratory phenotype and elevated creatine concentrations in plasma and urine.

Table 2 Mean age and creatine concentrations in fibroblasts ( $\mathrm{nmol}$ creatine/mg protein) under conditions of $5 \% \mathrm{CO}_{2}$ medium and $\mathrm{CO}_{2}$-independent medium in controls and the total and subgroups of the RTT populations

\begin{tabular}{|c|c|c|c|}
\hline Group (n) & $\begin{array}{l}\text { Mean } \\
\text { age } 2010\end{array}$ & $\begin{array}{l}\text { Mean } \mathrm{Cr} \\
5 \% \mathrm{CO}_{2}\end{array}$ & $0 \% \mathrm{CO}_{2}$ \\
\hline Controls $(n=3)$ & 12.67 & 13.04 & 14.15 \\
\hline Rett females Total group $(n=13)$ & 10.81 & 21.48 & 14.11 \\
\hline Forceful breathers Total group $(n=7)$ & 14.06 & 22.35 & 14.02 \\
\hline Forceful breathers normal creatine concentrations $(n=1)$ & 7.25 & 25 & 13.97 \\
\hline Forceful breathers elevated creatine concentrations $(n=6)$ & 15.19 & 21.91 & 14.03 \\
\hline Feeble breathers Total group $(n=5)$ & 5.37 & 19.71 & 13.69 \\
\hline Feeble breathers normal creatine concentrations $(n=4)$ & 5.33 & 19.24 & 15.14 \\
\hline Feeble breathers elevated creatine concentrations $(n=1)$ & 5.50 & 21.57 & 7.87 \\
\hline $\begin{array}{l}\text { Undetermined CRPh with elevated creatine } \\
\text { concentrations }(n=1)\end{array}$ & 15.25 & 24.2 & 16.93 \\
\hline Normal creatine concentrations $(n=5)$ & 5.72 & 20.39 & 14.91 \\
\hline Elevated creatine concentrations $(n=8)$ & 13.99 & 22.16 & 13.62 \\
\hline
\end{tabular}

$n$ Number of persons, $\mathrm{Cr}$ Creatine.

Measurements in the muscle biopsy showed low concentrations of creatine in the RTT female (28.4 umol/g muscle) as compared with healthy controls $(57.95$ +/$11.18 \mathrm{umol} / \mathrm{g}$ ). Also both PCr and ATP were lower in RTT tissue as compared with healthy controls (respectively 16.5 versus $45.28+/-26.32$ umol/g and 7.20 versus $21.00+/-5.15$ umol/g).

Research at our metabolic lab aimed at the functionality of the creatine transporter will be continued. 


\section{References}

Bergstrom, J. Percutaneous needle biopsy of skeletal muscle in physiological and clinical research. Scand J Clin Lab Invest 1975: 35(7): 609-16.

Halbach NSJ, Smeets EEJ, Bierau J, Keularts IMLW, Plasqui G, Julu POO, Witt Engerström I, Bakker JA, Curfs LMG. Altered Carbon Dioxide Metabolism and Creatine Abnormalities in Rett Syndrome. JIMD Reports 2012: 3: 117-124.

Harris RC, Hultman E, Nordesjo LO. Glycogen, glycolytic intermediates and high- energy phosphates determined in biopsy samples of musculus quadriceps femoris of man at rest: methods and variance of values. Scand J Clin Lab Invest 1974: 33: 109-120.

Motil KJ, Caeg E, Barrish JO, Geerts S, Lane JB, Percy AK, Annese F, McNair L, Skinner SA, Lee HS, Neul JL, Glaze DG. Gastrointestinal and nutritional problems occur frequently throughout life in girls and women with Rett syndrome. J Pediatr Gastroenterol Nutr 2012: 55(3): 292-8.

Motil KJ, Morrissey M, Caeg E, Barrish JO, Glaze DG. Gastrostomy placement improves height and weight gain in girls with Rett syndrome. J Pediatr Gastroenterol Nutr 2009: 49(2): 237-42.

Motil KJ, Schultz RJ, Wong WW, Glaze DG. Increased energy expenditure associated with repetitive involuntary movement does not contribute to growth failure in girls with Rett syndrome. $J$ Pediatr 1998: 132(2): 228-233.

Oddy WH, Webb KG, Baikie G, Thompson SM, Reilly S, Fyfe SD, Young D, Anderson AM, Leonard H. Feeding experiences and growth status in a Rett syndrome population. J Pediatr Gastroenterol Nutr 2007: 45(5): 582-590.

Platte $\mathrm{P}$, Jaschke $\mathrm{H}$, Herbert $\mathrm{C}$, Korenke GC. Increased resting metabolic rate in girls with Rett syndrome compared to girls with developmental disabilities. Neuropediatrics 2011: 42(5): 179-82.

Reilly S, Cass H. Growth and nutrition in Rett syndrome. Disabil Rehabil 2001: 23: 118-28. 


\section{Appendix 2 RTT Expertise Centre Maastricht University Medical Centre}




\section{RTT Expertise Centre}

The RTT Expertise Centre was founded in September 2011 at the Maastricht University Medical Centre (MUMC+). This clinical research centre offers highly specialised multidisciplinary medical care, including autonomic assessment of brainstem functions and serves as a centre of excellence in the Netherlands. In view of the important role of autonomic dysfunction in this thesis, we discuss here in some detail the autonomic assessment procedure as performed at the RTT Expertise Centre.

\section{Autonomic assessment background}

The neurophysiological technique used at the RTT Expertise Centre assesses brainstem function in real-time, continuously and synchronously. These functions are coupled with a time-locked 21 channel electroencephalogram (EEG) and video monitoring of behaviour in order to help to differentiate seizures from RTT specific breathing disturbances. The cardiovascular and respiratory vital signs originating from and regulated by the brainstem are quantified and recorded synchronously for the study of both temporal and causal relationships.

The cardiovascular signs quantified and recorded are:

- Cardiac Vagal Tone (CVT)

CVT is a measure of parasympathetic stimulation to the heart via the vagus nerve, i.e. it represents the cardiac index of parasympathetic activity. In ventricular systole an increase in blood pressure results in baroreceptor stretching, causing increased baroreceptor discharge to the nucleus of the tractus solitarius (NTS). This stimulus initiates reflex vagal nerve discharge leading to reduction in the rate of spontaneous depolarisation of the sino-atrial node, thus prolonging the RR interval. CVT can therefore be calculated from the R-R intervals in the $E C G$, because it is a form of R-R interval variability (Hamilton et al., 2003).

- Cardiac Sensitivity to Baroreflex (CSB)

The baroreflex mechanism has been recognized as a key part of cardiovascular regulation. CSB is defined as the change in R-R interval per unit change in systolic blood pressure (ms/mmHg; Julu et al., 1996). It represents the feedback effect of blood pressure on heart rate. Its measurement therefore requires synchronous recording of both ECG and the beat- to-beat blood pressure waveform.

- Arterial blood pressure (BP)

- Heart rate (HR)

The respiratory vital signs quantified and recorded are:

- Breathing rate and pattern of breathing

- Transcutaneous partial pressures of oxygen $\left.(\operatorname{tcpO})_{2}\right)$ and carbon dioxide $\left.(\operatorname{tcpCO})_{2}\right)$ 
- Oxygen saturation using plethysmography

\section{Autonomic assessment in practice}

The RTT Expertise Centre's autonomic assessment is performed at the Paediatric Intensive Care Unit (PICU). RTT females are admitted to the hospital for three days. On the second day, extensive autonomic assessment is performed. All procedures are non-invasive and painless. During these measurements, the female is comfortably relaxed in a hospital bed for the afternoon and throughout the following night. Because of the restrictive effect of these measurements, the beat-to-beat BP measurements are recorded only for up to two hours. All other parameters are recorded throughout the afternoon and night. BP waveforms are detected and recorded by a finger cuff, which are quantified and calibrated by the Nexfin $\left({ }^{\circledR}\right.$ Bmeye, Netherlands) resulting in calculated beat-to-beat systolic, mean and diastolic BP values. The ECG is measured to quantify HR, CVT and CSB. Two stretch-sensitive DCrecording belts around the patient's chest and abdomen record the frequency and amplitude of thoracic and abdominal breathing. Also mouth and nose respiration is monitored by a thermocouple and a capnograph to measure end-tidal $\mathrm{CO}_{2}$. Transcutaneous $\mathrm{tcpO}_{2}$ and $\mathrm{tcpCO} \mathrm{O}_{2}$ are quantified every second by an Intelliview MP50 monitor ( ${ }^{\circledR}$ Philips, The Netherlands). The EEG is recorded by a 21-channel EEG combined with time-locked video monitoring of behaviour.

\section{Defining cardiorespiratory phenotype}

Breathing irregularities are a common feature in RTT. Moreover breathing dysrhythmia was seen in nearly all RTT females who underwent autonomic assessment. Julu and Witt-Engerström (2005) have defined three different cardiorespiratory phenotypes in RTT. Research into the severe cardiorespiratory problems experienced by $R T T$ females, is performed by the European Scientific Rett Research Association (ESRRA; www.esrra.eu). A strategy for clinical management of the cardiorespiratory problems has been published in the Lancet (Julu et al., 2008) and the most recent publication involves treating hypoxia in a feeble breather (Julu et al., 2012).

In the characterisation of the breathing patterns, both frequency and amplitude are important. A normal breathing movement is a ramp inspiratory expansion of the chest terminated abruptly and immediately followed by a double phased expiratory reduction in the chest volume (Figure 1). This shape reflects the normal function of the brainstem respiratory neurons. Normal breathing rhythm in RTT is below 35 breaths/minute. To determine whether a given breath effort is sufficient to ventilate a person, transcutaneous partial pressures of the respiratory gases are measured, including $\mathrm{tcpO}_{2}$ and $\mathrm{tcpCO}$. 


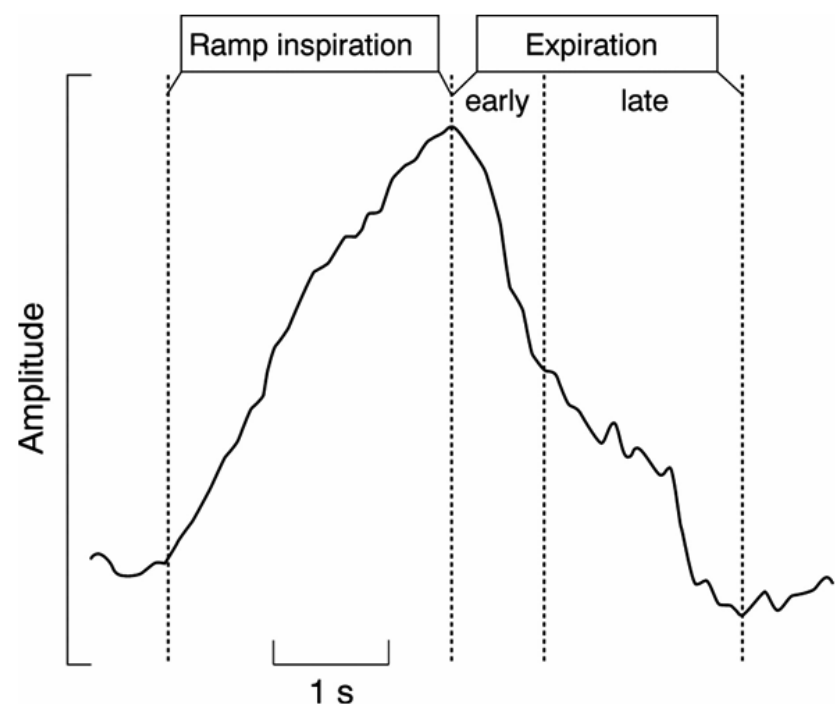

Figure 1 Normal breathing movement (Julu, 2001)

A total of 13 abnormal awake breathing rhythms have been described, with a subdivision into three cardiorespiratory phenotypes representing nine of these abnormal breathing rhythms. An additional four breathing rhythms are Valsalva breathing, Biot's breathing, Cheyne-Stokes breathing and atypical breathing. The latest types of breathing may be seen in all the cardiorespiratory phenotypes and do not appear to belong to one specific cardiorespiratory phenotype. To define the cardiorespiratory phenotype of the RTT female, the percentage of time spent in each rhythm of breathing is calculated. The majority of the females show almost all of abnormal breathing rhythm but one rhythm usually predominates and the cardiorespiratory phenotype diagnosis for that individual is made according to the predominant breathing rhythm.

\section{Forceful breathers}

Breathing rhythms belonging to this cardiorespiratory phenotype are: deep breathing, tachypnoea and hyperventilation. Due to these breathing rhythms, forceful breathers tend to have fixed low levels of $\mathrm{pCO}_{2}$, i.e. chronic respiratory alkalosis. 

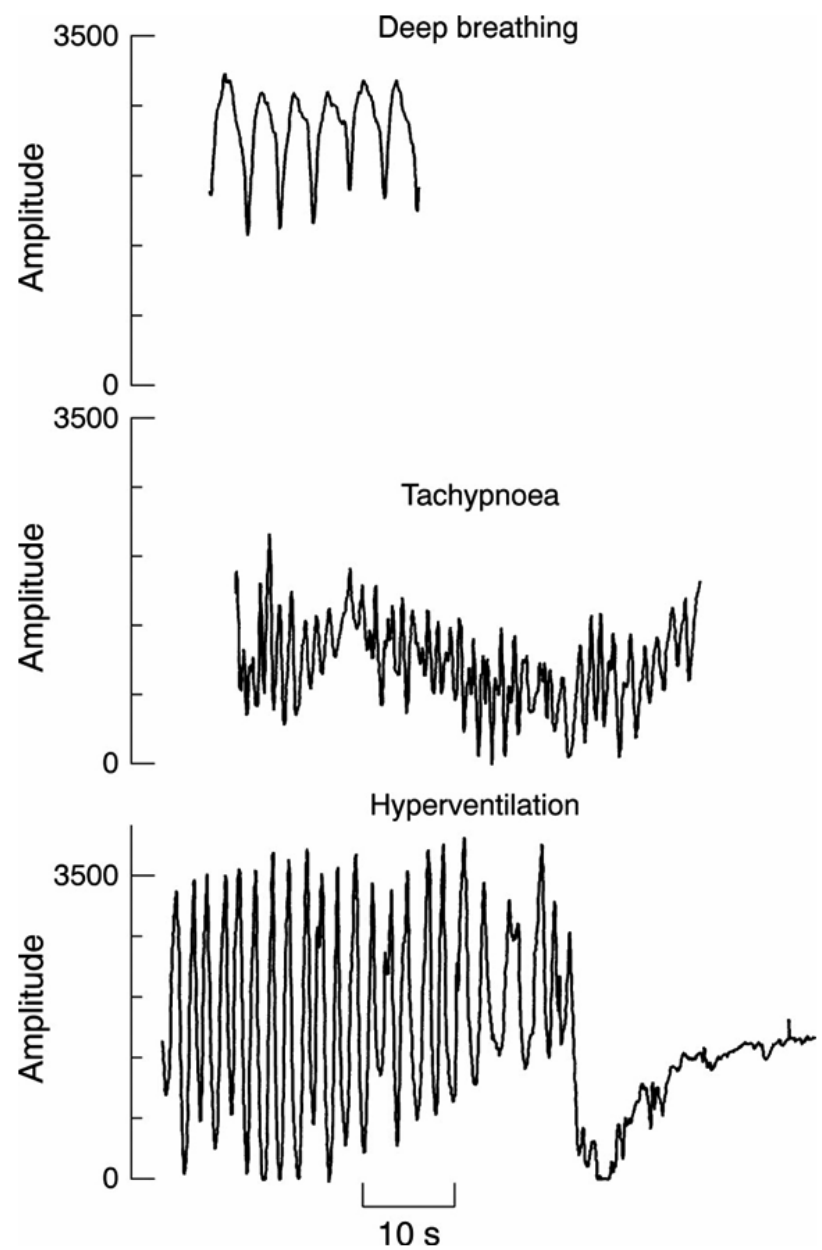

Figure 2 Abnormal breathing patterns belonging to the forceful cardiorespiratory phenotype (Julu, 2001)

\section{Feeble breathers}

Breathing rhythms belonging to this cardiorespiratory phenotype are: central apnoea and shallow and rapid shallow breathing. Due to long-term inadequate ventilation, feeble breathers tend to have fixed higher levels of $\mathrm{pCO}_{2}$, i.e. chronic respiratory acidosis. 

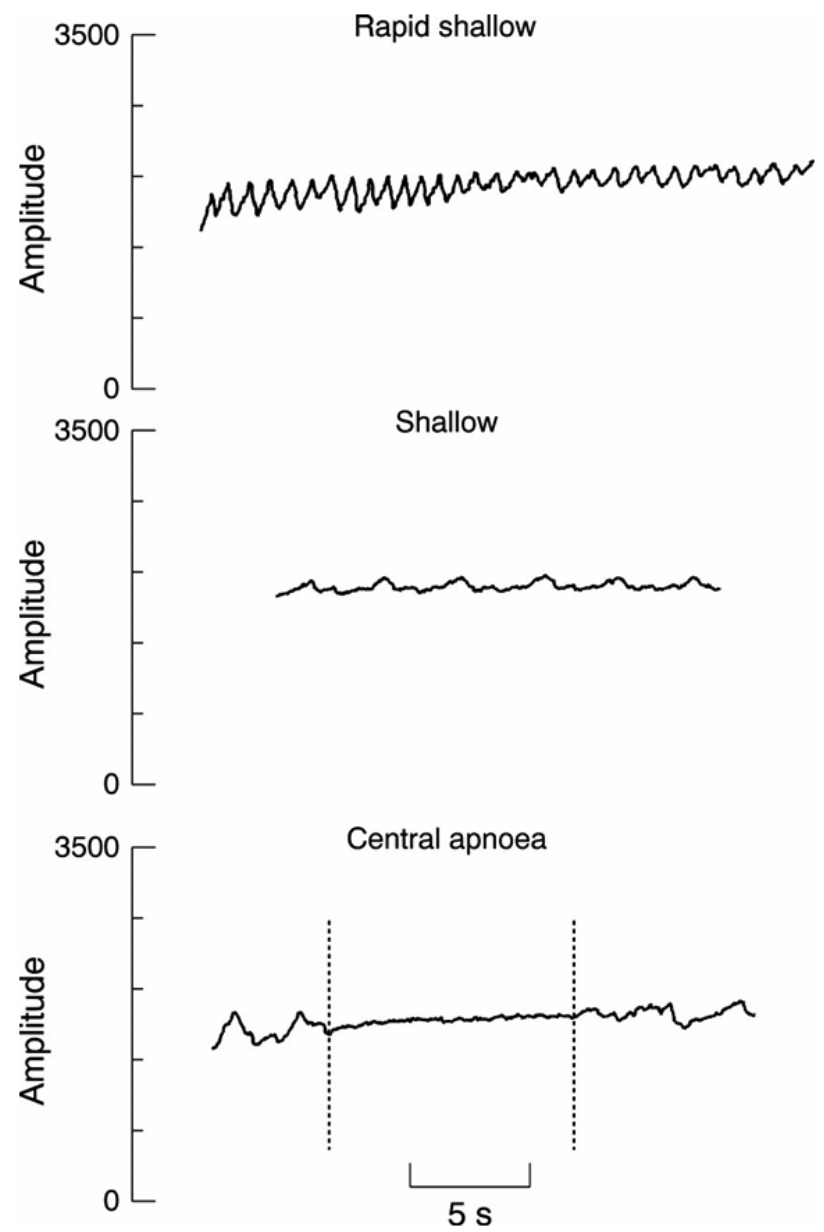

Figure 3 Abnormal breathing patterns belonging to the feeble cardiorespiratory phenotype (Julu, 2001)

\section{Apneustic breathers}

Breathing rhythms belonging to this cardiorespiratory phenotype are: protracted inspiration, breath holds and regular breath holds. Due to the delayed and inadequate expirations, apneustic breathers accumulate carbon dioxide and therefore tend to have fixed higher levels of $\mathrm{pCO}_{2}$. 


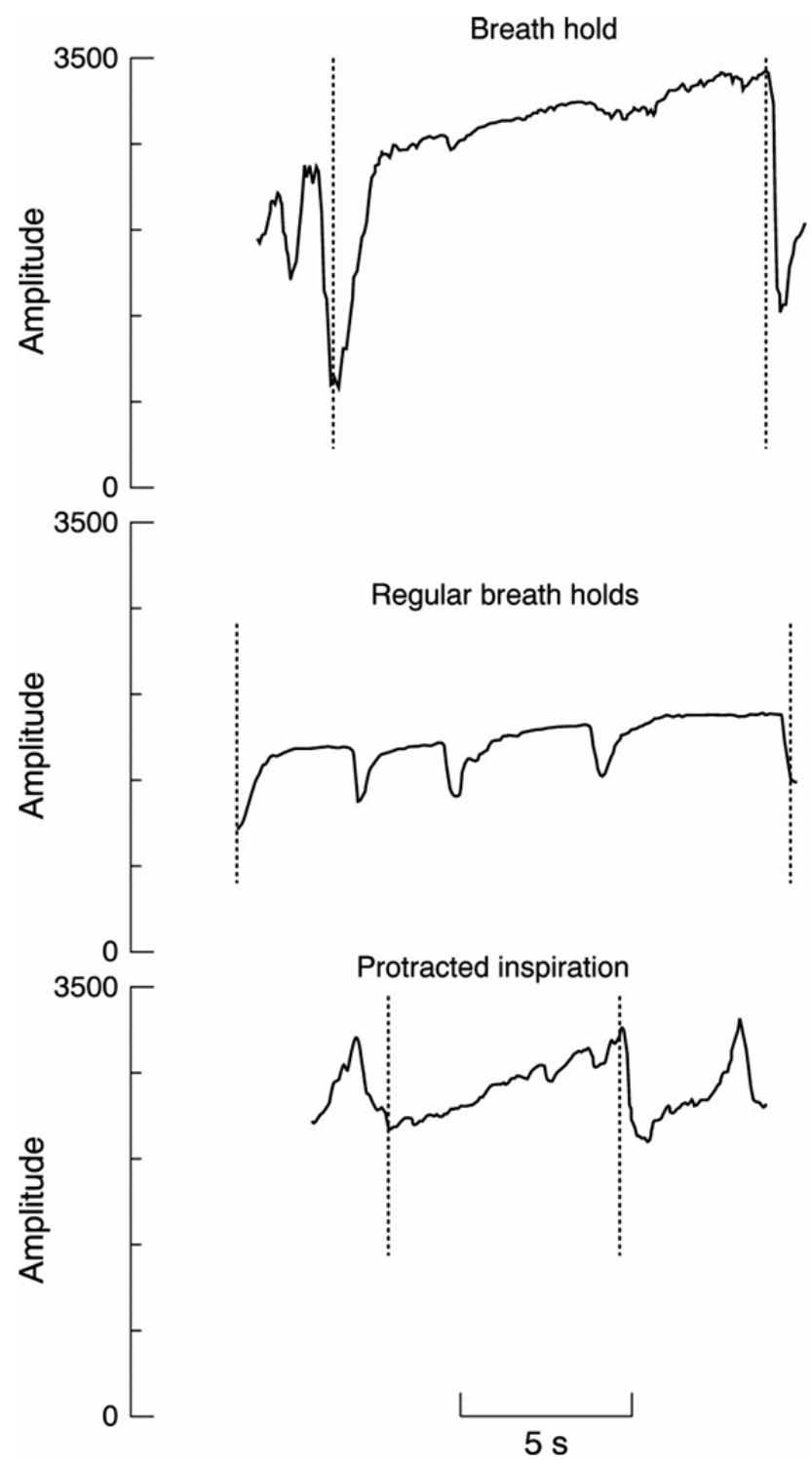

Figure 4 Abnormal breathing patterns belonging to the apneustic cardiorespiratory phenotype (Julu, 2001)

For more detailed information please refer to www.esrra.eu. 


\section{References}

Hamilton RM, Mckechnie PS, Macfarlane PW. Can cardiac vagal tone be estimated from the 10-second ECG? Int J of Cardiol 2004: 95: 109-115.

Julu POO. The central autonomic disturbance in Rett syndrome. In: Kerr AM, Witt Engerström I, editors. Rett Disorder and the Developing Brain. Oxford: Oxford University Press 2001: 131-181.

Julu PO, Engerström IW, Hansen S, Apartopoulos F, Engerström B, Pini G, Delamont RS, Smeets EE. Cardiorespiratory challenges in Rett's syndrome. Lancet 2008: 371: 1981- 1983.

Julu POO, Hansen S, Barnes A, Jamal GA. Continuous measurement of the cardiac component of arterial baroreflex (ccbr) in real-time during isometric-exercise in human volunteers. J Physiol (London) 1996: 497P: P7-8.

Julu PO, Witt Engerström I. Assessment of the maturity-related brainstem functions reveals the heterogeneous phenotypes and facilitates clinical management of Rett syndrome. Brain Dev 2005: 27(suppl 1): S43-S53.

Julu PO, Witt Engerström I, Hansen S, Apartopoulos F, Engerström B; The ESSRA group. Treating hypoxia in a feeble breather with Rett syndrome. Brain Dev 2012: Epub ahead of print. 
Summary 
Rett syndrome (RTT) is a severe, clinically defined neurodevelopmental disorder, affecting predominantly females. With an incidence of $1 / 10,000$ to $1 / 15,000$, RTT is recognized as a prominent genetic cause of severe intellectual disabilities in females. RTT is characterized by an apparently normal early development, followed by loss of intellectual functioning, communicative abilities and motor skills. The replacement of purposeful hand use by stereotypic hand movements, gait abnormalities, growth retardation, seizures and autonomic dysfunction become evident. The natural history of RTT is separated into four distinct stages: early stagnation, rapid regression, pseudo-stabilization and late motor deterioration. Mutations in MECP2 are detectable in up to $95 \%$ of classical RTT cases. Despite molecular genetics, RTT remains a clinical diagnosis. RTT is phenotypically complex with a wide variability in clinical evolution and severity and no clear genotype to phenotype relationships. Beside the classical form of RTT, several atypical variants have been recognised. Clinical management is essentially symptomatic and supportive, as at present there is no cure for the disorder.

In chapter 1 RTT is described historically and clinically, including the staging system and diagnostic criteria, followed by genetic background and clinical management. The aim of this thesis is presented with an outline of the individual chapters.

The first part of this thesis considers the role of the genotype in clinical management. Up until now, genotype-phenotype studies have shown conflicting results. Among the many factors which could play a role, in chapter $\mathbf{2}$ it was excluded that these limited correlations between genotype and phenotype could be due to the subjectivity among clinicians and researchers completing the scoring lists. Even within one mutation or mutation group, clinical severity was very variable, providing limited prognostic assistance in counselling young parents. In chapter 3 the results of a collaborative multicentre genotype-phenotype study are presented. In this study, the influence of genotype on autonomic functions was investigated. Autonomic dysfunction was shown to be present in all females, but there was no fixed relationship between the genotype and the autonomic variables studied. It was concluded that, whereas the exact genotype has limited relevance, clinical neurophysiological assessment is important for clinical management.

The second part of this thesis addresses the little understood pathophysiology of impaired nutritional status in RTT. In chapter $\mathbf{4}$ the possible role of altered metabolic processes was investigated. In half of the RTT females, systematic metabolic screening showed significantly elevated creatine concentrations in plasma and/or urine, for which there were considered to be several possible explanations. Further research on the function of the creatine transporter is ongoing, and is described in appendix 1. Early results confirmed elevation of creatine concentrations in plasma 
and/or urine. Investigations performed in the fibroblasts of RTT females strongly suggested that there was no primary creatine transporter defect, however there remained the possibility of an abnormality of the creatine transport regulation. It was suggested that creatine metabolism or transport in RTT may be influenced by $\mathrm{CO}_{2}$ levels in plasma, because within the RTT population, a difference was found between the creatine concentrations in $5 \% \mathrm{CO}_{2}$ medium and a $\mathrm{CO}_{2}$-independent medium. Significantly low concentrations of creatine, creatine phosphate and ATP measured in the myocytes of a RTT female could be due to increased energy requirements or to an abnormality in the creatine transport regulation. Alterations in the plasma membrane were also considered a possible factor. It was concluded that further research is required to clarify the state of creatine metabolism and transport in RTT and possible associations with malnutrition.

The third part of this thesis addresses the ageing process in RTT. Life expectancy of RTT females has improved substantially in the last decades, thereby increasingly challenging clinicians regarding the care of adult RTT women. However, little is known about the ageing process in RTT. Chapter 5 deals with a cross-sectional study that confirmed the recognised general disorder profile in RTT, including increasing incidence of kyphosis with better communication and autonomic functions. Chapter 6 reports a longitudinal study carried out in order to exclude a possible 'survivor' effect (whereby only the most fit survive). This study demonstrated a slow on-going deterioration of gross motor functioning, contrasting with better preserved cognitive functioning, reduced autonomic and epileptic features and improved general health. These findings justified recommendations for clinical management of RTT women, including continuing motor and communicative therapies, risk-awareness for pneumonia and the need for regular review of anti-epileptic medication and screening.

Chapter 7 summarises the most important findings and considers these from a broader perspective, including methodological matters, clinical challenges and recommendations for future research. Appendix 2 describes the autonomic assessment as performed at the RTT Expertise Centre of the Maastricht University Medical Centre. 



\section{Samenvatting}


Rett syndroom (RTT) is een ernstige, klinisch gediagnostiseerde ontwikkelingsstoornis, welke bijna uitsluitend bij meisjes voorkomt. Met een incidentie van 1 op 10.000 tot 15.000 , is RTT één van de belangrijkste genetische oorzaken van ernstige verstandelijke beperkingen bij meisjes. RTT wordt gekarakteriseerd door een ogenschijnlijk normale vroege ontwikkeling, gevolgd door verlies van cognitieve, communicatieve en motorische functies. In der tijd ontstaan handstereotypen waardoor geen gerichte handfunctie meer mogelijk is, een afwijkend looppatroon, groeiachterstand, epilepsie en autonome dysfunctie. Vier stadia worden onderscheiden in het ontstaan en de ontwikkeling van RTT: vroege stagnatiefase, snelle destructiefase, pseudo-stationaire fase en late deterioratiefase. Mutaties in het MECP2 gen worden in tot wel $95 \%$ van de meisjes met klassiek RTT gevonden. Ondanks deze moleculaire bevestiging, blijft RTT een klinische diagnose. RTT is een complexe aandoening met een grote variabiliteit in klinische evolutie en ernst, waarbij geen evidente relaties worden gezien tussen het genotype en fenotype. Naast de klassieke vorm van RTT, zijn er ook enkele atypische varianten beschreven. Klinisch management bij RTT is voornamelijk symptomatisch en ondersteunend, aangezien genezing vooralsnog niet mogelijk is.

In hoofdstuk 1 wordt een toelichting op RTT gegeven, waarbij wordt ingegaan op de geschiedenis, de diagnosestelling, de genetische achtergrond van en het klinisch management bij RTT. De vraagstellingen behorende bij dit proefschrift worden nader toegelicht, gevolgd door een overzicht van de verschillende hoofdstukken.

Het eerste gedeelte van dit proefschrift richt zich op de rol van het genotype in klinisch management. Vooralsnog laten genotype-fenotype studies tegenstrijdige resultaten zien. Als één van de mogelijke factoren voor de beperkt gevonden genotype-fenotype relaties, werd in hoofdstuk $\mathbf{2}$ de subjectiviteit onder clinici en onderzoekers bij het invullen van de vragenlijsten als mogelijk rol hierin geëxcludeerd. Binnen elke mutatie of mutatiegroep varieerde de ernst tussen de meisjes zodanig dat het moeilijk is om op basis van de mutatie informatie over de prognose te geven. In hoofdstuk 3 worden de resultaten van een multicenter genotype-fenotype studie naar de invloed van het genotype op de autonome functies besproken. Bij alle RTT meisjes was sprake van autonome dysfunctie, waarbij geen relatie werd gevonden tussen het genotype en de onderzochte autonome variabelen. Geconcludeerd werd dat de rol van het genotype in klinisch management beperkt is, echter het belang van klinisch neurofysiologisch onderzoek werd benadrukt.

Het tweede gedeelte van dit proefschrift richt zich op de pathofysiologie van ondervoeding bij RTT, welke grotendeels onbekend is. In hoofdstuk 4 wordt de mogelijke rol van veranderde metabole processen beschreven. De systematisch uitgevoerde metabole screening liet significant verhoogde creatine concentraties in plasma 
en/of urine bij de helft van de RTT meisjes zien. Deze creatine afwijkingen waren echter niet eenduidig te verklaren. Verder onderzoek is gaande naar de functionaliteit van de creatine transporter en is beschreven in appendix 1 . De eerste resultaten bevestigden de verhoogde creatine concentraties in plasma en/of urine. Fibroblastenonderzoek toonde geen primair defect in de creatine transporter aan, echter mogelijk is er sprake van een afwijking in de regulatie van het creatine transport. Gezien de verschillen bij de RTT populatie in creatine concentraties tussen het $\mathrm{CO}_{2}$ $5 \%$ medium en het $\mathrm{CO}_{2}$-onafhankelijke medium, lijkt het creatinemetabolisme of transport bij RTT beïnvloed te worden door $\mathrm{CO}_{2}$. De significant verlaagde concentraties van creatine, creatinefosfaat en ATP gemeten in myocyten van een RTT meisje kunnen mogelijk verklaard worden door een toegenomen energiebehoefte danwel de reeds genoemde afwijkingen in de creatine transportregulatie. Een andere mogelijk verklarende factor is celmembraanveranderingen. Verder onderzoek ter verheldering van het creatinemetabolisme en transport, en het mogelijke verband met ondervoeding bij RTT is gewenst.

Het derde gedeelte van dit proefschrift richt zich op het verouderingsproces bij RTT. De levensverwachting van RTT vrouwen is de afgelopen decennia dermate gestegen dat clinici toenemend geconfronteerd worden met de zorg voor volwassenen met RTT. Over het verouderingsproces bij RTT is weinig bekend. In hoofdstuk 5 wordt een cross-sectioneel verouderingsonderzoek beschreven. Het in de literatuur beschreven ontwikkelingsprofiel bij RTT werd bevestigd, gezien de toenemende incidentie van kyfose en de verbeterende communicatieve en autonome functies. Ter uitsluiting van een mogelijke overlevingsbias (waarbij de gezondste personen ofwel minst aangedane personen overleven), is in hoofdstuk 6 een longitudinale studie verricht. Het algemene ontwikkelingsprofiel van de RTT vrouwen in deze studie werd gekarakteriseerd door een langzame verslechtering van grove motoriek, in tegenstelling tot betere cognitieve functies, minder autonome problemen en epilepsie en een goede algemene gezondheid. Aanbevelingen met betrekking tot klinisch management werden gegeven, zoals het continueren van motorische en communicatieve therapieën, het bedacht zijn op de aanwezigheid van een longontsteking, frequente evaluatie van anti-epileptica en reguliere screeningsadviezen.

In hoofdstuk 7 worden de belangrijkste bevindingen samengevat en in een bredere context geplaatst. Daarbij is speciale aandacht voor methodologische overwegingen, klinische uitdagingen en aanbevelingen voor toekomstig onderzoek bij RTT. In appendix 2 wordt een nadere toelichting gegeven op het autonome onderzoek zoals uitgevoerd in het RTT Expertise Centrum van het Maastricht Universitair Medisch Centrum. 



\section{Dankwoord}


"Het aantal life-events heeft het aantal publicaties tijdens dit promotieonderzoek overstegen". Een citaat van mijn promotor prof. dr. L.M.G. Curfs, wat een goed beeld geeft van de afgelopen 4,5 jaar. Het is dan ook niet verwonderlijk dat ik op deze plek velen van jullie wil bedanken.

Omdat ik niet weet waar ik moet beginnen ga ik dit zoveel mogelijk op chronologische volgorde afwerken, in de hoop dat ik niemand vergeet. Mijn eerste ervaring met het Rett syndroom is geweest tijdens een lezing van dr. E.E.J. Smeets in 2003. Ik ontmoette hier Margo van Otterdijk, een prachtig jong blond Rett meisje die met haar blauwe sprekende ogen een onuitwisbare indruk heeft achtergelaten. Ik wil haar en haar familie dan ook in het bijzonder bedanken voor de aanwezigheid bij deze lezing. De verhalen en gevoelens welke jullie die dag, maar later ook in jullie uitgegeven boek met mij gedeeld hebben, heeft mijn interesse in het Rett syndroom gewekt. Ik hoop dan ook dat ouders deze lezing blijven vergezellen om ook toekomstige artsen in het Rett syndroom op te leiden en hopelijk ook te interesseren. Het gedichtje aan het begin van dit promotieboekje, is door de ouders van Margo destijds uitgedeeld en mijn blijvende herinnering aan deze bijzondere ontmoeting.

Daarnaast gaat mijn grote dank natuurlijk ook uit naar dr. E.E.J. Smeets, mijn copromotor. Beste Eric, vanaf het begin heb ik een enorme bewondering gehad voor jouw enthousiasme voor het Rett syndroom. Ouders noemen jou dan ook niet voor niks een pRETTige dokter. Ondanks jouw drukke leven, is jouw motivatie voor het syndroom blijven bestaan en de droom voor een Rett expertise centrum werkelijkheid geworden. Jouw enthousiasme is aanstekelijk en is een grote steun geweest gedurende mijn promotietraject.

In 2007 heb ik onder leiding van prof. dr. L.M.G. Curfs, prof. dr. C.T.R.M. SchranderStumpel en uiteraard dr. E.E.J. Smeets mijn GEZP-stage bij de klinische genetica gelopen. Beste Paul, mijn promotor, ik wil je bij deze bedanken voor je vertrouwen in mij, niet alleen tijdens deze WESP-stage, maar ook in 2008 toen je me als promovendus Rett Syndroom aanstelde. Jouw flexibele houding ten opzichte van thuiswerken hebben een positieve invloed gehad op de afronding van dit promotietraject, maar ook zeker op het in balans houden van werk en privé. Mijn oprechte dank hiervoor. Beste Connie, jouw werk binnen de MR is bewonderenswaardig. Het is dan ook terecht dat je in de top 3 van experts wordt ingedeeld door je collega's. Ik heb het dan ook een eer gevonden om met je samen te werken en ben trots dat je deel uitmaakt van de corona tijdens mijn verdediging.

$\mathrm{Na}$ afronding van mijn studie begon ik als ANIOS kindergeneeskunde in het voormalig Maaslandziekenhuis te Sittard. Een onvergetelijke periode met een geweldige team aan kinderartsen, verpleegkundigen, polidames en mede arts-assistenten. Ik wil jullie allemaal bedanken voor de fijne begeleiding en samenwerking welke iede- 
re pas beginnende arts-assistent zich zou wensen. In het bijzonder wil ik drs. J. Heynens en drs. K. Oberndorff bedanken. Beste Jan, als mijn begeleider bleef je betrokken en ben je ook de kinderarts van Anouk geweest. Ik kon altijd bij je terecht en heb $100 \%$ vertrouwen in jouw goede zorgen voor mij en mijn jongste dochter Anouk. Nu hopen dat we ons alleen nog maar buiten het ziekenhuis tegenkomen. Beste Karin, onze gezamenlijke interesse voor de genetica schepte een band en als we elkaar op de woensdagbesprekingen weer zagen, was het altijd gezellig om bij te kletsen. Ik hoop dat we contact zullen houden in de toekomst en jullie nog eens gezellig op "kraambezoek" komen. Maar ook mijn ex-collega's, in het bijzonder Jelleke, Jeanine, Agnes en Tanja wil ik bedanken. Na onze Sittard-tijd hebben we nog altijd contact gehouden en gaan we dan ook elke 2-3 maanden gezellig bij elkaar eten of bijvoorbeeld naar de 90's-party. Het is altijd gezellig en ik ben trots op onze vriendschap.

1 september 2008 begon ik aan mijn promotietraject, waarbij ik een kamer in de "kelder" deelde met dr. M. Sinnema. Een betere collega ofwel partner in crime zoals je ons in jouw proefschrift noemde kon ik me niet wensen. Lieve Margje, eigenlijk al vanaf mijn WESP-stage tot mijn laatste dag bij de genetica heb je voor mij klaar gestaan. Je was mijn grote voorbeeld, jouw hulp bij METC-protocollen, artikelen indienen, promotieboekje schrijven is zo belangrijk geweest. We hebben veel meegemaakt in de kelder, maar gelukkig is het nu tijd voor de positieve life-events: de geboorte van jullie dochter en jullie huwelijk staat voor de deur. Het is je zo gegund! Ik vond het bijzonder om je paranimf te zijn en nu draaien we de rollen om, wat ben ik trots dat jij achter mij zal staan op deze bijzondere dag. Maar naast Margje, zorgde ook Wilma, Wies, Judith en later ook Ingeborg voor de fijne sfeer in de kelder. De praatjes bij de waterkoker en lunches op het terras van het $\mathrm{NH}$-hotel waren een heerlijke afwisseling van het onderzoekswerk, dankjewel hiervoor. Als laatste was ik ook maar één deur verwijderd van prof. dr. J. Geraedts. Beste Joep, dank voor de deur die altijd heeft opengestaan en de steun die ik heb mogen ervaren. Jouw werk voor de genetica is onbeschrijfelijk en zal door niemand vergeten worden. Maar nu kun je lekker van je welverdiende pensioen en kleinkinderen genieten.

Nadat Margje in opleiding ging tot klinisch geneticus en 2 verdiepingen naar boven "promoveerde", kreeg ik 2 nieuwe collega's: Elke Mersy en Inge Smeets. Dames, ook jullie waren geweldige collega's. We hebben veel zorgen, maar ook mooie momenten gedeeld. Ik kijk nu al uit naar jullie promotieboekjes, dat zullen prachtwerken worden. Elke, wij waren aanwezig bij jouw bruiloft en zullen dadelijk ook je dochter komen bewonderen. Ik heb een enorme waardering voor jouw doorzettingsvermogen, gedrevenheid en werklust. Lieve Inge, ik ben erg blij dat we elkaar hebben kunnen steunen bij de moeilijkere perioden in ons leven. Weet dat ik ook in 
de toekomst altijd bereikbaar zal blijven, de vriendschap die we hebben opgebouwd is mij erg waardevol.

Maar naast mijn directe collega's, wil ik ook alle andere collega's van de polikliniek klinische genetica bedanken. De stafleden, de $A(N) I O S$, genetisch consulenten, polidames en secretariaat. Enkele hiervan zou ik graag in het bijzonder willen bedanken. Allereerst Suzanne, Kim, Felicia, Cynthia en Els, ik heb me altijd als een collega bij jullie gevoeld, dank hiervoor. Maar ook de genetisch consulenten, met in het bijzonder Sera en Joyce. Dames, dank voor jullie betrokkenheid, zowel op persoonlijk vlak als met betrekking tot mijn onderzoek. Jullie hebben allebei prachtige dochters, waar jullie terecht apetrots op zijn. Ik hoop dat we contact kunnen blijven houden. Maar ook Maud Seuren, wat heb ik een bewondering voor jouw keuze om voor de liefde te kiezen en naar Spanje te vertrekken. Je was een geweldige collega en ik mis onze woensdaglunches nog steeds. Ik wens jou, Rubén en jullie toekomstige tweeling alle goeds toe. Verder wil ik ook de polidames bedanken, in het bijzonder Sabrina en Tiny die de onderzoekspoli's en Rett expertise poli's mogelijk hebben gemaakt en altijd probeerde onderzoekskamer 3 voor ons vrij te houden.

Maar naast de collega's van de polikliniek, wil ik ook graag nog collega's van de andere units bedanken. Allereerst het lab EMZ, aangezien een groot deel van mijn promotieboekje zonder hun niet mogelijk zou zijn geweest. De stafleden dr. J. Bierau, dr. J. Bakker en dr. I Körver-Keularts, hartelijk dank voor jullie medewerking aan de onderzoeken, de expertise die jullie met mij hebben willen delen en het uiteindelijke resultaat waarbij hopelijk een puzzelstukje binnen Rett syndroom op zijn plaats gaat vallen. Beste Irene, jou wil ik nog in het bijzonder bedanken voor onze wekelijkse woensdaglunches die ook na vertrek van Maud naar Spanje zijn doorgegaan. Onze band ontstond al gelijk toen ik je vroeg of jouw vader mijn scheikundeleraar van de middelbare school zou kunnen zijn. Inmiddels kunnen we alles met elkaar bespreken en hebben we een bijzondere vriendschap opgebouwd. Maar naast mijn dank aan de stafleden, gaat er natuurlijk een grote dank uit naar de analisten op het lab met in het bijzonder Dennis, die alle bepalingen voor mijn onderzoek hebben uitgevoerd. Ook al kwam ik nog in de namiddag met bloed of urinesamples aanzetten, jullie gingen altijd enthousiast aan de slag. Dank voor het vele werk wat jullie hebben uitgevoerd. En Janine, bedankt voor onze gezellige treinritten samen met Tamara. De 45 minuten durende reis van Landgraaf naar Maastricht Randwyck vlogen om als we bijpraatten over zwangerschappen, baby's, verhuizingen etc. Ik wens je een prachtige en vooral gezond tweede kindje toe in jullie mooie nieuwe huis. Maar ook dr. Salomons, collega EMZ in Amsterdam wil ik bedanken voor de bijdrage aan het tweede deel van het metabole onderzoek. Zelfs 's avonds om 22:00 was je nog beschikbaar voor een telefonische brainstormsessie. Daarnaast wil ik ook de groep van prof. dr. van Loon, Department of Movement Sciences bedanken voor 
hun bijdrage aan dit vervolgonderzoek. Tenslotte heeft ook Clinical Genomics bijgedragen aan mijn promotieonderzoek en dan in het bijzonder drs. K. van Roozendaal. Beste Kees, dank voor je altijd inspirerende besprekingen en de tijd die je altijd voor me nam als ik weer eens aan je deur kwam kloppen.

Maar naast de afdeling Klinische Genetica, heb ik ook samengewerkt met vele andere afdelingen. Als eerste wil ik hier dr. Maaskant bedanken. Beste Marian, eerst de onderzoeksvraag bepalen voordat je aan de slag gaat met de statistische analyses, is de belangrijkste les die je iedere student bijbrengt. Het lijkt zo'n vanzelfsprekendheid, maar in de praktijk verlies je vaak door alle data toch uit het oog welke vraag je nu eigenlijk wilde beantwoorden. Jouw feedback op de artikelen was altijd van grote waarde, voor vragen was je altijd beschikbaar en was niks je teveel. Daarnaast bewonder ik ook je olifantengeheugen, je kent niet alleen mijn verjaardag, maar ook die van drs. drs. Beckers en mijn dochters uit je hoofd. Je altijd attente kaartjes zal ik niet snel vergeten.

De andere collega's welke ik wil bedanken, zijn werkzaam binnen het Rett expertise centrum. Allereerst de PICU (pediatric intensive care unit van het MUMC+). Wat een geweldig team aan mensen, die altijd mee willen denken en zoveel Rett gezinnen zich thuis hebben laten voelen. In het bijzonder wil ik dr. van Waardenburg, Hay Baggen, Judith Brands en Hilde Wielders bedanken. Beste Dick, jouw betrokkenheid bij het Rett expertise centrum is van grote waarde. Maar ook persoonlijk ben je betrokken geweest en zal ik je attente bezoekje tijdens mijn eigen ziekenhuisopname niet vergeten. Ik heb onze samenwerking altijd als zeer prettig ervaren. Beste Hay, wat ben je een ongelofelijk enthousiaste en bekwame nurse practitioner. Vanaf het begin van de Rett opnames heb je met ons meegedacht, een grote bijdrage geleverd aan het ontwikkelen van het rebreathingsmasker en zo ontzettend veel gezinnen hiermee begeleid. Zelfs als je vrij had, was je nog per telefoon of mail beschikbaar. Beste Judith en Hilde, casemanagers van het CASK, ik ben er zeker van dat de praktische zaken van het Rett expertisecentrum in goede handen zijn bij jullie. Dank voor jullie inzet en betrokkenheid.

Maar ook de afdeling KNF (klinische neurofysiologie) wil ik ontzettend bedanken voor hun samenwerking. De polidames voor de hulp bij het opstarten van de Rett PC, zodat ik de analyses vanuit mijn eigen werkplek kon uitvoeren. Maar ook zeker dr. van Kranen-Mastenbroek, dr. Reulen, Kevin van Schaijk en de laboranten. Beste Vivianne, als ik de EEG-registraties zag was ik altijd blij dat jij die taak op je nam. Ik weet hoe ongelofelijk moeilijk deze registraties te beoordelen zijn. Ik wil je dan ook bedanken voor de goede samenwerking (middels notes in de registratie) in de analyse van de autonome registratie, waarbij we vervolgens met het hele team de belangrijke antwoorden op de vragen van Rett ouders konden geven. Beste Jos, dankzij jou is de "Rolls Roys" versie van de Neuroscope werkelijkheid geworden. Jouw inzet is van grote waarde geweest om de metingen binnen het Rett expertise 
centrum mogelijk te maken. Beste Kevin, jij stond altijd paraat om mijn ICTproblemen bij de analyses op te lossen en hebt gezorgd voor mijn webex zodat ik de analyses zowel vanuit mijn werkplek als thuis kon verrichten. En last but not least de laboranten, dank voor jullie betrokkenheid voor de Rett meisjes en vrouwen en het engelengeduld dat jullie kunnen opbrengen tijdens het aansluiten van de "Rolls Roys" Neuroscope.

Tenslotte drs. H. Trines. Beste Hanneke, als personal assistant van prof. dr. L.M.G. Curfs, verzet ook jij enorm veel werk voor het Rett expertisecentrum. Maar ook voor mijn promotieonderzoek heb je altijd klaar gestaan, en zonder jou waren alle formele taken rondom de promotie niet gelukt.

Bij de verschillende onderzoeken heb ik ook hulp mogen ontvangen van verschillende studenten. Noortje, Petra en Catherine, dank voor jullie inzet voor de verschillende onderzoekslijnen. Ik heb het ontzettend leuk gevonden jullie te begeleiden en vooral ook samen te werken. Ik hoop dat jullie allemaal een mooie carrière tegemoet gaan. Daarnaast wil ik ook hier Emma bedanken. Emma, jij was tijdens mijn promotieonderzoek betrokken bij het ondervoedingsproject. Ik heb bewondering voor jouw onderzoeksinzicht en organisatorisch vermogen, want begeleiding was bij jou haast niet nodig. Ook in de grote stad Amsterdam zijn ze al onder de indruk van je werk. Ook voor jou een prachtige carrière en hopelijk blijven we contact houden.

Naast alle Nederlandse collega's, zou ik ook graag een aantal buitenlandse collega's bedanken en wel mijn ESRRA (European Scientific Rett Research Association) collega's. Dear Peter, Ingegerd, Bengt, Stig, Flora, Stephania, Giorgio and Shane. From the very first moment it felt I belonged to a big family. So many experts with one shared passion: Rett syndrome. It was an honour to work with all of you. Your work for RTT is amazing, just keep on doing this wonderful work. But also dr. A. Kerr, the Rett expert of the United Kingdom. Dear Alison, thank you very much for your useful comments and for checking my English writing.

Maar naast al mijn collega's, zijn er 13 meiden en hun families die ik enorm dankbaar ben: Annika, Celeste, Evi, Fenna, Fenne, Floortje, Jade, Kelly, Lieke, Margo, Nathalie, Terre en Willemijn. Jullie enthousiaste deelname aan mijn onderzoek hebben een grote indruk op mij gemaakt. Jullie zijn zo'n bijzondere meiden, waar jullie familie terecht heel trots op is. Ik zal jullie nooit vergeten. Beste Annika, jij hebt zelf nog een extra bijdrage geleverd en wel de prachtige omslag van dit proefschrift. Een Rett meisje dat schildert, hoe bijzonder!

Maar op deze plek zou ik ook graag de Nederlandse en Belgische Rett vereniging bedanken voor hun enthousiaste bijdrage aan het onderzoek. En in het bijzonder Stichting Terre, zonder jullie was dit promotie onderzoek en het Rett expertisecen- 
trum niet mogelijk geweest. Bedankt voor het vertrouwen dat jullie in mij hebben gehad. Ik ben er vast van overtuigd dat jullie net zo trots op dit boekje zijn als ik. Hopelijk zullen er nog vele promotieboekjes Rett syndroom volgen. Jullie inzet voor de "Rett wereld" is bewonderenswaardig.

En nu is het tijd om alle mensen buiten het werk te bedanken.

Lieve vrienden, jullie hebben altijd gezorgd voor de gezonde afwisseling tussen werk en privé. In de moeilijke tijden hebben jullie voor ons klaar gestaan, maar wat hebben we ook veel gelachen. Naast de mensen die ik in voorafgaande tekst reeds heb genoemd, wil ik nu ook Rik en Katrin, Maud en Mark, Ellen en Raymond, Debby en Kevin, Ben en Daniëlla, Bianca en Jeroen, Rianne, Roger en Jessica bedanken! Door de specifieke betrokkenheid in mijn promotietraject, wil ik Rik en Ellen in het bijzonder bedanken. Bij jullie was mijn promotietraject altijd een vast onderwerp van gesprek. Door jullie eigen onderzoek/promotie ervaringen, konden jullie je goed inleven in mijn situatie en was jullie advies van zeer grote waarde. Dankjewel, jullie waren mijn perfecte uitlaatklep. Ik hoop dat onze vriendschap nog lang moge bestaan.

Lieve familie, jullie zijn altijd betrokken geweest, al vragen jullie je soms af of ik pas klaar ben met studeren als ik met pensioen ga. Als ik op congres ging en een presentatie gaf in Parijs, New Orleans of een andere wereldstad, viel jullie mond open van bewondering. Tijdens je promotiettraject lijkt dat op een gegeven moment de normaalste zaak van de wereld, maar door jullie reactie wist ik dat ik inderdaad met iets bijzonders bezig was. Maar weet ook dat dit onderdeel is van mijn vak en ik jullie werk net zoveel waardeer. Het gaat er niet om wat we in het leven doen, maar wie we zijn. Lieve papa en mama, jullie altijd aanwezige steun en hulp is onbeschrijfelijk. Het gevoel altijd bij jullie terecht te kunnen is zo belangrijk voor mij in het leven. Ik ben er trots dat jullie mijn ouders zijn en hoop ooit voor Esmée en Anouk net zo'n goede ouder te worden. Jenna en Roy, zusje en schoonbroer, ondanks dat we ongeveer dag en nacht van elkaar verschillen staan we altijd voor elkaar klaar. Ik ben blij dat we zo'n goede en sterke band hebben en wat is het mooi onze kinderen samen te zien opgroeien. Jenna, ik ben dan ook super trots dat jij op deze bijzondere dag mijn paranimf wil zijn. Lieve oma, helaas ben je niet meer bij ons, maar wat zou je trots zijn geweest. Ik kan me nog goed herinneren dat je me vol lof vertelde dat je mijn naam op de radio had gehoord. Je schreef "Rett syndroom" op een briefje, zodat je iedereen kon vertellen wat ik deed. Maar ook tijdens onze bezoekjes bij de oncoloog, liet je weten dat je kleindochter arts was en goed op je lette. Oma, ik zal je nooit vergeten en weet dat je ook tijdens de verdediging dicht bij me zal zijn.

En als laatste de meest bijzondere mensen in mijn leven, die waarschijnlijk net als mij enorm blij zijn dat deze mijlpaal gehaald is. Frank, wat ben ik trots dat jij mijn 
man bent en de papa van onze meisjes. Samen kunnen wij de wereld aan, je maakt me echt gelukkig. Esmée en Anouk, mijn prachtige dochters, mijn grote trots, zodra jullie "mama" roepen als ik van het werk thuis kom, valt alles van mij af en GENIET ik alleen nog maar. Samen met papa zijn jullie de liefde van mijn leven, ik hou zo ontzettend veel van jullie drie! 
Curriculum vitae 
Nicky S.J. Beckers-Halbach werd op 14 september 1983 geboren te Heerlen. Haar VWO examen behaalde zij in 2001 aan het Eijckhagencollege te Landgraaf. Zij studeerde Geneeskunde aan de Universiteit Maastricht, waar in 2005 het doctoraalexamen cum-laude werd afgelegd. Tijdens deze studie heeft zij deelgenomen aan het keuzeonderwijs "aangeboren en erfelijke afwijkingen bij kinderen" en was haar wetenschapsstage gericht op veroudering bij Rett syndroom, hetgeen tot haar eerste publicatie leidde. In juni 2007 behaalde zij haar artsexamen.

Van juni 2007 tot september 2008 was zij werkzaam als ANIOS Kindergeneeskunde in het voormalig Maaslandziekenhuis te Sittard. Aansluitend werkte zij tot en met januari 2013 aan haar promotieonderzoek, onder leiding van prof. dr. L.M.G. Curfs en dr. E.E.J. Smeets. Zij presenteerde haar onderzoeksresultaten op nationale en internationale congressen, waaronder het NVK, IASSID, Europese en Wereld Rett congressen. Inmiddels is zij (mede-)auteur van verscheidene medische publicaties over het Rett Syndroom en lid van de internationale research groep ESRRA (European Scientific Rett Research Association).

Op 11 oktober 2012 is zij getrouwd met Frank Beckers. Zij hebben twee dochters, Esmée (3) en Anouk (2). 
List of publications 
Halbach NSJ, Smeets EEJ, Schrander-Stumpel CTRM, Van Schrojenstein Lantman de Valk HHJ, Maaskant MA, Curfs LMG. Aging in people with specific genetic syndromes: Rett syndrome. Am J Med Genet Part A 2008: 146A: 1925-32.

Flinsenberg TWH, Halbach NSJ, Robben SGF, Rosias PPR. Een kind met pijn op de borst door een spontaan pneumomediastinum. Ned Tijdschr Geneeskd 2009: 153: B336.

Halbach NSJ, Smeets EEJ, Bierau J, Keularts IMLW, Plasqui G, Julu POO, Witt Engerström I, Bakker JA, Curfs LMG. Altered carbon dioxide metabolism and creatine abnormalities in Rett Syndrome. JIMD Rep 2012: 3: 117-124.

Halbach NSJ, Smeets EEJ, van den Braak N, van Roozendaal KEP, Blok RMJ, Schrander-Stumpel CTRM, Frijns JP, Maaskant MA, Curfs LMG. Genotype-Phenotype Relationships as Prognosticators in Rett Syndrome Should be Handled With Care in Clinical Practice. Am J Med Genet Part A 2012: 158A: 340-350.

Halbach NSJ, Eric E.J. Smeets, Cathérine Steinbusch, Marian A. Maaskant, Dick van Waardenburg, Leopold M.G. Curfs. Aging in Rett syndrome: a longitudinal study. Clinical Genetics. Epub ahead of print.

Halbach NSJ, Smeets EEJ, Julu POO, Pini G, Bigoni S, Witt Engerström I, Hansen S, Apartopoulos F, Delamont RS, van Roozendaal KE, Candel M, Curfs LMG. Neurophysiology versus Clinical Genetics in Rett Syndrome: A Multicenter Study. Submitted. 